\title{
ISOTHERMAL OXIDATION COMPARISON OF THREE Ni-BASED SUPERALLOYS
}

By

\section{MALLIKARJUNA HEGGADADEVANAPURA THAMMAIAH}

\author{
A thesis submitted to \\ The Faculty of Graduate Studies \\ In partial fulfillment of the requirement for the degree of \\ MASTER OF SCIENCE
}

Department of Mechanical Engineering

The University of Manitoba

Winnipeg, Manitoba

May 2016 


\section{DEDICATION}

To My Parents

Mr. Thammaiah (late) and Mrs. Asha

And My Brother, Vinod Kumar H. T. 


\section{TABLE OF CONTENTS}

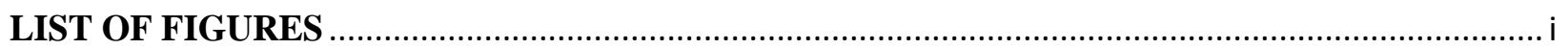

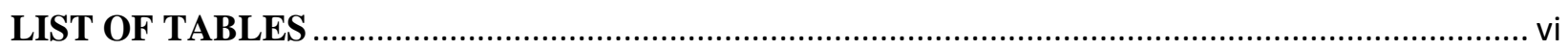

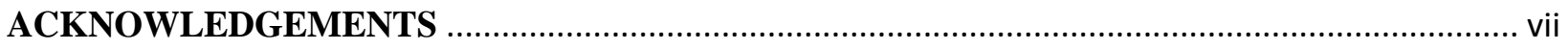

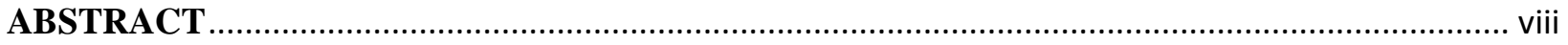

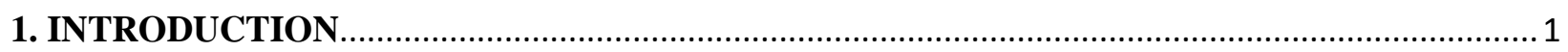

1.1 Application of nickel-based superalloys ….......................................................................... 1

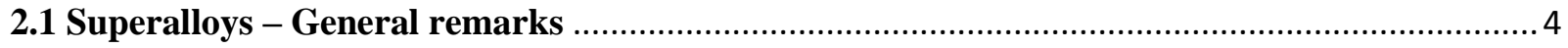

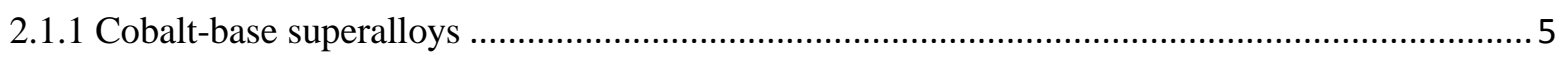

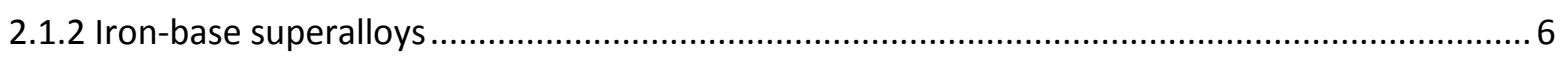

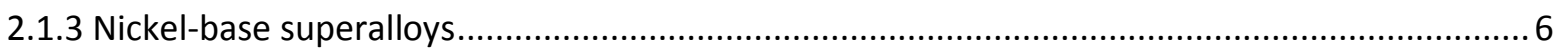

2.2 Nickel-base superalloys: chemistry and microstructure. …................................................. 7

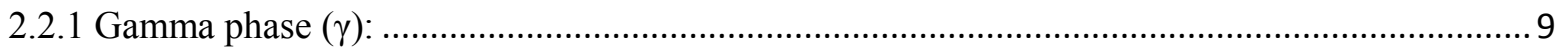

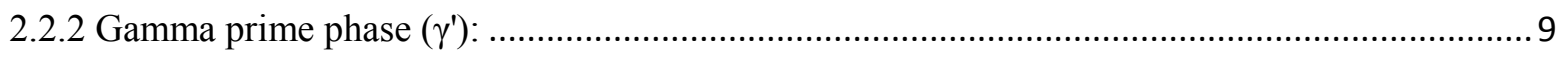

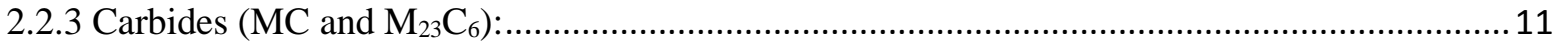

2.2.4 Topologically close packed (TCP) phases: ....................................................................... 12

2.3 Strengthening mechanism of nickel-base superalloys ....................................................... 12

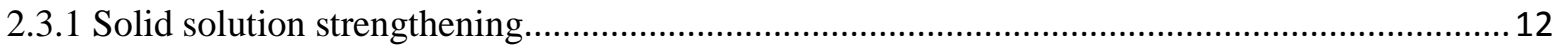

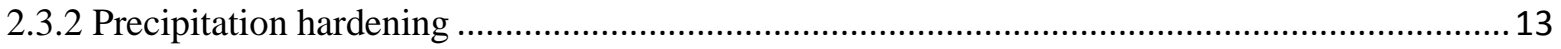

2.3.3 Grain boundary strengthening by carbides ................................................................... 14

2.4 Development of Ni-base superalloys processing ............................................................. 14

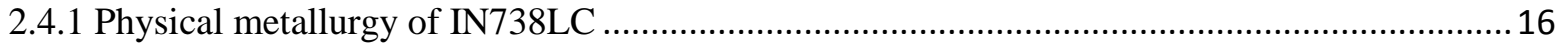

2.4.2 Physical metallurgy of single crystal N5 ....................................................................... 17

2.4.3 Physical metallurgy of modified IN600 (TAS) ............................................................... 17

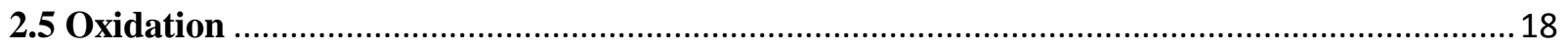

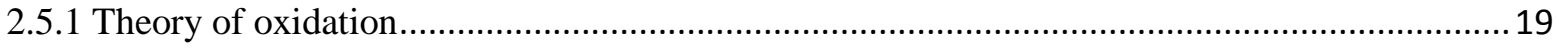

2.5.2 General formation of metal oxides................................................................................... 19

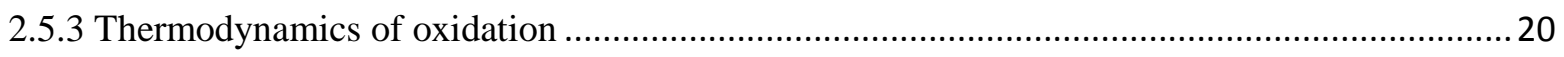

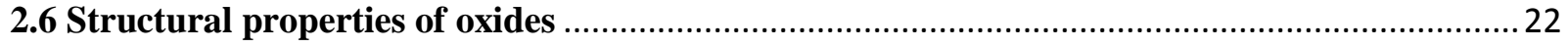

2.6.1 Point defect structures and mechanism of lattice diffusion....................................................23 
2.6.2 Line defect structures, plane defect structures and short-circuit diffusion.

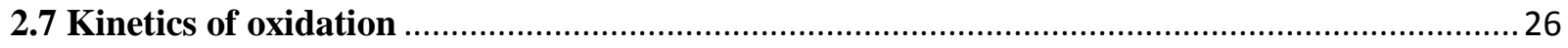

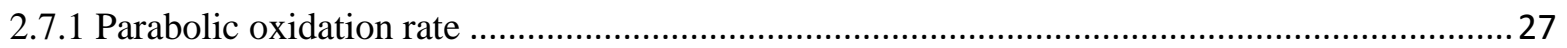

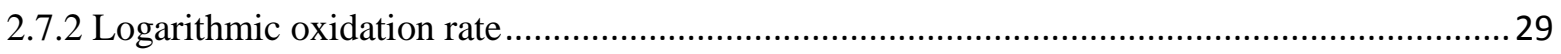

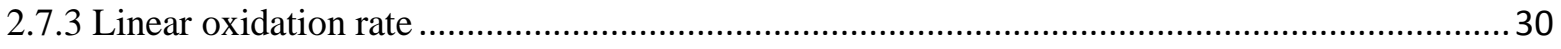

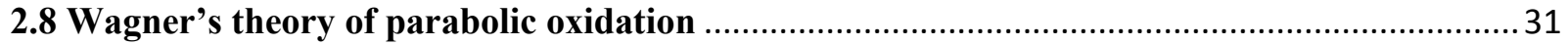

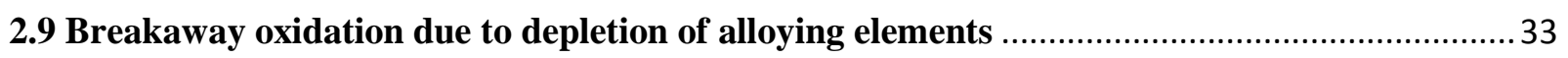

2.10 Effect of alloying elements on oxidation of superalloys .................................................... 34

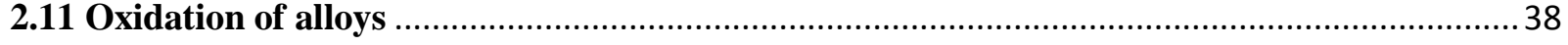

2.11.1 High-temperature oxidation of chromia-forming nickel-base superalloys ............................ 39

2.11.2 High-temperature oxidation of alumina-forming nickel-base superalloys............................. 43

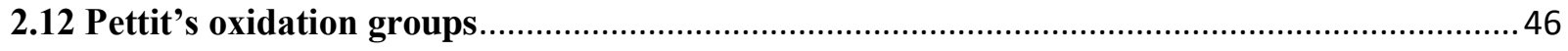

2.13 Phase transformation during high-temperature oxidation ................................................ 47

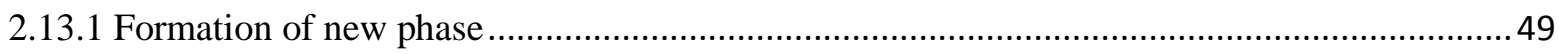

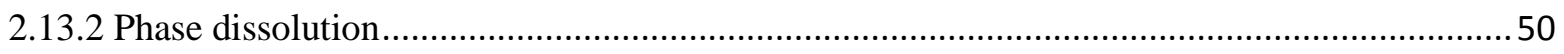

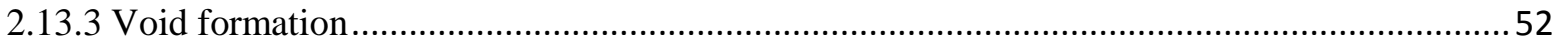

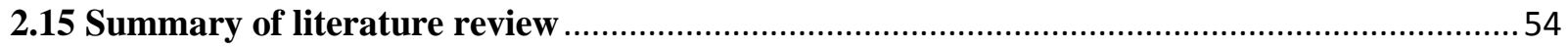

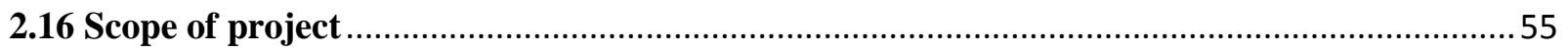

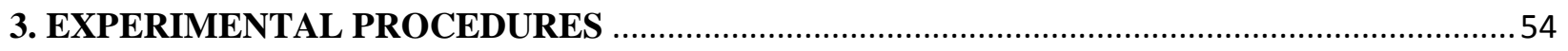

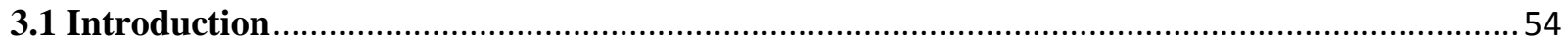

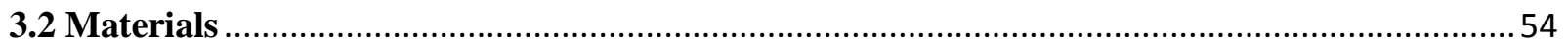

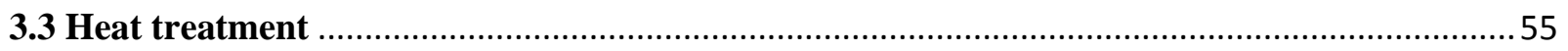

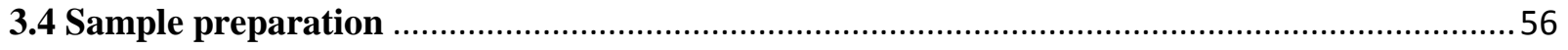

3.4.1 Electrical discharge machining-wire cutting (EDM-WC) ..................................................56

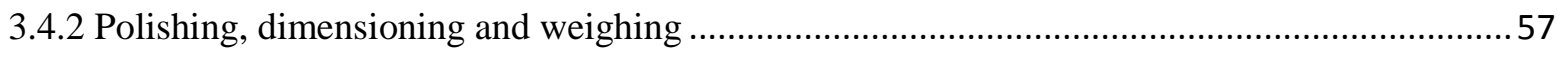

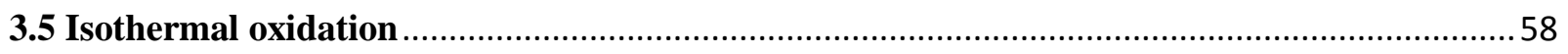

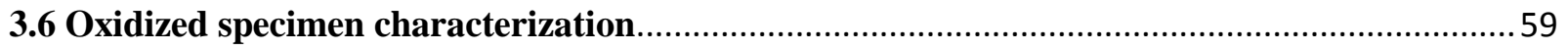

3.6.1 Cold mounting sample preparation of oxidized specimens ................................................... 59

3.6.2 Etching for alloy microstructure characterization ................................................................ 60

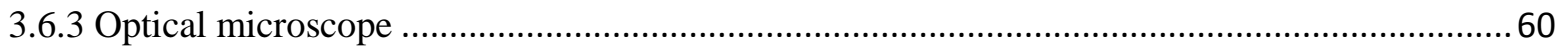

3.6.4 Scanning electron microscopy (SEM) / EDS analysis ........................................................... 60

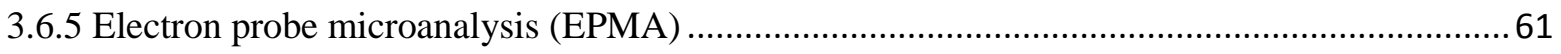




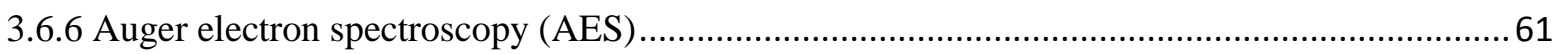

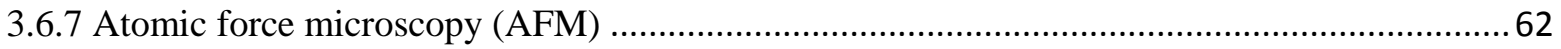

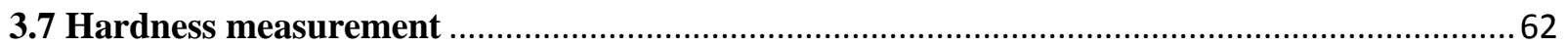

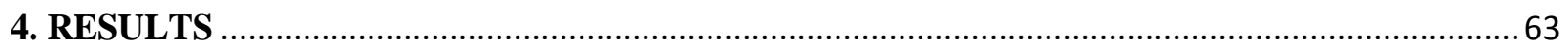

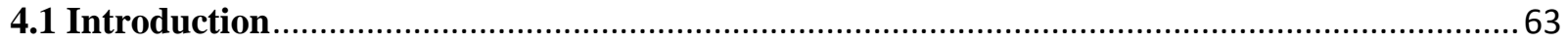

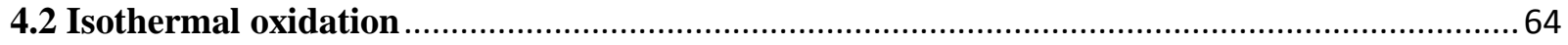

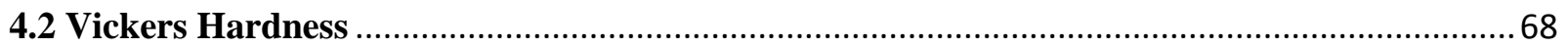

4.3 Microstructural characterizations of oxidized specimens .................................................. 69

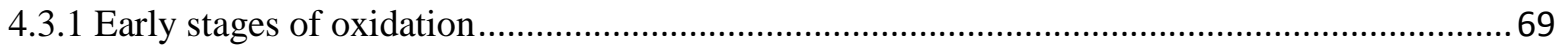

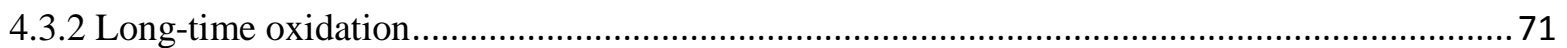

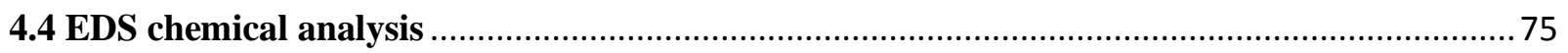

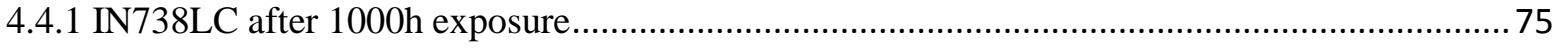

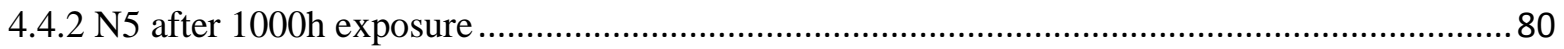

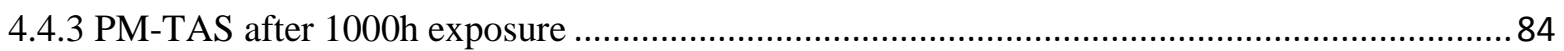

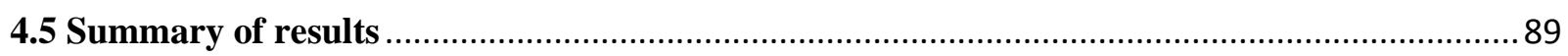

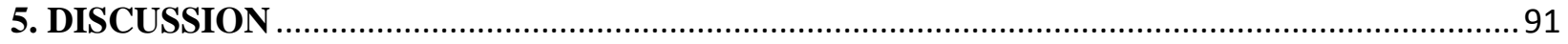

5.1 Microstructure, chemical composition and hardness ....................................................... 91

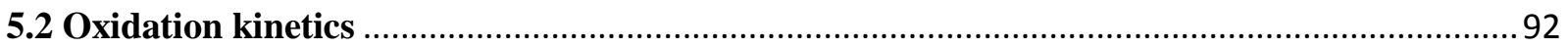

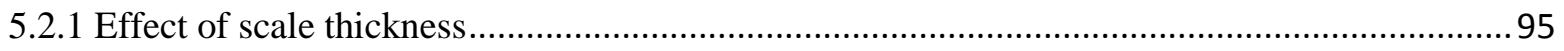

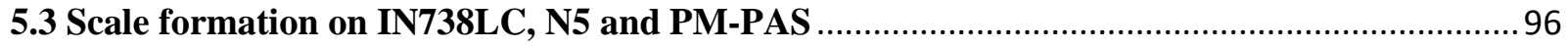

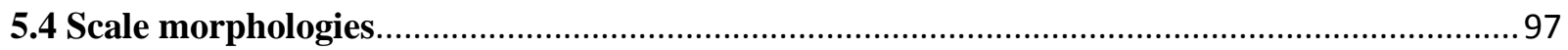

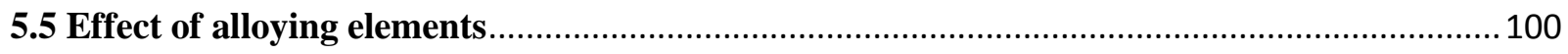

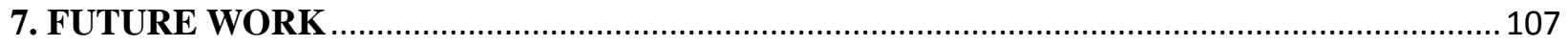

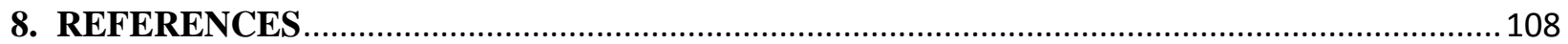




\section{LIST OF FIGURES}

Figure 2-1 Arrangement of $\mathrm{Al}$ and $\mathrm{Ni}$ atoms in Ni-base superalloys a) disordered gamma phase $(\gamma)$ and b) ordered gamma prime phase $\left(\gamma^{\prime}\right)$ [23] (Reproduced with permission from ASM International) 10

Figure 2-2 Nickel and aluminum phase diagram showing $\gamma$ and $\gamma^{\prime}$ phases [27] (Reproduced with permission from ASM International). 11

Figure 2- 3 Different stages of oxide scale formation: a) Oxygen adsorption, b) dissolution of oxygen ions and c) oxide scale formation. 20

Figure 2- 4 Schematics of point defects a) Schottky defect and b) Frenkel defect in a metal oxide [52] (Reproduced with permission from John Wiley and Sons). 24

Figure 2- 5 Weight gain or thickness versus oxidation duration for the kinetic laws of metal oxide scale growth [56] (Reproduced with permission from Prentice Hall, Inc.). 27

Figure 2- 6 Parabolic oxidation rate constant data for various metal/metal oxide systems as a function of reciprocal temperature [15] (Reproduced with permission from University of Cambridge). 29

Figure 2- 7 Transformation of parabolic to linear kinetics for oxidation of magnesium $500^{\circ} \mathrm{C}$ [56] [59] (Reproduced with permission from Prentice Hall). 31

Figure 2- 8 Schematic oxide scale formation according to Wagner's oxidation model [15] [60] (Reproduced with permission from University of Cambridge). 32

Figure 2- 9 Isothermal oxidation of binary $\mathrm{Ni}-\mathrm{Cr}$ alloy at $1000^{\circ} \mathrm{C}$ [85] (Reproduced with permission from Springer). 40 
Figure 2-10 Parabolic rate constant for the oxidation of $\mathrm{Ni}-\mathrm{Cr}$ alloys as a function of $\mathrm{Cr}$ content at $1000^{\circ} \mathrm{C}[15]$ (Reproduced with permission from University of Cambridge). 41

Figure 2- 11 Arrhenius plot of parabolic rate constant $\mathrm{kp}$ for the oxidation of a Ni-Al alloy [15] [90] (Reproduced with permission from Elsevier). 44

Figure 2- 12 Arrhenius plot of $\mathrm{kp}$ for $\mathrm{NiAl}$ and NiAl-Cr oxidation [90] (Reproduced with permission from Elsevier). 45

Figure 2- 13 Effect of composition on oxidation of Ni-Cr-Al ternary alloy [15] (Reproduced with

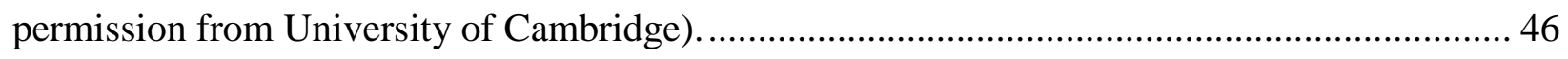
Figure 2- 14 Schematic diagram of oxide development on Ni-Cr-Al ternary alloys. a) Group I b) Group II and c) Group III [53] [69] (Reproduced with permission from Elsevier). 47

Figure 2- 15 Different modes of subsurface degradation as a result of oxidation [97] (Reproduced with permission from Elsevier). 48

Figure 2- 16 Diffusion profile in the subsurface region of two-phase alloy AB undergoing selective oxidation causing dissolution of solute rich B-phase to form oxide scale of BO [53] (Reproduced with permission from Elsevier).

Figure 3- 1 Metallographic cross-sections of partial solution heat treated nickel-base superalloys; a) IN738LC, b) N5 and c) PM TAS. 55

Figure 3- 2 Microstructure of a) IN738LC and b) N5 after ageing treatment in vacuum furnace, and c) PM TAS, d), e) and f) are the respective image analysis results. 56

Figure 3- 3 Hansvedt electrical discharge machine 57 Figure 3- 4 a) Image of the Carbolite high temperature box furnace and b) Test setup with samples in glazed porcelain crucibles prior to oxidation. 58 
Figure 4- 1 Isothermal oxidation of IN738LC in static air at $900^{\circ} \mathrm{C}$ a) weight gain as a function of oxidation duration and b) parabolic weight gain as a function of oxidation duration. 65

Figure 4- 2 Isothermal oxidation of N5 in static air at $900^{\circ} \mathrm{C}$ a) weight gain as a function of oxidation duration and b) parabolic weight gain as a function of oxidation duration. 66 Figure 4- 3 Isothermal oxidation of PM-TAS in static air at $900^{\circ} \mathrm{C}$ a) weight gain as a function of oxidation duration and b) parabolic weight gain as a function of oxidation duration. 67 Figure 4- 4 SEM microstructures of nickel-based superalloys exposed at $900^{\circ} \mathrm{C}$ in static air for one hour. a) IN738LC b) N5 and c) PM-TAS. 69

Figure 4- 5 SEM microstructures of the nickel-based superalloys exposed at $900^{\circ} \mathrm{C}$ in static air for three hours. a) IN738LC b) N5 and c) PM-TAS 69 Figure 4- 6 Typical AFM topographic 3D images of gas/alloy interface morphology after three hours of an oxidation at $900^{\circ} \mathrm{C}$. a) IN738LC b) N5 and c) PM-TAS.................................... 70 Figure 4- 7 Auger electron spectra of IN738LC oxidized at $900^{\circ} \mathrm{C}$ in static air for three hours.. 71 Figure 4- 8 Auger electron spectra of $\mathrm{N} 5$ oxidized at $900^{\circ} \mathrm{C}$ in static air for three hours. 71

Figure 4- 9 Optical micrographs of nickel-based superalloys oxidized at $900^{\circ} \mathrm{C}$ for $1000 \mathrm{~h}$. a) IN738LC, b) N5 and c) PM-TAS. 72

Figure 4- 10 SEM structural images of nickel-based superalloys exposed to $900^{\circ} \mathrm{C}$ for seven hours. a) IN738LC, b) N5 and c) PM-TAS. 72

Figure 4- 11 SEM structural images of nickel-based superalloys exposed to $900^{\circ} \mathrm{C}$ for $200 \mathrm{~h}$. i)

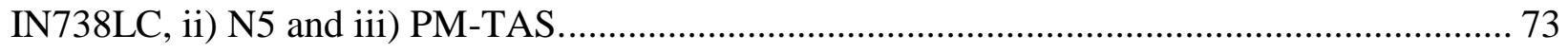
Figure 4- 12 SEM structural images of nickel-based superalloys exposed to $900^{\circ} \mathrm{C}$ for $600 \mathrm{hi}$ )

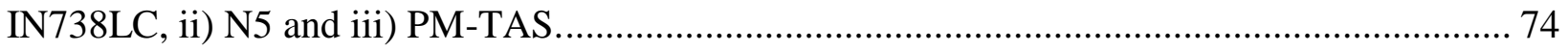


Figure 4- 13 SEM structural images of nickel-based superalloys exposed to $900^{\circ} \mathrm{C}$ for $1000 \mathrm{~h}$. i) IN738LC, ii) N5 and iii) PM-TAS 74

Figure 4- 14 Oxide scale growth plot for Ni-based superalloys exposed to air at $900^{\circ} \mathrm{C}$ for various times up to $1000 \mathrm{~h}$ with $95 \%$ confidence level. 75

Figure 4- 15 BSE image and EDS maps of IN738LC after $1000 \mathrm{~h}$ at $900^{\circ} \mathrm{C}$ oxidation showing distribution of elements in the oxide scale. 76

Figure 4- 16 BSE image and EDS quant mapping of IN738LC after $1000 \mathrm{~h}$ at $900^{\circ} \mathrm{C}$ oxidation showing distribution of elements in the oxide scale. 77

Figure 4- 17 An elemental EDS line scan across the oxide formed on IN738LC after 1000h at $900^{\circ} \mathrm{C}$ showing the site of interest and profiles for each element. 78

Figure 4- 18 EDS point scans of the external oxide layer on IN738LC as a function of oxidation duration from seven hours up to $1000 \mathrm{~h}$ at $900^{\circ} \mathrm{C}$. 79

Figure 4- 19 BSE image and EDS maps of an N5 specimen oxidized up to $1000 \mathrm{~h}$ at $900^{\circ} \mathrm{C}$ showing a distribution of elements in the oxide scale. 80

Figure 4- 20 BSE microstructure and EDS quant mapping of single crystal N5 oxidized specimen exposed at $900^{\circ} \mathrm{C}$ for $1000 \mathrm{~h}$ showing composition of elements. 81 Figure 4- 21 The EDS point scans result of the oxide scale on N5 as a function of oxidation duration up to $1000 \mathrm{~h}$ at $900^{\circ} \mathrm{C}$. 81 Figure 4- 22 SEM-microstructures showing voids at the scale/alloy interface in single crystal N5 exposed at $900^{\circ} \mathrm{C}$ a) Void initiation after $32 \mathrm{~h}$ and b) Larger voids after $1000 \mathrm{~h}$. 82 Figure 4- 23 The site of interest for the EDS point scan completed on the N5 oxide scale around the void region after $1000 \mathrm{~h}$ at $900^{\circ} \mathrm{C}$. 83 
Figure 4- 24 The EDS point scan spectrum of a thin layer of the oxide scale of N5 after 1000h at $900^{\circ} \mathrm{C}$. 83

Figure 4- 25 SEM microstructure (site of interest) and EDS maps of a PM-TAS specimen oxidized at $900^{\circ} \mathrm{C}$ up to $1000 \mathrm{~h}$ showing a distribution of elements in the oxide scale. 84

Figure 4- 26 SEM microstructure (site of interest) and EDS quant mapping of a PM-TAS specimen oxidized at $900^{\circ} \mathrm{C}$ up to $1000 \mathrm{~h}$ showing composition of elements 85 Figure 4- 27 An elemental EDS line scan across the oxide scale on PM-TAS after 1000h exposure at $900^{\circ} \mathrm{C}$ showing the site of interest and profiles for each element. 86 Figure 4- 28 The EDS point scans of oxide scale on PM-TAS against oxidation duration up to $1000 \mathrm{~h}$ at $900^{\circ} \mathrm{C}$. 87

Figure 4- 29 An elemental EDS line scan across the plate-like structure in PM-TAS after 1000h at $900^{\circ} \mathrm{C}$ showing the site of interest and profiles for each element. 88

Figure 5- 1 Specific weight change with exposure duration for IN738LC, N5 and TAS specimens after isothermal oxidation in air at $900^{\circ} \mathrm{C}$ up to $1000 \mathrm{~h}$ 92

Figure 5- 2 Oxidation map for ternary $\mathrm{NiCrAl}$ alloys during isothermal oxidation in air at $1000^{\circ} \mathrm{C}$ [65] [69] (Reproduced with permission from University of Cambridge). Compositions of IN738LC, N5 and PM-TAS are inserted in the oxidation map, taking only their $\mathrm{Cr}$ and $\mathrm{Al}$ contents into account. 97

Figure 5- 3 JMatPro thermodynamic modelling; effect of 3.44 wt. \% Ti on chromium activity in IN738LC at $900^{\circ} \mathrm{C}$. 102

Figure 5- 4 JMatPro thermodynamic modelling; effect of 1 wt. \% Ti on chromium activity in IN738LC at $900^{\circ} \mathrm{C}$. 102 


\section{LIST OF TABLES}

Table2- 1 Functions of various alloying elements in Ni-base superalloys [12] [20] [23]............ 8

Table2- 2 Nominal composition of a IN738LC polycrystalline cast nickel-base superalloy [43].

Table2- 3 Nominal composition of N5 single crystal nickel-base superalloy [43] 17

Table2- 4 Nominal composition of TAS nickel-base alloy [1]. 18

Table 3- 1 Chemical compositions of IN738LC, N5 and TAS alloy in wt. \%. 54

Table 4- 1 Rate constant, kp for three superalloys oxidized at $900^{\circ} \mathrm{C}$ in static air. 68

Table 4- 2 Vickers micro-hardness values for superalloys in various heat treated conditions..... 68 Table 4- 3 The EDS point scan results for the external oxide scale on IN738LC with 95\% confidence level.

Table 4- 4 The EDS point scan results of the oxide scale on N5 with $95 \%$ confidence level...... 82 Table 4- 5 The EDS point scans result of oxide scale on powder metallurgy TAS with $95 \%$ confidence level. 87

Table 5- 1 Parabolic rate constants, $\mathrm{kp}$ values for various nickel-based superalloys including alloys used for the present study [84] [112] [125] [126]. 95 


\section{ACKNOWLEDGEMENTS}

I wish to express my gratitude and deep appreciation to my supervisors, Prof. William Caley and Prof.

Norman Richards, for nurturing me till the end of this research work, when all hope seems to have lost. I will remain grateful, for effective supervision, mentorship, dedication, and understanding and moral support. Thank you and cheers!

I would like to thank Prof. Ojo for providing constant encouragement and mentorship. Also, Dr. Ravi Sidhu and Dr. Abdul Khan are thanked for their assistance during EPMA and SEM analysis. I acknowledge Guilherme Garrido Damaceno for the support accorded during this research. I would also like to acknowledge technicians Mike Boskwick and Trevor Smith for their support.

I am indeed grateful to the natural science and engineering research council of Canada (NSERC) for funding this research and providing other financial support.

To all my family and friends, especially Ravikumar. H., Huzefa F. D., Harish. N., Adarsh. L., Madhu. N., Praveen. R., Vipin. J., Manoj. R., Mithun. M. and host of others. 


\section{ABSTRACT}

Ni-based superalloys are used for high-temperature components of gas turbines in both industrial and aerospace applications due to their ability to maintain dimensional stability under conditions of high stress and strain. The oxidation resistance of these alloys often dictates their service lifetime.

This study focuses on the isothermal oxidation behaviour of three nickel-based superalloys; namely, polycrystalline cast IN738LC, single-crystal N5 and a ternary Ni-Fe-Cr (TAS) powder metallurgy alloy. The isothermal oxidation tests were conducted at $900^{\circ} \mathrm{C}$ in static air up to $1000 \mathrm{~h}$ and the specific aspects studied were the oxidation behaviour of these chromia-forming and alumina-forming alloys that are used extensively in industry. In particular, the behaviour of oxide scale growth and subsurface changes were analysed in detail using various techniques such as SEM, EDS and AFM. From the isothermal oxidation kinetics, the oxidation rate constant, kp was calculated for each alloy and found to be; $\mathrm{kp}=2.79 \times 10^{-6} \mathrm{mg}^{2} \cdot \mathrm{cm}^{-4} \cdot \mathrm{s}^{-1}$ for IN738LC, $\mathrm{kp}=$ $1.42 \times 10^{-7} \mathrm{mg}^{2} \cdot \mathrm{cm}^{-4} \cdot \mathrm{s}^{-1}$ for $\mathrm{N} 5$ and $\mathrm{kp}=1.64 \times 10^{-7} \mathrm{mg}^{2} \cdot \mathrm{cm}^{-4} \cdot \mathrm{s}^{-1}$ for TAS. Based on a microstructural analysis, IN738LC exhibited a continuous dense outer scale of $\mathrm{Cr}_{2} \mathrm{O}_{3}$ and discontinuous inner scale of $\mathrm{Al}_{2} \mathrm{O}_{3}$, whereas N5 and TAS showed a dense outer scale of $\mathrm{Al}_{2} \mathrm{O}_{3}$ alone. The results suggested that the N5 and PM-TAS alloys are more oxidation resistant than the IN738LC under these conditions. 


\section{INTRODUCTION}

\subsection{Application of nickel-based superalloys}

Superalloys are used in applications where superior heat and oxidation resistance are required while the material must concurrently maintain its mechanical integrity and microstructure. These properties of superalloys were developed over the past 60 years for applications involving aggressive operating conditions like those experienced by components of gas turbine engines [1]. Aviation gas turbines take up to three quarters of all applications of superalloys, the other quarter going to power generation gas turbines, the chemical industry, nuclear reactors and various applications involving high temperature and oxidation/chemical resistance. Traditionally, the superalloys are classified into three broad classes according to their base element: Ni-based, Cobased and Fe-based alloys [2].

The basic working principle of an engine typically used in an aeronautical application is explained as follows. In order to produce the thrust, the incoming air is compressed in a compressor section before the fuel is added, thus increasing the pressure. The compressed air is then fed into the combustion chamber, where the air is mixed with fuel and ignited, creating a high temperature (up to about $1400^{\circ} \mathrm{C}$ ) gaseous product which is very high in stored energy [3]. These high temperature gasses are directed to the blades in the turbine section (temperature range from $750^{\circ} \mathrm{C}$ to $1100^{\circ} \mathrm{C}$ ), which then convert the stored energy to rotational mechanical energy [4] [5]. The gasses from the turbine section, then become low in energy, but not so low that they 
cannot be utilized further. These less energetic gasses can be subsequently fed through another set of nozzles to convert even more energy to create thrust.

Alternatively, in an industrial stationary turbine, where the thrust is not important, the exhaust gasses can be used for secondary heating applications within the power generation cycle to increase the efficiency of the process.

The high temperature within either an industrial gas turbine or in an aircraft engine is the main consideration in determining compositional requirement of the superalloys. Considering environmental safety, a gas turbine engine is designed in such a way that power is generated with increased efficiency and lower fuel consumption. The thermodynamic efficiency of a gas turbine engine depends on the temperature and pressure inside the engine. For example, a higher inlet temperature, such as $1400^{\circ} \mathrm{C}$ and a pressure of $3 \mathrm{MPa}$ in the combustion chamber will result in a higher efficiency. However, the tolerance of the turbine entry temperature is based on the material used in the combustion chamber and the material used in blading for the turbine section. The material must have good oxidation and corrosion resistance and good mechanical properties, such as fatigue and creep resistance at temperatures up to $1100^{\circ} \mathrm{C}$ [6] [7]. As a result, superalloys have been developed for these applications.

Nickel based superalloys find widespread use of high temperature components of gas turbines in both industrial and aerospace applications due to their excellent mechanical, thermal and surface stability (dimensional stability) at elevated temperatures [8]. These alloys can contain up to $60 \%$ $\mathrm{Ni}$ with the remaining elements being varied depending on the applications. Over time, several changes have been made in the manufacturing of Ni-based superalloys to improve the processing methods and to optimize the chemical composition and microstructure [9]. For vanes and blades, 
wrought alloys are now replaced by cast materials and nowadays the use of single-crystal $\mathrm{Ni}$ based superalloys is gradually increasing. The fatigue life of single-crystal Ni-based superalloy is much superior to that of polycrystalline Ni-based superalloys due to the absence of grain boundaries.

In recent years, there also have been attempts to produce Ni-based superalloys through powder metallurgy processing techniques [10]. The main disadvantage of this process compared to other processes is the preserved residual porosity and fine grain size. The porosity can increase the oxidation rate and may also have a detrimental effect on the physical properties of the material such as creep and fatigue. The fine grains can lead to crack initiation, but also may benefit in terms of strengthening. The powder metallurgy method of production can have excellent compositional control, homogeneous distribution of secondary phases and precipitates as well as being a near net shape process with little post sinter machining required compared to polycrystalline cast and single-crystal alloys [11].

Superalloys derive their strength through solid solution strengthening and in some alloys through precipitation hardening [12]. The nickel based superalloys which are used in the high temperature zones of a gas turbine always contain a certain amount of aluminum and chromium, which form protective oxides of alumina $\left(\mathrm{Al}_{2} \mathrm{O}_{3}\right)$ and chromia $\left(\mathrm{Cr}_{2} \mathrm{O}_{3}\right)$, thereby preventing further removal of the material in a harsh environment. However, during long term exposure, the protective oxide film can spall off and evaporation of chromium may lead to further dissolution of other alloying elements. This oxidation process may finally cause material degradation and eventually negatively affect the mechanical properties of the alloys. 


\section{LITERATURE REVIEW}

\subsection{Superalloys - General remarks}

Over the past 100 years there has been significant development in the field of superalloys. In the 1910-1915 eras austenitic stainless steel was discovered and developed to increase the corrosion resistance in copper and iron alloys [13]. The gamma ( $\gamma$ - face centered cubic) austenite field of stainless steel became an important physical zone from which superalloys have been developed.

With the simultaneous effort of Bedford and Pilling [13], and also Merica [14], the significant creep strength of superalloys was increased by adding small amounts of titanium and aluminum to the well-known nickel-chromium alloy (80/20).

Since superalloys are exposed to the high temperature exhaust gas and steam, the oxidation resistance at high temperatures needs to be considered for as well [15]. The best and optimum performance of the superalloys can be adjusted by adding alloying elements to the material depending on their application requirement [16]. Therefore, the general requirements for any superalloys include high temperature strength at elevated temperature, corrosion and oxidation resistance, creep and mechanical fatigue resistance, light weight and finally microstructural and mechanical stability at high temperatures.

The superalloys are divided into three groups: (1) Cobalt-base superalloys, (2) Iron-base superalloys, and (3) Nickel-base superalloys. These alloys are particularly applicable in the temperature range $650^{\circ} \mathrm{C}-980^{\circ} \mathrm{C}$, where they excel in strength/weight ratio and oxidation resistance, both characteristics considered to be of prime importance for the aerospace application. 


\subsubsection{Cobalt-base superalloys}

Generally cobalt-base superalloys are non-magnetic, wear resistant, oxidation and heat-resistant (high strength even at elevated temperatures) up to $1090^{\circ} \mathrm{C}$. As a result, these alloys have found to be useful in high-temperature blades, rotors and turbo superchargers and in the aerospace engines. The cobalt-base superalloys are not developed much as compared to the nickel-based alloys (discussed in section 2.1.3) and their usage is been limited because of their manufacturing difficulty [17].

Numerous properties of cobalt base superalloys arise from the crystal structure (FCC) of the cobalt and they are stable at room temperature. These alloys benefit from the solid solution strengthening effect of refractory elements niobium, tungsten and molybdenum as well as carbide formation. The oxidation resistance is imparted by the addition of chromium [18]. Cobalt-base superalloys comprise an appreciable amount of chromium (18 wt. \%-20 wt. \%) and carbon (0.2 wt. \%-0.6 wt. \%) and derive their strength through the precipitation of chromium carbide [19] [20]. These grain boundary carbides inhibit grain boundary sliding. The carbides present in these alloys are in the form of $\mathrm{M}_{7} \mathrm{C}_{6}$ and $\mathrm{M}_{23} \mathrm{C}_{6}$ (where $\mathrm{M}$ denotes a cation such as chromium) [20]. The cobalt is not stable at high temperature in cobalt-base superalloys. The mechanical properties of the cast alloys at elevated temperatures are improved by adding boron and titanium to the wrought alloys.

Although cobalt-base superalloys are lower in strength than their nickel-base equivalent, one must also be aware of the fact that, mainly cast cobalt-base superalloys are more stable in the temperature range of $750^{\circ} \mathrm{C}$ to $1000^{\circ} \mathrm{C}$. Because of this characteristic, cobalt-base alloys are more useful than other superalloys at elevated temperatures for long duration applications. 


\subsubsection{Iron-base superalloys}

The iron-base superalloys are the most underdeveloped alloys in the field of superalloys because of their low mechanical strength compared to nickel and cobalt-base superalloys, but they are very resistant to corrosion and oxidation [12].

The chemical composition of these superalloys will determine their microstructure and properties. However, there are number of drawbacks to iron-base superalloys. First, the electronic structure of iron has a greater tendency to promote the formation of brittle TCP phases ( $\sigma$ and Laves) other than the ordered FCC $-\mathrm{L}_{2} \gamma^{\prime}$ (gamma prime) phase, which when often at best only metastable [12] [21]. Second, replacement of nickel by iron as the base element decreases the oxidation resistance. The basic strengthening mechanism is similar to that of cobalt-base superalloys, namely carbide precipitation. These alloys are responsive to heat treatment.

\subsubsection{Nickel-base superalloys}

Nickel-base superalloys have evolved from the nickel-chromium (80Ni-20Cr) binary alloy to complex precipitation hardening alloys. Generally, superalloys are high temperature materials that are based mostly on the nickel and less on cobalt and iron. The nickel-base superalloys have high-strength at elevated temperature; high resistance to environmental attack (oxidation, nitridation, carburization and sulphidation) and to thermal fatigue and corrosion; good stress rupture strength, creep strength and toughness and microstructural stability. Typically, elevated temperature is defined from a characteristic of the material rather than that of the application itself. For an example, the superalloys can be used in load-bearing applications at temperatures in 
excess of $50 \%$ of melting temperatures $\left(\mathrm{T}_{\mathrm{m}}\right)$ and often in environments approaching $90 \%$ of melting temperature.

\subsection{Nickel-base superalloys: chemistry and microstructure.}

The ability of the nickel-base superalloys to maintain their mechanical properties under extreme conditions of high temperatures and stress is due to their microstructure, which is the product of their composition and method of processing. Although, the strength of nickel-base superalloys is from solid-solution strengthening of substitutional atoms within the face centered cubic nickel rich matrix, the main strength comes from the $\mathrm{Ni}_{3}(\mathrm{Al}, \mathrm{Ti}$,) intermetallic precipitate phase, which is coherent within the matrix [12] [13]. This phase has the ordered FCC-L1 2 structure such as $\mathrm{Cu}_{3} \mathrm{Au}$-type, where the centers of the cube faces occupy by the nickel atoms and the corners of the cube occupy by (Al or $\mathrm{Ti}$ ) atoms with suitable shape, size and volume fraction [22].

The microstructure of superalloys with different phases is formed by the number of alloying elements present in the matrix [13]. The behaviour of alloying elements depends on their position in the periodic table. The atomic radius of the chromium, cobalt, ruthenium, rhenium, tungsten, iron and molybdenum elements are close to the atomic radius of nickel and therefore also take part in the stabilization of the $\gamma$ phase. The $\gamma^{\prime}$ phase is stabilized by the larger atomic radii elements such as aluminum, niobium, tantalum and titanium. The other class of alloying elements like boron, carbon and zirconium acts as grain boundary strengtheners in $\gamma$ phase [1]. Aluminium and chromium are also necessary to improve the surface stability through the formation of $\mathrm{Cr}_{2} \mathrm{O}_{3}$ and $\mathrm{Al}_{2} \mathrm{O}_{3}$ respectively. The effects of various alloying elements on the microstructure of nickel-base superalloys are shown in Table 2-1. 
Table2- 1 Functions of various alloying elements in Ni-base superalloys [12] [20] [23].

\begin{tabular}{|l|l|}
\hline \multicolumn{1}{|c|}{ Effect } & \multicolumn{1}{c|}{ Alloying elements } \\
\hline Solid solution strengtheners & $\mathrm{Co}, \mathrm{Cr}, \mathrm{Fe}, \mathrm{Mo}, \mathrm{W}, \mathrm{Ta}, \mathrm{Re}, \mathrm{Ru}, \mathrm{Al}$ \\
\hline Forms $\mathrm{MC}$ carbides & $\mathrm{W}, \mathrm{Ta}, \mathrm{Ti}, \mathrm{Mo}, \mathrm{Nb}, \mathrm{Hf}$ \\
\hline Forms $\mathrm{M}_{23} \mathrm{C}_{6}$ carbides & $\mathrm{Cr}, \mathrm{Mo}, \mathrm{W}$ \\
\hline Forms $\mathrm{M}_{6} \mathrm{C}$ carbides & $\mathrm{Mo}, \mathrm{W}, \mathrm{Nb}$ \\
\hline Forms $\gamma^{\prime} \mathrm{Ni}_{3}(\mathrm{Al}, \mathrm{Ti})$ & $\mathrm{Al}, \mathrm{Ti}$ \\
\hline Raises solvus temperature of $\gamma^{\prime}$ & $\mathrm{Co}$ \\
\hline Hardening precipitates and/or intermetallic & $\mathrm{Al}, \mathrm{Ti}, \mathrm{Nb}$ \\
\hline Oxidation resistance & $\mathrm{Al}, \mathrm{Cr}, \mathrm{Y}, \mathrm{Si}$, \\
\hline Improves creep properties & $\mathrm{B}, \mathrm{Ta}$ \\
\hline Retards $\gamma^{\prime}$ coarsening & $\mathrm{Re}, \mathrm{Fe}, \mathrm{Co}, \mathrm{Mo}, \mathrm{Nb}, \mathrm{Ti}$ \\
\hline
\end{tabular}

According to studies done on Ni-base superalloys, deformation resistance increases with an increase in tungsten content, but decreases with increase in molybdenum [1]. Thus, the recent trend is for a higher concentration of tungsten and reduction in the molybdenum concentration to increase solid solution strengthening and coarsening of the gamma prime $\left(\gamma^{\prime}\right)$ precipitates. The volume fraction of gamma prime slightly reduces with an increase in concentration of titanium, niobium and tantalum, but increases the antiphase boundary (explained in section 2.2.2) and mismatch between the precipitate and the matrix $\left(\gamma^{\prime} / \gamma\right)[12]$.

When deciding how the existing alloy composition may be modified to increase the mechanical and physical properties, care should be taken such that a detrimental side effect does not occur along with the desired effect. For example, the addition of higher chromium content to a nickelbase superalloy composition increases the oxidation and corrosion resistance of the alloy, but 
also increases the gamma prime coarsening rate. Depending on the application requirement of the alloy, the higher $\gamma^{\prime}$ coarsening rate might be not required.

The ability of nickel-base superalloys to resist corrosion, oxidation and deformations under extreme conditions of high temperatures and stress is due to their microstructure and phases, which is a result of their composition and processing method. The most significant microstructural features are:

\subsubsection{Gamma phase $(\gamma)$ :}

The gamma phase exhibits a face centered cubic structure, as shown in Figure 2-1 (a). Generally, it forms a continuous matrix phase with other phases residing in it. The matrix phase is primarily composed of chromium, molybdenum, cobalt, aluminum, titanium, tungsten and rhenium in a solid-solution. These elements occupy a substitutional solid solution lattice position in a nickel crystal structure giving a disordered system.

\subsubsection{Gamma prime phase $\left(\gamma^{\prime}\right)$ :}

This phase may also contain a number of elements, but it is strictly considered to be an intermetallic phase in the form of $\mathrm{Ni}_{3} \mathrm{Al}$ precipitates. These intermetallic phases give major strength to nickel-based superalloys [24]. The $\mathrm{Ni}_{3} \mathrm{Al}$ phase is considered to be an ordered FCC structure with $\mathrm{L1}_{2}$-type phase, which is shown in Figure 2-1 (b). These precipitate strengthening phases will form when aluminum and titanium solubility exceeds in the nickel matrix during cooling. Titanium can also be readily substituted for aluminum to form this phase, which is generally termed as $\mathrm{Ni}_{3}(\mathrm{Al}, \mathrm{Ti})$. Generally, the strengthening mechanism in nickel-base superalloys is attributed to that which arises from the small structural difference between $\gamma$ and $\gamma^{\prime}$ 
phases, i.e. the long range order and lattice misfit. The lattice mismatch among $\gamma$ and $\gamma^{\prime}$ phases is measured to be very small, about $0.5-1 \%$ [25]. The small mismatch is accommodated by the elastic coherency strains and low interfacial energy. The dislocations which pass through intermetallic phase $\gamma^{\prime}$ are known as a superlattice dislocations and the energy required for these dislocations to move through $\gamma^{\prime}$ precipitates are known as an anti-phase boundary (APB) energy. Basically, this process is a direct result of the slip of superlattice dislocations in ordered crystals i.e. slip system between the $\gamma$ and $\gamma^{\prime}$ phases [22] [26]. The APB energy can be altered by changing the structure of the $\gamma$ and $\gamma^{\prime}$ phases and this can be achieved by the addition of alloying elements to the matrix. However, the ordered FCC structure $\gamma^{\prime}$ precipitates usually make up anywhere from $50 \%$ to $70 \%$ volume fraction of the material and they are coherent with the surrounding nickel-matrix $(\gamma$ phase $)$.
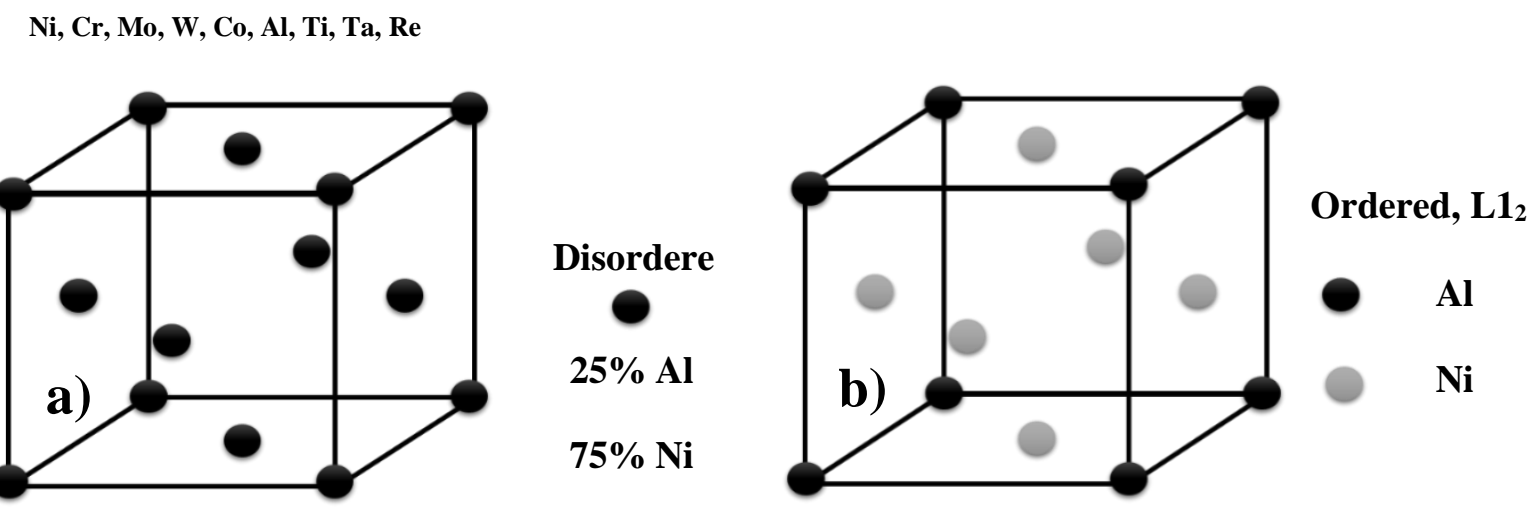

Figure 2-1 Arrangement of $\mathrm{Al}$ and $\mathrm{Ni}$ atoms in Ni-base superalloys a) disordered gamma phase $(\gamma)$ and b) ordered gamma prime phase $\left(\gamma^{\prime}\right)$ [23] (Reproduced with permission from ASM International).

According to the $\mathrm{Ni}-\mathrm{Al}$ binary phase diagram, the $\gamma$ and $\gamma^{\prime}$ phases exist over a range of compositions. This is comprehensible in the case of $\gamma$ but it is also true for $\gamma^{\prime}$ phase as well, which is shown in Figure 2-2. 


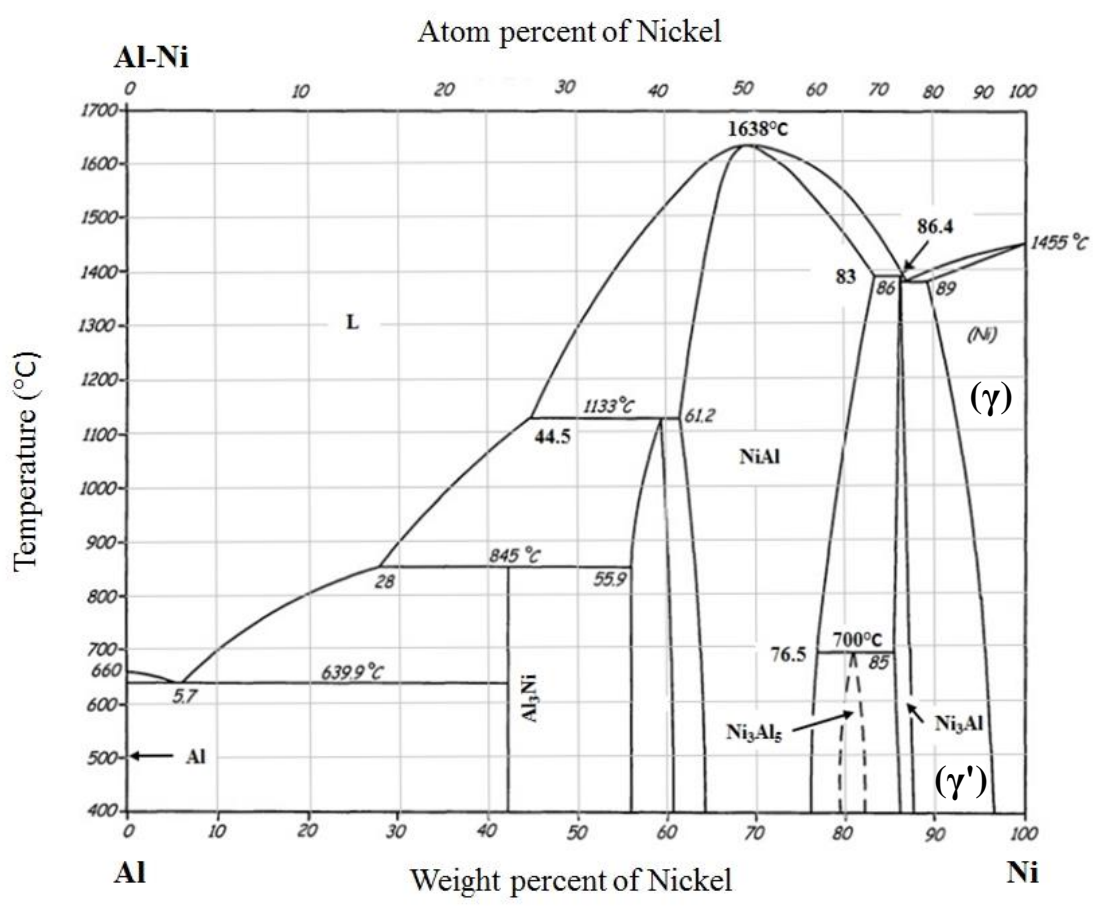

Figure 2-2 Nickel and aluminum phase diagram showing $\gamma$ and $\gamma^{\prime}$ phases [27] (Reproduced with permission from ASM International).

\subsubsection{Carbides ( $\mathrm{MC}$ and $\mathrm{M}_{23} \mathrm{C}_{6}$ ):}

The carbides can take many forms, both compositionally and morphologically. Generally, carbides are present as MC carbides in the cast structure of nickel-base superalloys with sizes ranging from one micron to hundreds of microns, which appear as blocky and nodular morphologies. The MC carbides are very stable and form at temperatures between the liquidus and solvus of the alloy. Some of the MC carbide precipitates present in nickel-base superalloys are (Ta, W, Ti, Mo, and Hf) C [28], from which TiC and HfC are most stable compounds.

$\mathrm{M}_{23} \mathrm{C}_{6}$ carbides usually appear at alloy grain boundaries as irregular blocky particles [29]. They form mainly in alloys with high chromium content. Fine granular and discontinuous $\mathrm{M}_{23} \mathrm{C}_{6}$ carbides mainly form at lower temperatures $\left(750^{\circ} \mathrm{C}-980^{\circ} \mathrm{C}\right)$ during heat treatment and also 
during service time as a result of decomposition of $\mathrm{MC}$ carbides [30]. $\mathrm{M}_{23} \mathrm{C}_{6}$ and $\mathrm{M}_{6} \mathrm{C}$ carbides are often called as secondary carbides. The morphology of these carbides strongly influences the properties of the nickel-base superalloys. The rupture strength of the materials is improved by the presence of these carbide precipitates through the inhibition of grain boundary sliding [20]. However the failures in the material can start either by de-cohering of the carbide precipitates from the matrix interface or by fracture of carbide precipitates.

\subsubsection{Topologically close packed (TCP) phases:}

The TCP phases take a plate or needle like structure that may form in superalloys for some compositions under certain conditions. Basically, if the nickel-base superalloys composition has not been carefully controlled, these types of undesirable phases can form through the heat treatment and also can be commonly seen during the service [16]. These phases are very brittle and low in strength, which can reduce the rupture strength and ductility of the material. Nickelbase superalloys that contain a high level of reactive elements like chromium, niobium, tungsten, molybdenum and cobalt are susceptible to formation of TCP phases such as $\sigma$ and $\mu$ [11].

\subsection{Strengthening mechanism of nickel-base superalloys}

Generally the high strength of nickel-base superalloys is due to three mechanisms: 1) solid solution strengthening, 2) precipitation hardening from a $\gamma^{\prime}$ phase and c) grain boundary strengthening by carbides.

\subsubsection{Solid solution strengthening}

The solid-solution strengtheners in nickel-base superalloys are Cr, Mo, Ta, Re, Co and W. These elements have different radii compared to base material (Ni) and addition of the above elements 
as substitutional solute atoms to the original lattice creates distortion in the system. The solidsolution then attains the strength from these lattice distortions (i.e. strain area).

The solute atoms decrease deformation of material at high-temperature by decreasing the lattice stacking fault energy. The aluminum acts as both a solid-solution strengthener and a precipitate hardener. The addition of solid solution strengtheners increases the strength until the solubility limit is reached. After that, precipitate strengthening becomes more effective [2]. In the case of solid solution strengthening, the strength can be estimated by solutionizing all the precipitates and measuring the increase in hardness over that of pure nickel.

\subsubsection{Precipitation hardening}

The main strength of a nickel-base superalloy comes from precipitation hardening. The precipitation hardening of a nickel-base superalloy is performed in the same temperature range as the operating temperature of the material; this results in a metastable microstructure. The precipitation of $\gamma^{\prime}$ precipitates occurs by homogeneous nucleation and the growth stage is normally very rapid. The growth of precipitate phases during an age hardening process reduces the total free energy of the system [31]. Since the $\gamma^{\prime}$ phase is coherent in all crystalline directions (small precipitate size), coarsening of these precipitates is not restricted in any one direction. The particle growth is then influenced by the elastic strain energy and interfacial energy between the $\gamma^{\prime}$ and $\gamma$, and the surrounding diffusion field and the solute saturated matrix [32]. Generally the interfacial energy is the energy associated with the generation of interface within a single crystal of $\gamma$, and is proportional to the interfacial area. Similarly, the strain energy is the lattice mismatch between the $\gamma^{\prime}$ and the $\gamma$ phases, and is proportional to the precipitate volume. This interfacial 
energy dominates the strain energy in small precipitates, when the precipitates reach a critical size, the strain energy takes over.

\subsubsection{Grain boundary strengthening by carbides}

The formation of carbides is also very important for the strengthening purpose, at least for the alloys which are not single-crystals. The carbides serve three functions in superalloys. First, strengthens the grain boundary by preventing the grain boundary sliding at high temperature. Second, the presence of fine carbides such as $\mathrm{M}_{23} \mathrm{C}_{6}$ which precipitates in matrix resulting in high strength. Third, carbides can join with certain elements which causes the phase instability during service.

\subsection{Development of Ni-base superalloys processing}

Over the past 50 years, there have been dramatic improvements in casting techniques. These developments allowed industries to produce components from the nickel-base superalloys with the addition of lower amounts of oxide forming elements such as aluminum and chromium. There are three main processing methods to produce superalloys, wrought processing, casting and powder metallurgy.

Generally, the processing of wrought superalloys is done by re-melting either by vacuum arc or electro-slag re-melting [33]. The wrought superalloys derive their strength from precipitation hardening and also from non-precipitation strengthening [34]. The wrought superalloys have higher strength at lower temperature, but the thermal stability of the alloy decreases at elevated temperatures $\geq 650^{\circ} \mathrm{C}$. The transformation of intermetallic $\gamma^{\prime}$-phase to $\delta$-phase has been found to deteriorate the mechanical properties of the material [35]. 
Compared to the earlier developments, the advanced cast nickel-base superalloys are subjected to higher aluminum and chromium contents in order to obtain the optimum combination of reduction in the TCP phase formation and increase in creep rupture strength. However, the grain boundaries in the cast alloys decrease the creep deformation resistance of the material [36]. Development of directionally solidified (DS) casting method resulted in a substantial increase in creep strength, ductility and thermal fatigue resistance. The DS processing method produces parts with long columnar and parallel grains with approximately the same orientation, i.e. (100) [37]. The DS process decreases the number of grains drastically.

The single crystal cast processing method uses the same procedure as directionally solidified cast process to produce single crystal material without any grain boundaries. The columnar grains starting with this methodology are thereabouts limited that one of the crystals will develop further and become larger with a dendritic structure characteristic [37].

There has been a critical development in the field for powder metallurgy in both powder manufacturing and also routines for compaction [38]. This method has distinct advantages over the wrought and cast products. The parts produced by this method showed better mechanical properties results compared to those corresponding to the conventionally cast parts. Additionally, higher ductility and toughness make a powder metallurgy methodology more attractive [39]. By adjusting the process parameters, $100 \%$ dense parts can be produced, which are corrosion and oxidation resistant. Some of the advantages of this process include tighter composition control, composition homogeneity, decreases in micro-segregation and also improved morphological control [40]. 
For this study a conventional cast polycrystalline nickel base alloy IN738LC, single crystal nickel-based superalloy N5 and a powder metallurgy Ni-Cr-Fe ternary alloy with $6 \% \mathrm{Al}$ and $0.5 \% \mathrm{Si}$ (TAS) were chosen. These are reviewed in the following sections.

\subsubsection{Physical metallurgy of IN738LC}

The alloy IN738LC is a vacuum melted and investment cast, precipitation hardenable nickelbase superalloy. The cast IN738LC superalloy may be subjected to hot isostatic processing (HIP) to remove the micro porosity formed during solidification [41]. The alloy possesses exceptional creep-rupture strength at high temperature combined with oxidation and hot corrosion resistance compared to high-strength low chromium content superalloy [42]. The main feature of IN738LC is its thermodynamic metastability, which results in morphology change, composition, distribution and properties of various phases during exposure to high temperature with or without superimposed stresses in varying environments. IN738LC is a polycrystalline nickel-base superalloy with FCC $\gamma$ phase containing hard precipitates of $\gamma^{\prime}$ that may contain one or more alloying elements such as chromium, aluminum, tungsten, tantalum, titanium, cobalt, molybdenum as well as grain boundary strengtheners like boron and zirconium. The volume of $\gamma$-matrix consists up to $50 \%$ of $\gamma^{\prime}$ precipitates. The interaction between the $\gamma^{\prime}$ phase and the dislocations are the main reason for high strength and increase in resistance to plastic deformation [20]. The nominal composition of IN738LC is presented in Table 2-2.

Table2- 2 Nominal composition of a IN738LC polycrystalline cast nickel-base superalloy [43].

\begin{tabular}{|c|c|c|c|c|c|c|c|c|c|c|c|c|c|}
\hline Element & C & Co & Cr & Mo & W & Ta & Al & Ti & B & Nb & Zr & Fe & Ni \\
\hline Weight \% & 0.11 & 8.5 & 16 & 1.75 & 2.6 & 1.75 & 3.4 & 3.4 & 0.01 & 0.9 & 0.028 & 0.05 & Balance \\
\hline
\end{tabular}




\subsubsection{Physical metallurgy of single crystal N5}

The single crystal N5 is the second-generation of rhenium-containing superalloys, which are distinguished from the first generation single crystal superalloys developed by General Electric Company [44]. The microstructural stability in these alloys involved control of TCP phases that could precipitate in moderate amounts over a long time at temperatures above $900^{\circ} \mathrm{C}$, but were detrimental to mechanical properties such as fatigue and creep resistance [45]. The addition of rhenium increases the alloy strength by acting as barrier against dislocation movement in the $\gamma$ matrix 1. The level of aluminum concentration is recorded as approximately 6 wt. \% in N5, while the chromium level is relatively low ( $8 \mathrm{wt} . \%)$. With the combination of aluminum and rhenium, the alloy shows better oxidation resistance and decreases the $\gamma^{\prime}$ coarsening rate [1]. The nominal composition of single crystal N5 nickel-base superalloy is presented in Table 2-3.

Table2- 3 Nominal composition of N5 single crystal nickel-base superalloy [43].

\begin{tabular}{|c|c|c|c|c|c|c|c|c|c|c|c|c|c|}
\hline Element & $\mathbf{C}$ & $\mathbf{C o}$ & $\mathbf{C r}$ & $\mathbf{M o}$ & $\mathbf{W}$ & $\mathbf{T a}$ & $\mathbf{A l}$ & $\mathbf{T i}$ & - & $\mathbf{R e}$ & $\mathbf{H f}$ & $\mathbf{Y}$ & $\mathbf{N i}$ \\
\hline Weight \% & 0.5 & 7.5 & 7.5 & 1.5 & 5 & 6.5 & 6.2 & 0 & 0.004 & 3 & 0.15 & 0.01 & Balance \\
\hline
\end{tabular}

\subsubsection{Physical metallurgy of modified IN600 (TAS)}

The powder metallurgy (PM) TAS alloy used in this thesis was manufactured by a press and sinter process [40]. The sintering process exposes a powder compact at high temperature i.e. $>0.8 \mathrm{~T}_{\mathrm{m}}$ to promote diffusion between adjacent particles to eliminate the porosity and produce a dense part with good mechanical integrity. The initial driving force during the sintering of the fine powders are capillary effects from powder surface curvature and the high surface energy connected with those substantial allowed surface zone for fine powders. The curvature at the interface of touching particles creates a driving force for neck creation. The TAS specimen used 
in this thesis consists nickel, chromium and iron as a base matrix composition. With the addition of aluminum to the base alloy, the formation of $\gamma^{\prime}$ precipitates was promoted and the refractory element silicon was also added to increase the corrosion and oxidation resistance. The higher level of chromium content in the ternary alloy increases the coarsening rate of gamma prime $\left(\gamma^{\prime}\right)$ precipitates [1]. The nominal composition of the PM Ni-Cr-Fe alloy used is shown in the Table 2-4.

Table2- 4 Nominal composition of TAS nickel-base alloy [1].

\begin{tabular}{|c|c|}
\hline Element & Weight \% \\
\hline $\mathrm{Ni}$ & 72 \\
\hline $\mathrm{Cr}$ & $14-17$ \\
\hline $\mathrm{Fe}$ & $6-10$ \\
\hline $\mathrm{Al}$ & 6 \\
\hline $\mathrm{Si}$ & 0.5 \\
\hline
\end{tabular}

\subsection{Oxidation}

As previously mentioned, gas turbine engines work in aggressive environments such as hightemperature exhaust gases and cyclic stresses. Hence, the service life time of the components is influenced by different factors, among these, oxidation resistances of the materials viewed as important. Oxidation is an electrochemical chemical process where oxygen ions and metal ions interact to produce a new substance called oxides. To be more precise, oxidation is defined as the loss of at least one electron when two substances interact. Although the oxidation is a sub-atomic level process, the major impact can occur with the formation of free radicals on the surface which may then break away. 


\subsubsection{Theory of oxidation}

Most metals if subjected to an oxidizing environment will form an oxide scale. The rate of oxidation and the properties of the oxides determine whether the oxide scale is protective or not. Generally, a protective oxide scale should be thermodynamically stable, dense, thin and adherent to the metal and slow growing, within the working temperature range. The fundamentals of oxidation and the oxide scale formation are explained in section 2.5.2. Commonly, when the gas turbine materials exposed to an oxidizing environment, such as high temperature exhaust gases, chromia and/or alumina scale formation will occur.

\subsubsection{General formation of metal oxides}

When a fresh metal $\mathrm{M}$ interacts with an oxidizing environment to form a metal oxide, it is represented by the equation;

$$
x M(s)+\left(\frac{y}{2}\right) O_{2}(g) \rightarrow M_{x} O_{y}
$$

Where $\mathrm{M}(\mathrm{s})$ is the metal in the solid state and $\mathrm{M}_{\mathrm{x}} \mathrm{O}_{\mathrm{y}}$ is the resulting oxide. The schematic diagram of oxidation is shown in Figure 2-3. Initially, oxygen gets adsorbed on the surface of the metal and as the reaction proceeds, the oxygen ions start to dissolve in the metal. Further reaction leads to either a film of oxide, or separate oxide islands nucleate on the metal surface. When a continuous metal oxide film $\mathrm{M}_{\mathrm{x}} \mathrm{O}_{\mathrm{y}}$ forms, it becomes a barrier between the metal and oxidizing environment. The next step of oxidation can only happen by solid state diffusion through the oxide film [20]. If the oxide scale which is formed on the surface of metal is not dense enough i.e. the oxide scale is porous, it is no longer the solid state diffusion barrier between the reactants, because the oxide scale porosity provides more paths for transport of the 
metal and oxygen ions. The oxidation is much more rapid due to the high mobility of oxygen ions and it cannot be slowed down unless there is newer barrier built up forming a dense and stable oxide layer.
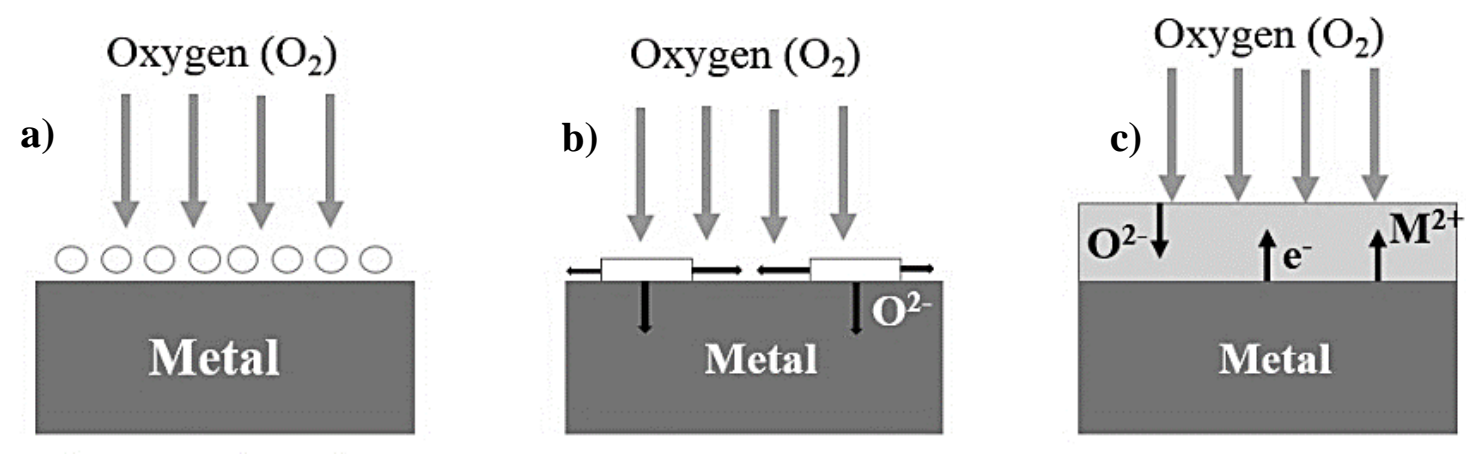

Figure 2- 3 Different stages of oxide scale formation: a) Oxygen adsorption, b) dissolution of oxygen ions and c) oxide scale formation.

\subsubsection{Thermodynamics of oxidation}

As discussed in the previous section 2.5.2, most metals tend to oxidize to some extent when they are exposed to an oxidation environment. Whether this process is likely to occur, is defined by the change in Gibbs free energy connected with the formation the oxide. The scale formation can be explained by the second law of thermodynamics:

$$
\Delta G_{M_{x} O_{y}}=\Delta H_{M_{x} O_{y}}-\mathrm{T} \Delta S_{M_{x} O_{y}}
$$

Where $\Delta \mathrm{G}$ is the change in Gibb's free energy, $\Delta \mathrm{H}$ and $\Delta \mathrm{S}$ the change in enthalpy and the entropy of the metal-oxygen system, and $\mathrm{T}$ the absolute temperature.

As most high-temperature oxidation takes place at constant temperature and pressure, the $\Delta \mathrm{G}$ is an appropriate criterion for a prediction whether an oxidation process may occur at a given temperature or not. As the second law states, the free energy change for a process has to be 
negative $\left(\Delta \mathrm{G}_{\mathrm{MxOy}}<0\right)$ for formation of oxide to occur; if the $\Delta \mathrm{G}_{\mathrm{MxOy}}>0$, then the reaction is thermodynamically not possible and finally, if the $\Delta \mathrm{G}_{\mathrm{MxOy}}=0$, the metal and oxide coexist in equilibrium.

The Gibbs free energy of formation for oxidation reaction (2) can be expanded consistent with the Van't Hoff isotherm [15] [46],

$$
\Delta \mathrm{G}_{M_{x} O_{y}}=\Delta G^{o}{ }_{M_{x} O_{y}}+\mathrm{RT} \ln \left(\frac{a_{M_{x} O_{y}}}{\left(a^{x}{ }_{M^{*} a_{O_{2}}} \frac{y}{2}\right.}\right)
$$

Where $\Delta \mathrm{G}^{\circ}{ }_{\mathrm{MxOy}}$ is the standard free energy of formation, $\mathrm{T}$ is absolute temperature and $\mathrm{R}$ is the gas constant. The activity of the oxide element $M$ is represented by $a_{M o}$ and $a_{M}$ is the activity of element $\mathrm{M}$ in the multi-component system which is subjected to oxidation. The thermodynamic activity which is represented by $a_{i}$ is a quantitative measure of the deviation from the standard state for a given species and is expressed as [15],

$$
a_{i}=\frac{p_{i}}{p_{i}^{o}}
$$

The term $p_{i}$ is the partial pressure gaseous species and $p_{i}{ }^{\circ}$ is the partial vapour pressure of the species in the standard state. The chemical activity for a pure component is equal to unity. When metal and oxygen are at equilibrium, the change in free energy $\Delta \mathrm{G}_{\mathrm{MxOy}}$ becomes zero and equation (3) reduces to,

$$
\Delta G^{o}{ }_{M_{x} O_{y}}=-\mathrm{RT} \ln \left(\frac{a_{M_{x} O_{y}}}{\left(a^{x}{ }_{M^{*}} a_{O_{2}} \frac{y}{2}\right.}\right)
$$

Where, $\frac{a_{M_{x} O_{y}}}{\left(a^{x}{ }^{*} a_{O_{2}}{ }^{\frac{y}{2}}\right.}$ represents the equilibrium constant for the reaction. 
The activities of solids $\mathrm{M}$ and $\mathrm{M}_{\mathrm{x}} \mathrm{O}_{\mathrm{y}}$ are often taken as unity and in this case the oxygen activity can be substituted by the oxygen partial pressure $\mathrm{p}^{*}{ }_{\mathrm{O} 2}$ at which the metal and oxide coexist.

$$
\begin{gathered}
\Delta G^{o}{ }_{M_{x} O_{y}}=\frac{y}{2} \mathrm{RT} \ln \left(p^{*}{ }_{O_{2}}\right) \\
\text { or } \\
p_{{ }_{O_{2}}}^{*}=\exp \left(\frac{2}{y} \cdot \frac{\Delta G^{\circ}{ }_{M_{x} O_{y}}}{R T}\right)
\end{gathered}
$$

The $p^{*}{ }_{O_{2}}$ term is also defined as the dissociation pressure of the oxide. Metal oxide $\mathrm{M}_{\mathrm{x}} \mathrm{O}_{\mathrm{y}}$ will form when the dissociation pressure $p^{*}{ }_{O_{2}}$ is higher than the partial pressure of the environment.

\subsection{Structural properties of oxides}

As previously discussed in section $\mathbf{2 . 4 . 2}$, the solid state diffusion of metal ions and oxygen ions takes place through a continuous and dense oxide film. The diffusion and the ionic transport occur because of the presence of defects or imperfections in crystal structure [47]. Basically, in the oxide scale a small fraction of atoms and ions can occupy positions that are normally empty, creating interstitial atoms or ions, and leaving behind empty sites or vacancies. An atom or ion next to a vacancy can then jump into the empty sites. It is very important to know the defect structure and how defects are helping in solid-state diffusion to understand the high temperature oxidation process. Relying upon the type of defects in the alloy, the diffusion mechanism could be divided into lattice diffusion and shortcut diffusion [48].

Typically the defects are divided into three main groups: point defects, line defects and plane defects. The point defects are responsible for lattice diffusion, while the shortcut diffusion is 
mainly due to the existence of line and plane defects. However, the relative contributions to scale

growth by bulk or grain boundary diffusion will depend on the temperature and the oxide grain sizes [49].

\subsubsection{Point defect structures and mechanism of lattice diffusion}

Point defects are the local defects in which an atom is missing from a perfect atomic configuration of a pure crystal. Point defects are used to identify whether a diffusion mechanism is intrinsic or extrinsic. The intrinsic diffusion can be seen in the pure metals and the extrinsic diffusion is driven by solute or impurities.

A pure crystal structure can contain two types of point defects. First, an atom can be missing from its lattice site to create a vacancy, which may occur during crystal growth. Second, during crystallization there are chances of addition of an extra atom to the crystal structure which is again required to take a position in the structure of the pure crystal. The site which is filled by an extra atom is called an interstitial site and the atom is an interstitial atom. If the interstitial atom replicates the lattice atom in the structure then it is called as self-interstitial atom.

A multiple component system with an ordered structure has more complex intrinsic defects [50]. For the metal oxides, there are two groups of point defect structures: stoichiometric defect structures, in which point defects are formed to maintain the charge balance between metal and oxygen atoms, and non-stoichiometric defect structures, which are always depleted in oxygen or metal ions relative to the stoichiometric composition.

The stoichiometric defect structures consists of Schottky and Frenkel defects in the crystal structure. The Schottky defect contains equivalent concentrations of anionic $\left(\mathrm{V}_{\mathrm{o}}\right)$ and cationic 
$\left(\mathrm{V}_{\mathrm{M}}\right)$ vacancies in the crystal structure. This type of disorder involves defects in both the anion and cation lattices, as shown in Figure 2-4 (a). For an example, in $\mathrm{NaCl}$ crystal structure, the charge imbalance created by the $\mathrm{Na}^{+}$vacancy is balanced by nearby $\mathrm{Cl}^{-}$vacancy [50] [51]. Alternatively, the difference in charge created by the vacancy can also be neutralized by the addition of an interstitial of the same species, i.e., with the addition of $\mathrm{Na}^{+}$interstitial to the crystal structure $\mathrm{Na}^{+}$vacancy can be balanced. The Frenkel defect, on the other hand, is either in the cationic or in the anionic lattice, as shown in Figure 2-4 (b) [52]. A pair neutral Frenkel defect involves vacancies and interstitial atoms of the same component (like $\mathrm{V}_{\mathrm{M}}$ and $\mathrm{M}_{\mathrm{i}}$ ) and in equivalent concentrations.
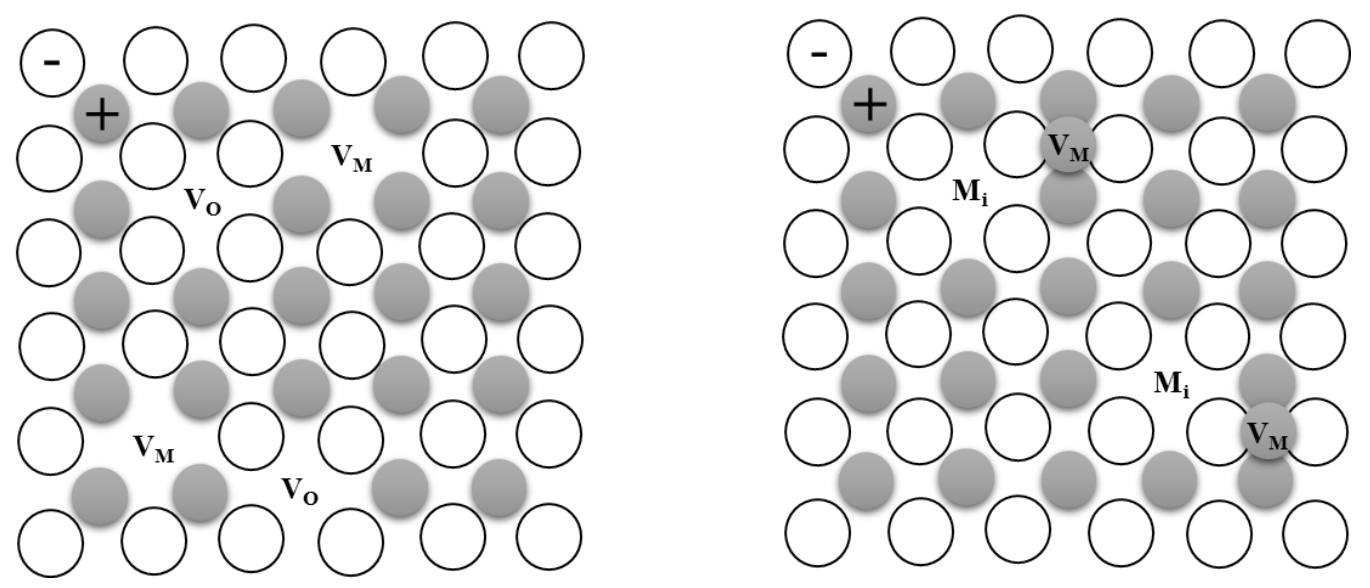

Figure 2- 4 Schematics of point defects a) Schottky defect and b) Frenkel defect in a metal oxide [52] (Reproduced with permission from John Wiley and Sons).

The non-stoichiometric defects are more common in metal oxides and have either metal excess or metal deficit. This leads to the fact that the predominant defects are either metal interstitial ions or vacancies. 
When an oxide has an excess of cations, e.g., $\mathrm{M}_{1+\mathrm{y}} \mathrm{O}_{2}$, the interstitial metal ions dominate. Alternatively, if an oxide is deficient in an oxygen, e.g., $\mathrm{MO}_{2-\mathrm{x}}$, there will be an oxygen vacancy in the structure. If such types of defect structures are charged, they will have a positive net charge, which will be compensated by the formation of an equivalent amount of negative electronic defects. Thus, such oxides are n-type semiconductors. On the other hand, the nonstoichiometric oxides with a metal deficit, like $\mathrm{M}_{1-\mathrm{y}} \mathrm{O}_{2}$, or oxygen excess, e.g., $\mathrm{MO}_{2+\mathrm{x}}$, have metal vacancies and oxygen interstitials as dominating defects, respectively. Such nonstoichiometric oxides belong to p-type semiconductors [15] [53].

\subsubsection{Line defect structures, plane defect structures and short-circuit diffusion}

If a crystal system consists defects that introduce disorder along the line, this is termed as a line defect. The most common line defects are edge and screw dislocations. Both the line defects are the result of shear stresses. Edge dislocations are caused by missing or addition of an extra plane in the crystal structure whereas the screw dislocations result in shifting one of the plane in the structure by one atomic distance along the axis parallel to the other plane. Line defects are either closed loops or occur at the end of the surface. On the other hand, stacking faults in FCC structure occur due to minimization of energy via splitting of a single dislocation into two partials bounded on 111 planes by Schockley partials resulting in a stacking fault. The surface energy posed by the stacking fault is smaller than the grain boundary [54]. The stacking faults

are important to determine the dislocation size. These are the examples for the two-dimensional defects. The extra planes are usually intrinsic and the missing planes are termed as extrinsic. Grain boundaries are also considered as two-dimensional planar defects. They are separate crystalline regions of different crystal orientation [52] [54]. 
The diffusion along line and surface defects require less activation energies than lattice diffusion, typically $50 \%$ to $70 \%$ of the activation energy of lattice diffusion. In addition, the diffusion coefficients are $10^{4}-10^{6}$ times larger than lattice diffusion coefficients [49]. This type of diffusion is often termed as short-circuit diffusion and the defects are high diffusivity paths due to the rapid diffusion provided by the grain boundaries, surfaces and cracks [55]. The shortcut diffusion is dominant at low temperature, while at high-temperature the diffusion mechanisms are either lattice diffusion or short-cut diffusion.

\subsection{Kinetics of oxidation}

Generally, kinetics are used to estimate the rate of an oxidation process, although equilibrium thermodynamics may explain which oxidation process is likely to occur. This is not sufficient for complete understanding of an oxidation process. There are many factors which determine oxidation kinetics such as temperature, oxygen partial pressure, metal pre-treatment and oxidation duration. The oxidation rate is highly dependent on the method of heating be it isothermal oxidation or cyclic oxidation. The isothermal oxidation method is used to characterize the oxide scale growth as a function of exposure duration at constant temperature, whereas cyclic-oxidation involves rapid heating and cooling.

For the present study, only isothermal oxidation is considered. Generally, oxide scale thickness increases with respect to the oxidation duration and the oxidation rate can be fitted mathematically using one or more of three rate laws, namely, parabolic, logarithmic and liner as shown in Figure 2-5 [56]. 


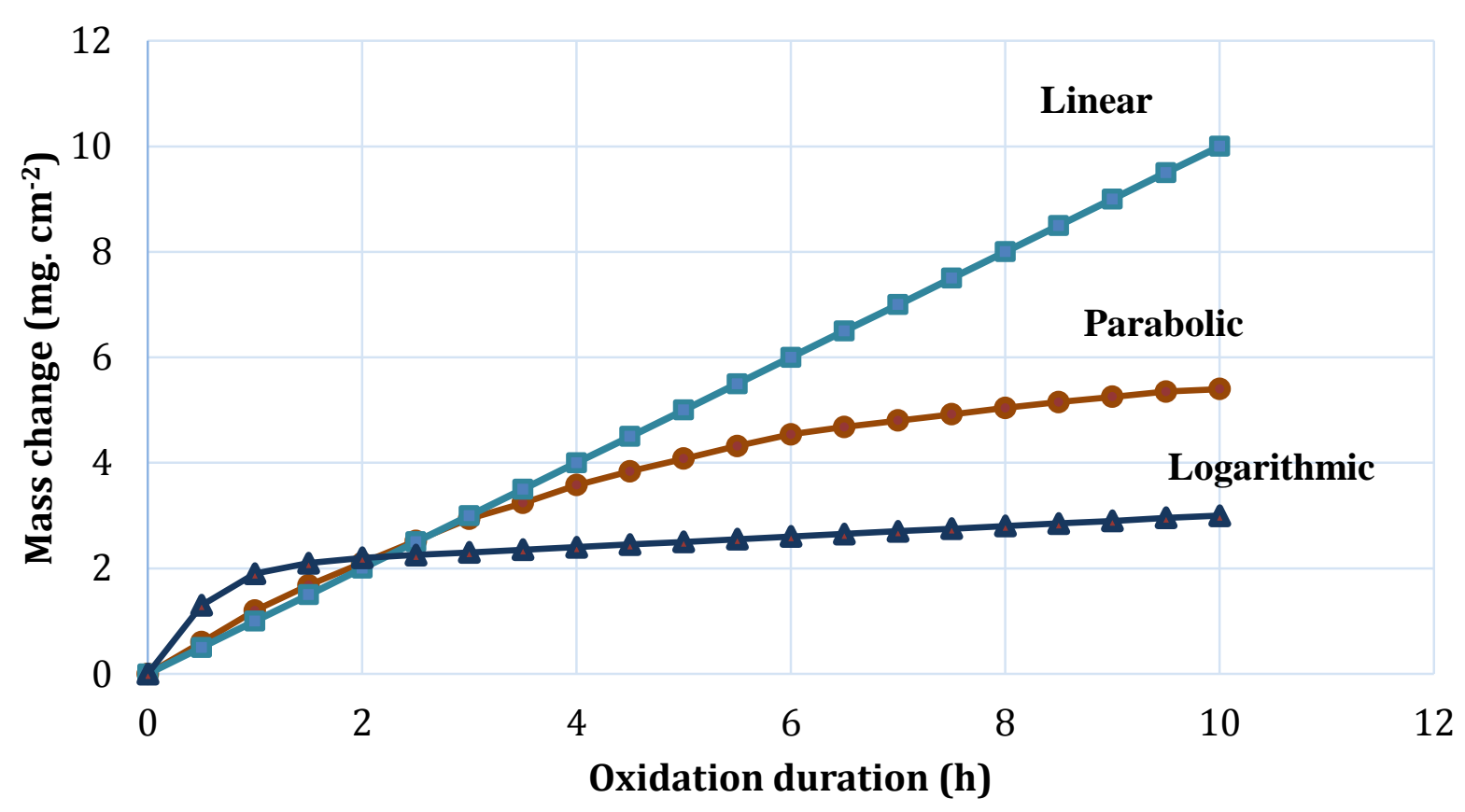

Figure 2- 5 Weight gain or thickness versus oxidation duration for the kinetic laws of metal oxide scale growth [56] (Reproduced with permission from Prentice Hall, Inc.).

\subsubsection{Parabolic oxidation rate}

The oxidation rate of many metals follows parabolic oxidation behaviour at high temperature as shown in Figure 2-6., which results from the fact that film thickness, $x$, is proportional to time, t, and since this corresponds to the diffusion distance increasing, the oxidation rate decreases. Hence, the rate of oxidation is inversely proportional to the oxide scale thickness [56].

$$
\frac{d x}{d t}=\frac{k^{\prime} p}{x}
$$

Where, $\mathrm{k}_{\mathrm{p}}^{\prime}$ is a proportionality constant. Integrating the equation (8) gives,

$$
x^{2}=k_{p} \cdot t+\mathrm{C}
$$


Where $\mathrm{k}_{\mathrm{p}}$ is the parabolic rate constant with the units of $\mathrm{cm}^{2} / \mathrm{s}$. Another form of the parabolic rate equation is given by the weight gain $\left(\mathrm{g} / \mathrm{cm}^{2}\right)[40]$ [57]:

$$
\Delta W^{2}=k_{p} \cdot t+\mathrm{C}
$$

The parabolic rate constant units in this case are $\mathrm{g}^{2} \cdot \mathrm{cm}^{-4} \cdot \mathrm{s}^{-1}$.

This mechanism is valid when the oxide scale is dense, continuous, and perfectly adherent. Also the migration of ions must occur by solid state diffusion, which is the rate controlling step. In general, the parabolic law can be applicable to the reaction rate, where diffusion is controlled through relatively thick oxide scales. The parabolic rate equation may not hold in the initial stages of oxidation before the scale has developed sufficiently.

Since the parabolic rate constant is controlled by diffusion through the oxide scale and hence, is thermally dependent, it increases exponentially with temperature. This may be expressed by Arrhenius equation [15]:

$$
k_{p}=k_{o} \cdot \exp \left(\frac{-Q}{R T}\right)
$$

Where $\mathrm{k}_{\mathrm{o}}$ is pre-exponential constant that is a function of the oxide concentration and oxygen pressure, $\mathrm{Q}$ is the activation energy of the oxide scale growth in $\mathrm{kJ} / \mathrm{mol}$., $\mathrm{R}$ is a gas constant and $\mathrm{T}$ is the absolute temperature in kelvin. The parabolic rate constant for various pure metal oxides as a function of temperature are shown in Figure 2-6 [15]. 


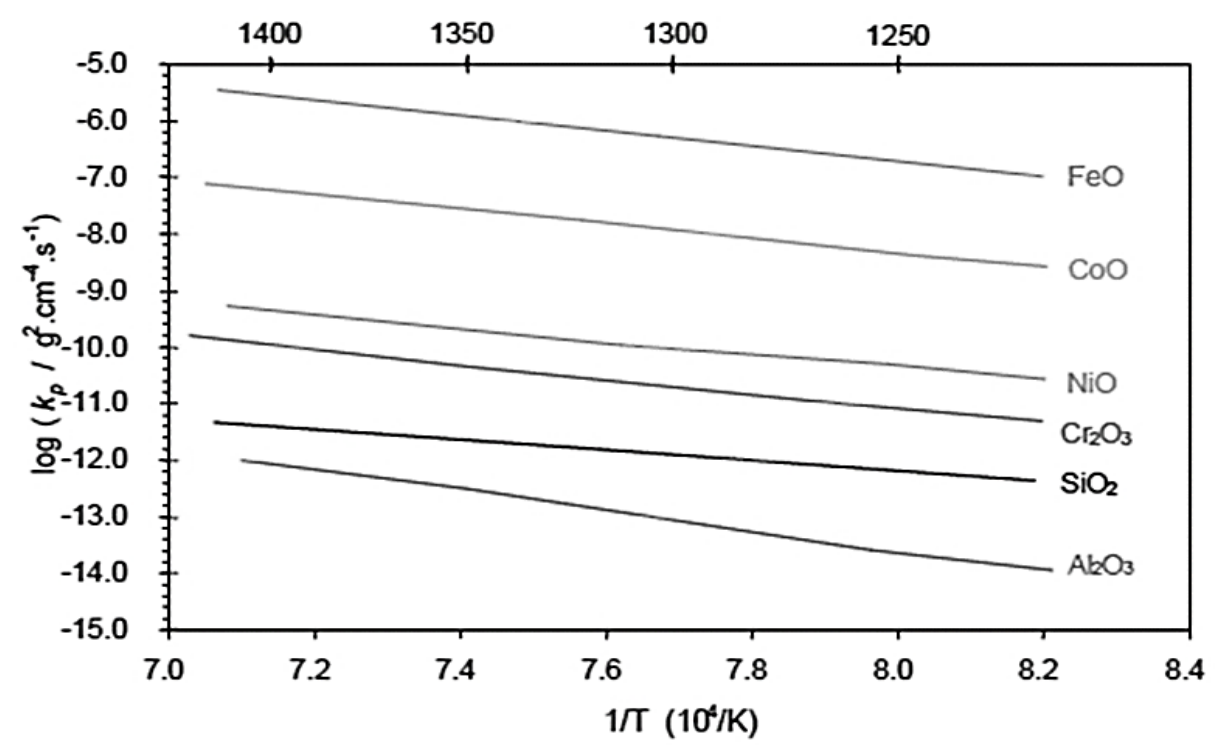

Figure 2- 6 Parabolic oxidation rate constant data for various metal/metal oxide systems as a function of reciprocal temperature [15] (Reproduced with permission from University of

Cambridge).

\subsubsection{Logarithmic oxidation rate}

The metals which are exposed to low temperature (below $400^{\circ} \mathrm{C}$ ) always obey the logarithmic law by forming a thin oxide scale as follows [56] [57]:

$$
x=k_{e} \log (a t+1)
$$

Where $\mathrm{k}_{\mathrm{e}}$ is the rate constant of the logarithmic process, $\mathrm{x}$ is the weight gain or thickness, $\mathrm{t}$ is the oxidation duration and ' $a$ ' is a constant. At low temperature the oxidation rate is often logarithmic in thin oxides, but when the oxide scale become thicker the parabolic kinetics will take over [58]. 


\subsubsection{Linear oxidation rate}

In contrast with the parabolic and logarithmic conditions, the linear oxidation rate does not change with time. During linear oxidation, the oxidation of a metal proceeds at a constant rate and follows the linear rate law as follows [56] [57],

$$
x=k_{1} \cdot t+C
$$

Where $\mathrm{x}$ is the oxide scale thickness or weight gain, $\mathrm{k}_{1}$ is the oxidation rate constant and $\mathrm{t}$ is the exposure time. A linear law may result under the condition where a phase-boundary process is the rate limiting step for the reaction. Thus, any oxide films or scales that may be present must be non-protective. During initial stage of the reaction, the oxide scale thickness may be sufficiently thin to allow for the linear oxidation kinetics. As the film thickness increases the rate transforms to parabolic kinetics. On the other hand, micro-cracking and porosity in the oxide scale due to the stress development in the oxide scale reduces the protectiveness of the oxide. The parabolic rate law may then fail and the kinetics approach linearity after the start of oxidation reaction and oxide scale growth. For an example, the transformation of parabolic to linear kinetics for magnesium at $500^{\circ} \mathrm{C}$ and low oxygen pressure is shown in Figure 2-7 [56] [59]. 


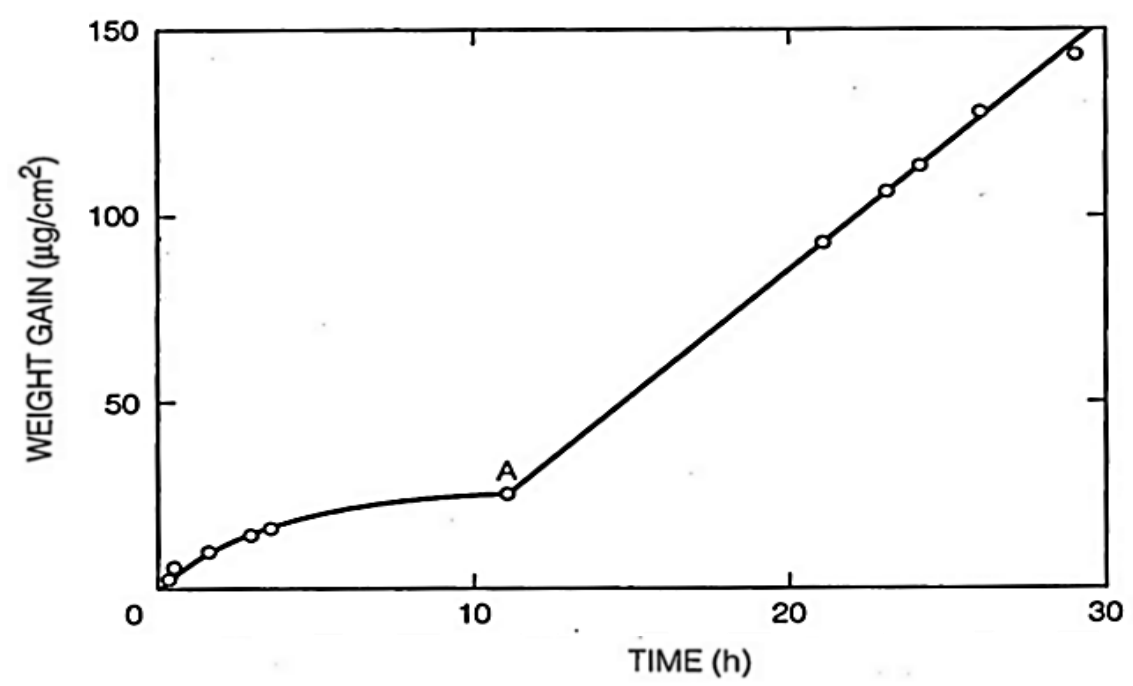

Figure 2- 7 Transformation of parabolic to linear kinetics for oxidation of magnesium $500^{\circ} \mathrm{C}$ [56] [59] (Reproduced with permission from Prentice Hall).

\subsection{Wagner's theory of parabolic oxidation}

As explained before, most metals when exposed to oxidizing environment at elevated temperature show rapid oxidation with a thin protective oxide scale. An increase in the exposure time will decrease the oxide scale growth rate due to the formation of a protective oxide layer. Further oxidation is controlled by solid state diffusion through oxides and metals, which follows parabolic oxidation kinetics. Carl Wagner has given a model to describe the parabolic oxidation behavior [55] [60]. Wagner's theory can be used when the oxide film has favourable properties which include: 1) Good adherence of oxide scale, to prevent flaking and spalling. 2) The higher melting point of the oxide scale. 3) The vapour pressure of the oxide scale should be low to resist evaporation. 4) The thermal expansion co-efficient or both metal and metal oxide should be the same. 5) The oxide film should have low diffusion co-efficient and electrical conductivity for metal ions and oxygen. 
Since thermodynamic equilibrium is established on both interfaces, metal/scale and scale/gas, an activity gradient of both metal and oxygen occurs across the scale. The transport of metal occurs as an outward flux of metal interstitials or as an inward flux of metal vacancies. When the diffusion of anions is faster than the cations then they form an oxide at the metal/scale interface. Conversely, when the cationic diffusion is faster than anionic, cations diffuse outwards and the formation oxide occurs at the scale/gas interface. Figure 2-8 illustrates that the transfer rates of cations, anions and electrons are in balance so that no net charge transfer occurs across the oxide scale [60] [15].

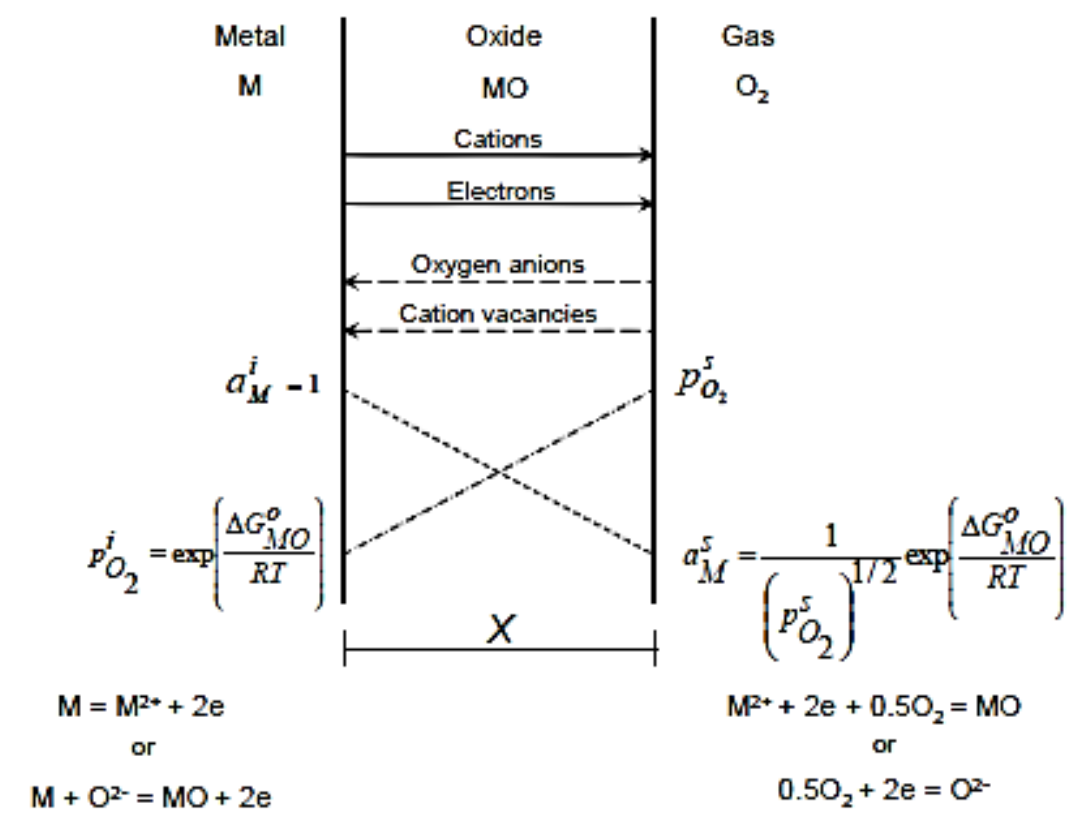

Figure 2- 8 Schematic oxide scale formation according to Wagner's oxidation model [15] [60] (Reproduced with permission from University of Cambridge).

There are several limitations for Wagner's theory of oxidation model as explained before. The main assumption which can't be fulfilled is that the oxide is more or less stoichiometric, which is very rare to observe in oxidation. Another assumptions is that the oxide scale is dense and 
adherent, but this is not possible for many oxides and also there is a reactive evaporation of the scale forming oxides [61]. The transport of ions in many oxides is partly accompanied by grain boundary diffusion or short circuit diffusion, where Wagner's model doesn't take in to consideration. The parabolic oxidation rate constants for various oxides as a function of temperature is shown in Figure 2-6.

\subsection{Breakaway oxidation due to depletion of alloying elements}

Most of the alloys which are developed for high temperature applications depend on excellent oxidation resistance. A good oxidation resistant alloy should show dense, continuous, welladherent protective oxide scale formation on the surface. However, during a long service time, the formation of a protective oxide layer and the dissolution of scale forming elements from the alloy eventually result in the breakdown of the protective oxide scale [62].

When a slow growing oxide scale (e.g. chromia or alumina scale in the case of Ni-base alloys) is no longer protective i.e., the oxide layer spalls or cracks then other alloying elements start to oxidize [53]. This phenomenon of breakdown or breakaway oxidation behaviour is unavoidable when the interfacial concentration of the oxide scale forming elements decreases to a value lower than the minimum value required to sustain the selective growth of the desired scale (chromia or alumina) [63] [64]. 


\subsection{Effect of alloying elements on oxidation of superalloys}

The role of the alloying elements used to promote the oxidation resistance in superalloys are summarized below.

Chromium: Addition of chromium is an excellent choice for high temperature alloys (below $\left.950^{\circ} \mathrm{C}\right)$ by virtue of a natural protective layer of chromium oxide $\left(\mathrm{Cr}_{2} \mathrm{O}_{3}\right)$ which adheres to a surface. The critical chromium concentration to form a protective $\mathrm{Cr}_{2} \mathrm{O}_{3}$ oxide layer is $15 \%$ or 20-25\% depending on the application requirements [57] [65]. The addition chromium is also better for hot corrosion resistance in high temperature alloys [66]. However, chromium is not effective element at temperatures above $1000^{\circ} \mathrm{C}$ due to its volatility above that temperature [11].

Aluminum: Aluminum is the one of the best solid solution strengthening elements. Aluminum also offers very good oxidation resistance by forming a continuous $\mathrm{Al}_{2} \mathrm{O}_{3}$ layer, which is thermodynamically stable and adherent at temperatures well above $1000^{\circ} \mathrm{C}$.

Silicon: Silicon is present as a residual element in most of superalloys. The addition of silicon promotes high temperature oxidation resistance. The silicon content in high temperature alloys is limited to less than $3 \%$ because of mechanical and thermal stability constraints. Silica is more stable than chromia and tends to form beneath or at the alloy/scale interface. The formation of a $\mathrm{SiO}_{2}$ scale may or may not be possible with the low concentrations of silicon in a system but it's presence enhances the $\mathrm{Cr}_{2} \mathrm{O}_{3}$ scale formation by facilitating oxygen transfer to it [67] [68]. Jones and Stringer [68] revealed that the, addition of $0.05 \%$ of silicon to $\mathrm{Co}-25 \mathrm{Cr}$ alloy increases the rate formation and growth of a protective $\mathrm{Cr}_{2} \mathrm{O}_{3}$ scale. V. M. Robert [67] study on variation of silicon concentration from $0-1 \%$ in nickel-base superalloy found an increase in the volume fraction of $\gamma^{\prime}$ precipitates in eutectic nodules. In the alloys IN713C and Mar-M200, an increase in 
silicon content decreases the liquidus, solidus and MC dissolution temperatures, but increases the $\gamma^{\prime}$ solvus [67]. In alloys containing major amounts of molybdenum, cobalt, tungsten, iron or other refectory elements, the addition of silicon can stabilize the metal carbides and deleterious intermetallic phases [20]. The formation of the $\mathrm{SiO}_{2}$ scale provides excellent oxidation resistance for an alloy although it also has a tendency to vapourize more rapidly than chromia [67].

Titanium: The addition of a small quantity of titanium to precipitation hardenable alloys increases the intermetallic phases such as $\gamma^{\prime}$ in nickel based superalloys. It has been reported by Akinlade et al [38], that addition of titanium (1-3 wt. \%) to a quaternary Ni-Cr-Fe-Al alloy increases the lattice parameter of $\gamma^{\prime}$ precipitate. At high temperatures $\left(600^{\circ} \mathrm{C}\right.$ to $\left.1000^{\circ} \mathrm{C}\right)$, titanium oxidizes to $\mathrm{TiO}_{2}$ and shows parabolic behaviour. The titanium enhances the selective oxidation by acting as an oxygen getter and thus causes the diffusion of chromium in an alloy to be deceased [69] [70]. However, the presence of titanium is generally detrimental to the oxidation resistance of chromia-forming alloys. $\mathrm{TiO}_{2}$ is thermodynamically more stable than $\mathrm{Cr}_{2} \mathrm{O}_{3}$ and thus titanium oxide may form below an external scale of chromia as an internal oxide. In chromium rich alloys, the titanium tends to oxidize at both the gas/scale interface and metal/scale interfaces. According to Yang [71], addition of $1 \%$ of titanium to the nickel-base superalloy changes the oxidation resistance the same alloy with $3 \%$ titanium exhibits a higher oxide scale thickness at $1000^{\circ} \mathrm{C}$. Therefore, the titanium oxide decreases the adherence of the oxide layer thus being detrimental to the high temperature oxidation resistance in nickel-based superalloys.

Nickel: This is used as the base material in most of the high temperature alloys such as aero engines. Nickel is the base material in nickel-base superalloys and accounts for $40-60 \mathrm{wt} \%$ of 
total alloy composition [1] [13] [27]. Nickel readily oxidises to form nickel oxide (NiO), which is not thermodynamically stable and will not prevent further oxidation.

Iron: Typically, iron is used in superalloys to reduce the cost rather than to promote the high temperature oxidation resistance. At temperatures above $570^{\circ} \mathrm{C}$, iron may take three types of oxide forms, namely, $\mathrm{FeO}, \mathrm{Fe}_{2} \mathrm{O}_{3}$ and $\mathrm{Fe}_{3} \mathrm{O}_{4}$. All are porous in nature and provide an easy path for metal and oxygen ions to transport, thus increasing the scale growth rate. The diffusion coefficient of iron in $\mathrm{FeO}$ is orders of magnitude larger than for the $\mathrm{Fe}_{2} \mathrm{O}_{3}$ and $\mathrm{Fe}_{3} \mathrm{O}_{4}$ oxides, if the reaction is controlled by solid state diffusion [62]. Superalloys with iron as a major element are not often preferred in the alloys used for high temperature applications.

Cobalt: The oxidation resistance of cobalt is similar to that of nickel. At high-temperatures the oxidation rate of cobalt increases with the porous un-protective oxide layer. The oxidation rate of unalloyed cobalt in air is reported to be 25 times than that of nickel [72]. Cobalt is also used to reduce the level of solid solution strengthening elements such as aluminum and titanium in $\gamma^{\prime}$.

Niobium and tantalum: The addition of tantalum and niobium to an oxidation resistant alloy will stabilize any grain boundary carbide precipitates. The presence of these elements may decrease the intergranular oxidation rate. These elements also help in solid solution strengthening at high temperatures [1]. Niobium substitutes for aluminum in $\gamma^{\prime}$ as does titanium [73]. Tantalum is not the best material in terms of oxidation; at extended service in air at temperatures above $260^{\circ} \mathrm{C}$ oxidation is rapid but the oxidation resistance can be improved with the combination of niobium [1]. It has been reported that by replacing the $\mathrm{Ti}$ with $\mathrm{Ta}$ increases the oxidation resistance considerably [71]. However, increasing the Ta concentration by $1 \%$ to $3 \%$ made formation of $\mathrm{Al}_{2} \mathrm{O}_{3}$ less favourable. 
Boron: There have been very few studies on effect of boron on the oxidation resistance of nickel-base superalloys, and the possible combination/reaction of boron into internal and external oxides during high temperature oxidation [74]. The addition of boron to nickel-base superalloys has been reported to have a detrimental effect on the oxidation resistance by promoting the formation of a porous nickel oxide layer [75]. In Ni-Cr-Al alloys, boron addition hinders the external alumina scale formation [76]. Interestingly, in contrast, Unocic [77] concluded that the addition of boron to Ni-Cr-Al alloy did not affect depth of an internal alumina scale.

Rhenium: The addition of rhenium to nickel base superalloys increases the oxidation resistance at high temperatures by lowering the subsurface aluminum depletion in $\gamma^{\prime}$. Czech [78] stated that rhenium act as a diffusion barrier inhibiting the inward and outward diffusion of Ni and Al. Liu's [79] experiments on nickel-based superalloys DD32 and DD32M also agree with Czech. Furthermore, Liu stated that a pure $\mathrm{Al}_{2} \mathrm{O}_{3}$ oxide scale formed without $\mathrm{NiAl}_{2} \mathrm{O}_{4}$, thereby decreasing the oxidation rate.

Yttrium: Yttrium addition to nickel-based superalloys improves oxide scale adhesion and also reduces the oxide scale growth rate. It has been recorded that the yttrium doped alloys show a planar morphology oxide scale. Also any sulphur present is segregated into substrates of stable yttrium-sulphide particles [80]. The addition of $0.5 \%$ of yttrium to $\mathrm{Ni}-30 \mathrm{Cr}$ alloy was also reported to lower the oxidation rate and to improve the inherent strength of the metal/scale interface [81]. Overall, yttrium helps in nucleating $\mathrm{Cr}_{2} \mathrm{O}_{3}$ during the early stages of oxidation and promotes the formation of a continuous protective $\mathrm{Cr}_{2} \mathrm{O}_{3}$ scale [82].

Molybdenum: All three elements are solid solution strengtheners and carbide formers $\left(\mathrm{M}_{6} \mathrm{C}\right.$ and MC type). Molybdenum and tungsten enhance the selective oxidation of aluminum by acting as 
oxygen getters [69]. The disadvantage of using molybdenum in high temperature alloys is that, its rapid and catastrophic oxidation in air at temperatures above $790^{\circ} \mathrm{C}$. Oxidation produces molybdenum trioxide $\left(\mathrm{MoO}_{3}\right)$, which is very volatile and sublimes readily from the solid. The molybdenum initially forms $\mathrm{MoO}_{2}$ at $795^{\circ} \mathrm{C}$, which is the oxide that forms at the metal/oxide interface region. This subsequently forms a eutectic with $\mathrm{MoO}_{3}$. Even though the eutectic is nonvolatile, it allows molybdenum and oxygen ions to pass through the oxide scale [1].

Zirconium and hafnium: Significant improvements in mechanical properties can be achieved by additions of zirconium and hafnium. The grain boundary diffusion rates and carbide agglomeration can be decreased in the presence of these elements. Hafnium contributes to the formation of $\gamma-\gamma^{\prime}$ eutectic phases at the grain boundaries [1]. These elements are oxygen getters and help in formation of healing layers of alumina and chromia.

\subsection{Oxidation of alloys}

Nickel-base superalloys are the most complex and widely used materials for high-temperature applications. The properties required for these superalloys for applications such as gas turbine engine components are tensile strength, fatigue and creep resistance, low coefficient of thermal expansion and also oxidation resistance. The oxidation behaviour of these superalloys is very complicated because each alloying element has a different affinity towards oxygen. Since these affinities in metal/oxide systems are nearly proportional to the change in Gibbs free energy, one may estimate the relative order of oxide formation of each alloying element by comparing their free energies of formation. When the free energy change of the reaction, $\Delta \mathrm{G}_{\mathrm{MO}}$ is more negative, the oxide scale is thermodynamically more stable. According to the Ellingham/Richardson diagram, oxides of chromium and aluminum form more readily compared to most other alloying 
elements. In nickel-based superalloys $\mathrm{NiO}$ also forms because $\mathrm{Ni}$ is the major constituent of the alloy.

As explained above, depending on the affinity of an element towards oxygen and stability of its oxide, one or two alloying elements are selectively oxidized. Generally, the element which has high affinity for oxygen forms an oxide showing resistance to diffusion of metal and oxygen ions. At lower partial pressure of oxygen i.e., limited oxygen availability at the surface, oxidation is selective [49]. The lower partial pressure of oxygen can be seen at the metal/scale interface. Hence, if a metal is covered with a continuous and dense protective oxide layer adhering to substrate, then the selective oxidation takes place at the metal/scale interface. The formation of complex oxides is a function of composition, temperature, partial pressure of oxygen and oxidation duration.

\subsubsection{High-temperature oxidation of chromia-forming nickel-base superalloys}

The high temperature oxidation resistance of chromia forming nickel-base superalloys has been recorded by number of authors [70] [83] [84]. The purpose of chromium addition to nickel-base superalloys is to form thermodynamically stable and protective chromia scale $\left(\mathrm{Cr}_{2} \mathrm{O}_{3}\right)$. Chromium oxide has the corundum structure and low ionic conductivity.

In nickel-base superalloys, at an early stage of oxidation, a porous $\mathrm{NiO}$ is formed because nickel is the major element. As the reaction proceeds, the inward diffusion of oxygen toward the substrate and the reaction of oxygen with the next higher level of constituent chromium results to form $\mathrm{Cr}_{2} \mathrm{O}_{3}$. Some of these oxides may be formed inside the porous $\mathrm{NiO}$ layer, resulting in the solid state reaction to form a spinel type oxide such as $\mathrm{NiCr}_{2} \mathrm{O}_{4}$ [15] [83]. Since the diffusion of cation through the $\mathrm{NiCr}_{2} \mathrm{O}_{4}$ layer is lower than it is through $\mathrm{NiO}$, the spinels act as diffusion 
barrier for the $\mathrm{Ni}$ ion movement; thus the total $\mathrm{Ni}^{+}$flux through the oxide scale will decrease. Since the diffusion rate of $\mathrm{Ni}^{+}$in $\mathrm{NiO}$ is much greater than the diffusion rate of $\mathrm{Cr}^{3+}$ in $\mathrm{Cr}_{2} \mathrm{O}_{3}$, a large amount of $\mathrm{NiCr}_{2} \mathrm{O}_{4}$ and $\mathrm{NiO}$ can occur before $\mathrm{Cr}_{2} \mathrm{O}_{3}$ formation. This depends on the chromium level in the system and the partial pressure of oxygen. This process is known as transient oxidation. The isothermal oxidation of a binary $\mathrm{Ni}-\mathrm{Cr}$ alloy at $1000^{\circ} \mathrm{C}$ is shown in the

Figure 2-9 [85].

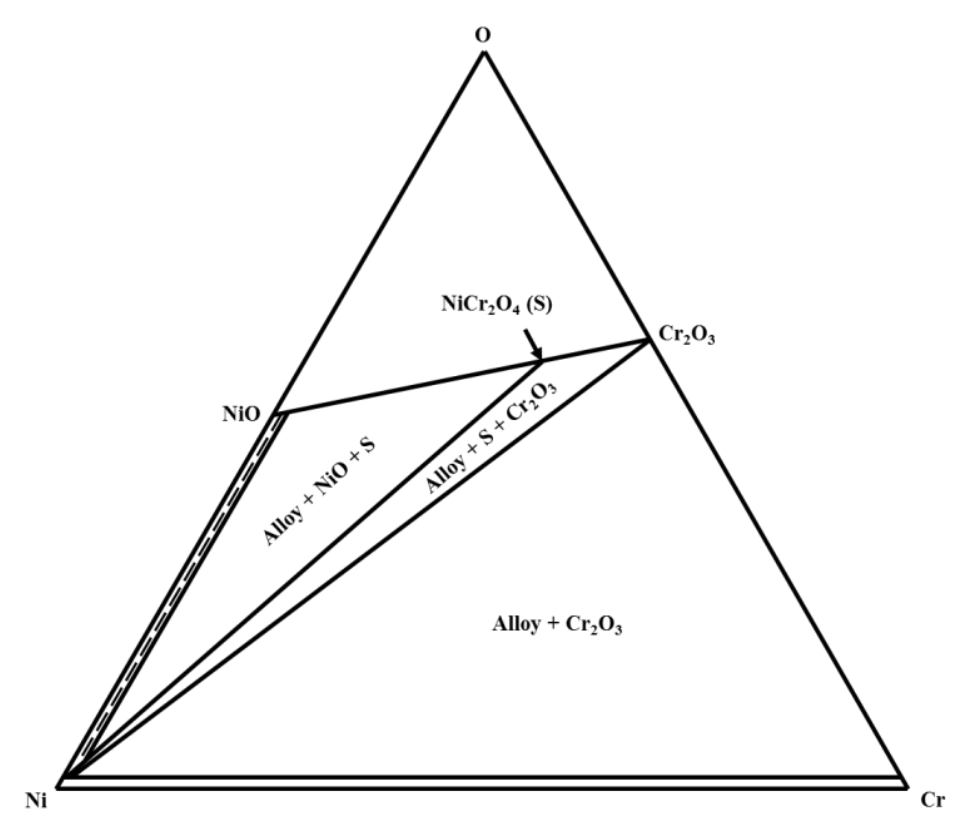

Figure 2- 9 Isothermal oxidation of binary Ni-Cr alloy at $1000^{\circ} \mathrm{C}$ [85] (Reproduced with permission from Springer).

Above a certain critical chromium content at $1000^{\circ} \mathrm{C}$, the continuous $\mathrm{Cr}_{2} \mathrm{O}_{3}$ formation on the surface of metal and the oxidation rate fall abruptly to values more typical of chromium than of $\mathrm{Ni}$ as shown in Figure 2-10. 


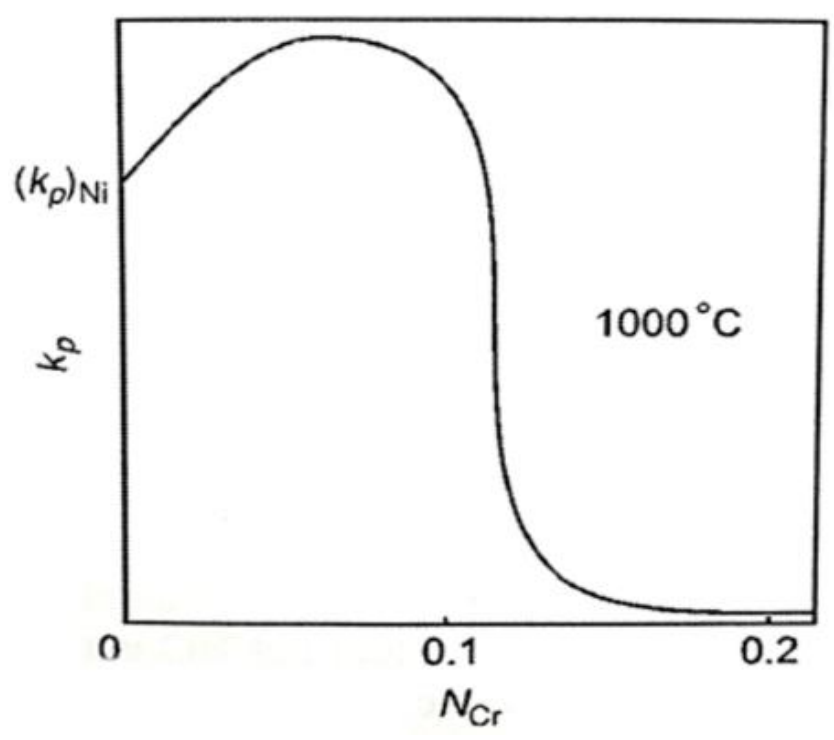

Figure 2-10 Parabolic rate constant for the oxidation of $\mathrm{Ni}-\mathrm{Cr}$ alloys as a function of $\mathrm{Cr}$ content at $1000^{\circ} \mathrm{C}$ [15] (Reproduced with permission from University of Cambridge).

In the Ni-Cr binary alloy system, for a chromium oxide scale to form and be maintained two criteria are needed. First, the chromium concentration must be higher than the critical chromium composition for outer diffusion to prevent the internal oxidation. Here equation (14) can be used to calculate the critical value of chromium [60].

$$
N_{C r}>\left[\left(0.1 \pi N_{o}\right) \frac{D_{o} V_{M}}{D_{C r} V_{O}}\right]
$$

Where, $\mathrm{N}_{\mathrm{o}}$ is the oxygen solubility in the metal, $\mathrm{N}_{\mathrm{Cr}}$ is the critical value of chromium, $\mathrm{D}_{\mathrm{O}}$ is the diffusivity of oxygen in metal, $\mathrm{D}_{\mathrm{Cr}}$ is the inter-diffusion coefficient, $\mathrm{V}_{\mathrm{M}}$ and $\mathrm{V}_{\mathrm{O}}$ are the molar volume of the metal and oxide respectively. 
Second is the solute flux towards the scale/metal interface should be sufficient to maintain the external oxide layer once it is formed. This can be expressed as equation (15).

$$
N_{C r}>\left[\left(\frac{V_{M}}{32 v}\right)\left(\frac{\pi k_{p}}{D_{C r}}\right)^{\frac{1}{2}}\right]
$$

The term $\mathrm{k}_{\mathrm{P}}$ is the parabolic rate constant for external oxide scale growth. As stated by Croll and Wallwork [86], the critical chromium concentration required was calculated to be 10 atomic percent for the Ni-Cr alloys. In agreement with this, Wallwork's [87], work on the effect of oxidation with different chromium contents $(8,13.5$ and 22 at. \%) revealed an alloy with lower chromium content had an outer $\mathrm{NiO}$ scale and spinel in the subsurface region. The alloy with the chromium content greater than that of the critical level at the interface showed only a chromia layer. Therefore, to sustain the chromium oxide scale on the surface and to maintain chromium concentration of 10 at. $\%$ at metal/scale interface, the alloy should have minimum of 20 at. $\%$ chromium.

In some cases, liquid oxide phases may also form on a surface. This may occur when the materials are exposed to the vapour of a low melting oxide during oxidation. For an example, $\mathrm{MoO}_{3}$ is a low melting oxide that forms a liquid phase on the surface of an alloy when exposed to $795^{\circ} \mathrm{C}$. This type of phenomenon may also exist in the case of volatile oxide $\mathrm{CrO}_{3}$. $\mathrm{The} \mathrm{CrO}_{3}$ forms in the temperature range of $950^{\circ} \mathrm{C}$ to $1020^{\circ} \mathrm{C}$ [88] and it is volatile at temperatures above $1000^{\circ} \mathrm{C}$. 


\subsubsection{High-temperature oxidation of alumina-forming nickel-base superalloys}

Generally, alumina formers have better oxidation resistance at high-temperatures than that of chromia formers. In alumina-forming nickel-base superalloys, the high-temperature oxidation resistance is higher because the transportation of species through an alumina scale is inherently slower than through a chromia scale. Additionally, alumina-forming alloys can be used at hightemperatures $\left(>1000^{\circ} \mathrm{C}\right)$ because alumina, unlike chromia, does not suffer from volatilization at the temperatures above $1000^{\circ} \mathrm{C}[89]$.

During the oxidation of binary nickel-aluminum alloys, $\mathrm{Al}_{2} \mathrm{O}_{3}$ can be formed in different crystallographic phases. In the early stages of oxidation, metastable oxides such as $\gamma-\mathrm{Al}_{2} \mathrm{O}_{3}, \delta$ $\mathrm{Al}_{2} \mathrm{O}_{3}$ and $\theta-\mathrm{Al}_{2} \mathrm{O}_{3}$ are formed [90]. These alumina phases contain high concentrations of cation vacancies. It is suspected that, the diffusion of oxygen ions in $\theta-\mathrm{Al}_{2} \mathrm{O}_{3}$ phase is much faster than that of $\gamma-\mathrm{Al}_{2} \mathrm{O}_{3}$ resulting in higher oxidation rates. After longer oxidation at $900^{\circ} \mathrm{C}$ all three alumina phases transform to a nearly perfect stoichiometric structure, stable $\alpha-\mathrm{Al}_{2} \mathrm{O}_{3}$, which exhibits low diffusivity for both cations and anions [91]. Therefore the formation of stable $\alpha$ $\mathrm{Al}_{2} \mathrm{O}_{3}$ scales reduces the oxide growth rate. The nucleation of $\alpha-\mathrm{Al}_{2} \mathrm{O}_{3}$ phase occurs at the oxide/gas interface and the transformation sequence of metastable alumina to the stable $\alpha$ alumina phase depends on temperature. This can be expressed as [92],

$$
\boldsymbol{\gamma}-\mathbf{A l}_{\mathbf{2}} \mathbf{O}_{\mathbf{3}} \stackrel{700^{\circ} \mathrm{C}-800^{\circ} \mathrm{C}}{\rightarrow} \quad \boldsymbol{\delta}-\mathbf{A l}_{\mathbf{2}} \mathbf{O}_{3} \stackrel{900^{\circ} \mathrm{C}-1000^{\circ} \mathrm{C}}{\rightarrow} \quad \boldsymbol{\theta}-\mathbf{A l}_{\mathbf{2}} \mathbf{O}_{3} \stackrel{1000^{\circ} \mathrm{C}-1100^{\circ} \mathrm{C}}{\rightarrow} \quad \boldsymbol{\alpha}-\mathbf{A l}_{2} \mathbf{O}_{3}
$$


The oxidation kinetics for the three metastable structures of $\mathrm{Al}_{2} \mathrm{O}_{3}$ is summarized on an Arrhenius plot are shown in Figure. 2-11 [90]. The metastable $\delta$ and $\theta-\mathrm{Al}_{2} \mathrm{O}_{3}$ phases appear only after shorter exposure of $\mathrm{Ni}-\mathrm{Al}$ alloys to high-temperature oxidation and may also form at relatively low temperature.

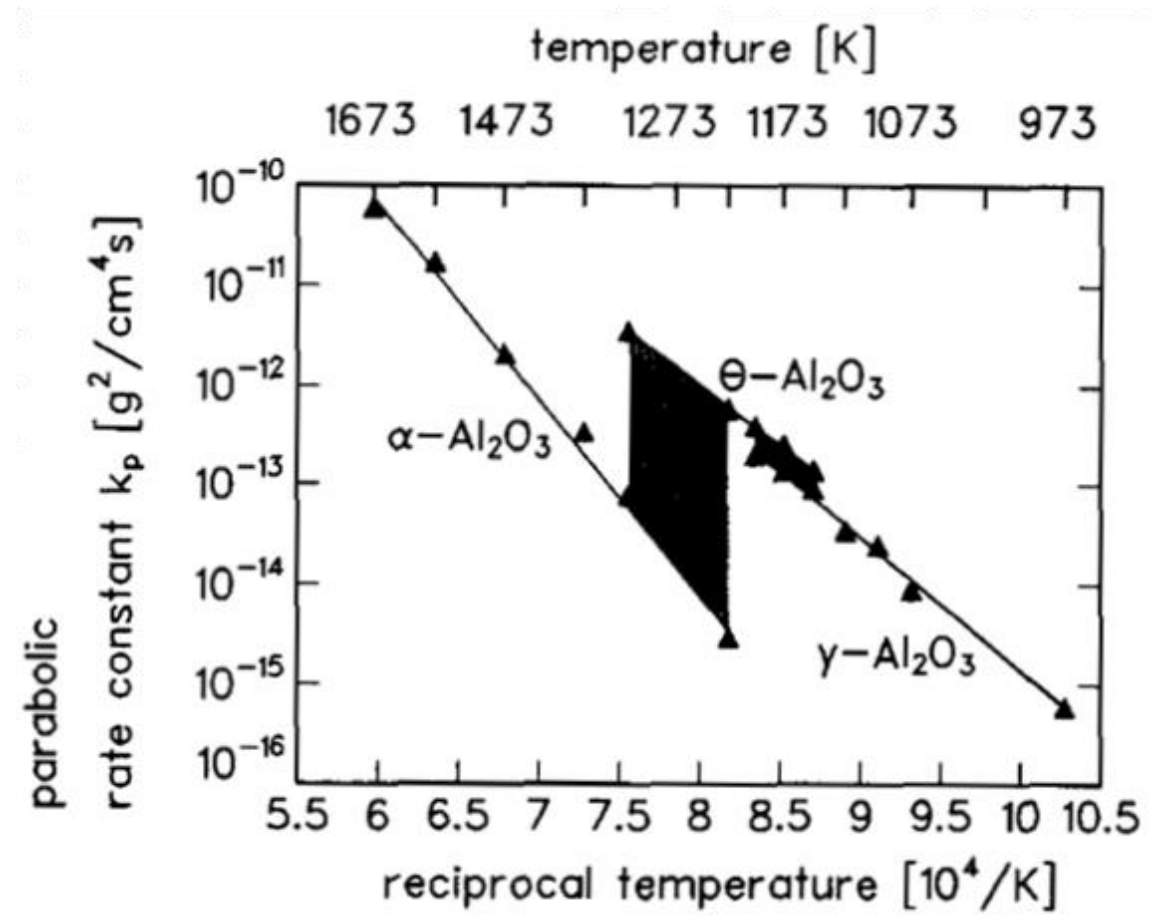

Figure 2- 11 Arrhenius plot of parabolic rate constant $\mathrm{kp}$ for the oxidation of a Ni-Al alloy [15] [90] (Reproduced with permission from Elsevier).

The presence of a third element in binary NiAl alloy such as chromium has been found to have no significant effect on $\theta-\mathrm{Al}_{2} \mathrm{O}_{3}$; this is shown in Figure. 2-12. Brumm and Grabke [90] reported an increase in the final parabolic oxidation rate for $\theta-\mathrm{Al}_{2} \mathrm{O}_{3}$ in a transition regime with an increase in the chromium content. The reason for this mechanism is the presence of $\mathrm{Cr}_{2} \mathrm{O}_{3}$ in $\gamma$ or $\theta-\mathrm{Al}_{2} \mathrm{O}_{3}$ increases the nucleation sites for $\mathrm{Al}_{2} \mathrm{O}_{3}$ [90] [93]. This creates a finer grain size of $\mathrm{Al}_{2} \mathrm{O}_{3}$, 
which increases the number of diffusion paths for both aluminum and oxygen resulting in the increase in oxidation rate.

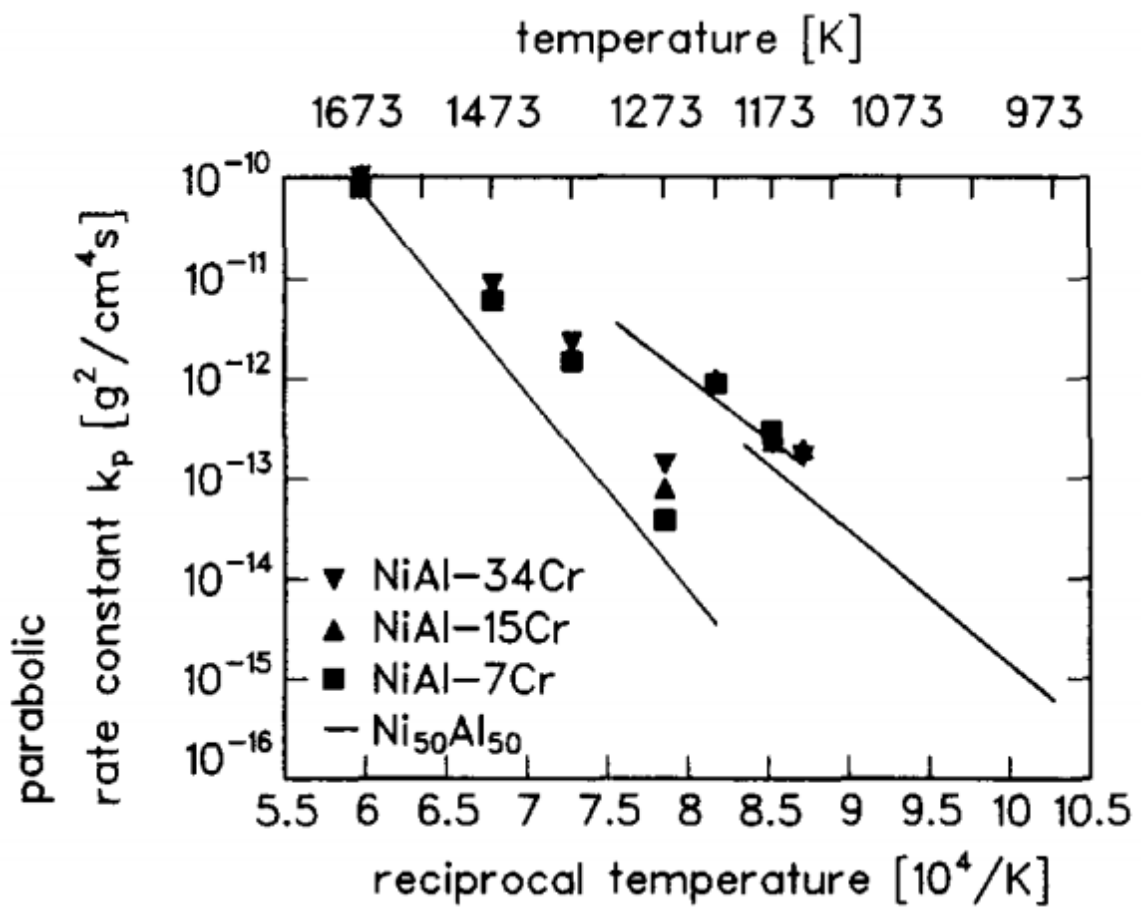

Figure 2- 12 Arrhenius plot of kp for NiAl and NiAl-Cr oxidation [90] (Reproduced with permission from Elsevier).

The kinetics for oxide dispersion strengthened (ODS) Fe-Cr-Al and also the transformation of transition alumina to $\alpha$-alumina were studied by Huntz [94]. The oxidation rate of the ODS alloy was much slower than the alloy without ODS and the scale growth was limited by oxygen diffusion. The diffusion rate through a thin equiaxed outer layer formed by a cationic diffusion and an inner columnar layer grown by oxygen diffusion agrees with those obtained for $\mathrm{O}^{18}$ diffusion in alumina doped with yttrium [95]. The transport mechanism in $\theta-\mathrm{Al}_{2} \mathrm{O}_{3}$ has been studied by Pint [96] using ${ }^{18} \mathrm{O} /{ }^{16} \mathrm{O}$. The study confirms that $\theta-\mathrm{Al}_{2} \mathrm{O}_{3}$ grows primarily by the 
outward diffusion of $\mathrm{Al}^{3+}$-cation rather than inward transport of oxygen anions as seen in the growth of $\alpha-\mathrm{Al}_{2} \mathrm{O}_{3}$.

\subsection{Pettit's oxidation groups}

For Ni-Cr-Al alloys exposed to high temperature exhaust gases different oxidation modes can be observed depending on the alloy composition as shown in Figure 2-13 [15].

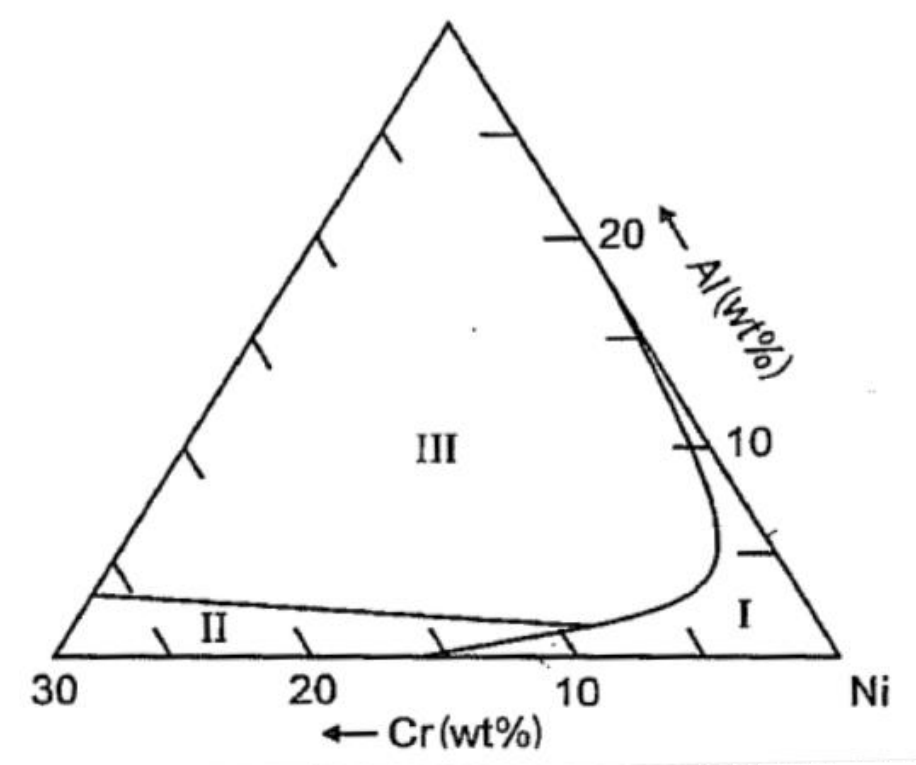

Figure 2- 13 Effect of composition on oxidation of Ni-Cr-Al ternary alloy [15] (Reproduced with permission from University of Cambridge).

Giggins and Pettit [65] summarized the major three different oxidation modes in Ni-Cr-Al ternary alloys at $1000^{\circ} \mathrm{C}$. For the initial stage of oxidation at $1000^{\circ} \mathrm{C}$, a compact outer scale of $\mathrm{NiO}$ is formed and a subscale precipitate of $\mathrm{Cr}_{2} \mathrm{O}_{3}, \mathrm{Al}_{2} \mathrm{O}_{3}, \mathrm{Ni}(\mathrm{Cr}, \mathrm{Al})_{2} \mathrm{O}_{4}$ forms below the $\mathrm{NiO}$ layer. This type of oxidation is termed as 'Group I' oxidation mode or NiO formers. The oxidation rates of Group I alloys are the same as or even worse than for pure Ni; thus, the Group I oxidation modes are lethal to nickel-base superalloys. The group II oxidation mode can be seen 
in alloys with higher chromium content and less aluminum such as $\mathrm{Ni}-20 \mathrm{Cr}-2 \mathrm{Al}$. A continuous chromia scale without $\mathrm{NiO}$ layer occurs on the surface of the alloy after oxidation. For the alloys with higher aluminum concertation such as $\mathrm{Ni}-20 \mathrm{Cr}-4 \mathrm{Al}$ alloy, the group III oxidation mode can be observed. Here, $\mathrm{Al}_{2} \mathrm{O}_{3}$ forms as a continuous subscale which controls the rate of oxidation. The ionic transport in group III alloys are much slower than for those in group I and Group II. The schematic diagram of above-mentioned oxide scale development on Ni-Cr-Al alloys as a function of time is shown in Figure 2-14 [15] [65].
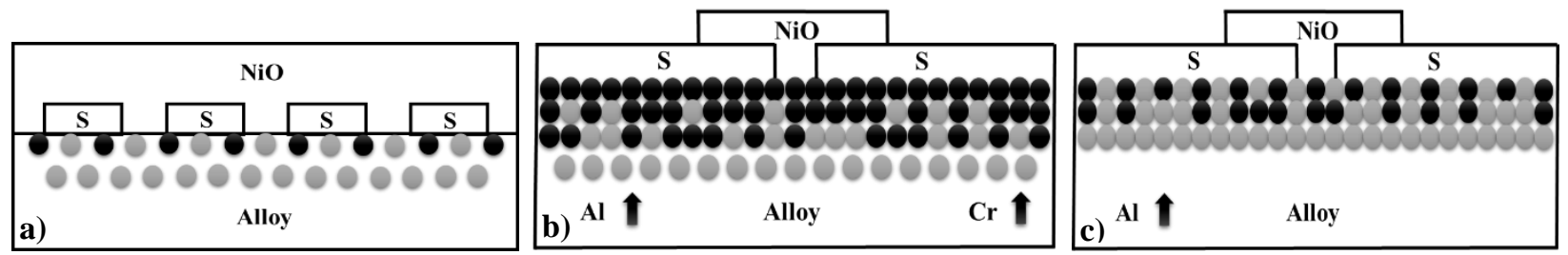

Figure 2- 14 Schematic diagram of oxide development on Ni-Cr-Al ternary alloys. a) Group I b) Group II and c) Group III [53] [69] (Reproduced with permission from Elsevier).

\subsection{Phase transformation during high-temperature oxidation}

In general, the selective oxidation of certain elements such as chromium or aluminum in alloys leads to the formation of a continuous, dense and adherent protective oxide layer on the surface and eventually results in compositional changes in the subsurface region of the alloy. Depending on the diffusion process in an alloy, phase transformation in the subsurface region involves either phase formation or phase dissolution. In both cases the compositional changes in the subsurface region results in change of the original microstructure of the alloy. The different modes of subsurface changes are volume changes, internal oxide precipitation, phase transformation, void formation and phase dissolution [97] which are represented in Figure 2-15. These modes have a 
deleterious effect on the alloy because, the toughness and the ductility are reduced at low temperature, the oxidation resistance is lowered and also the internal stress are elevated which leads to cracking and deformation in the alloy.
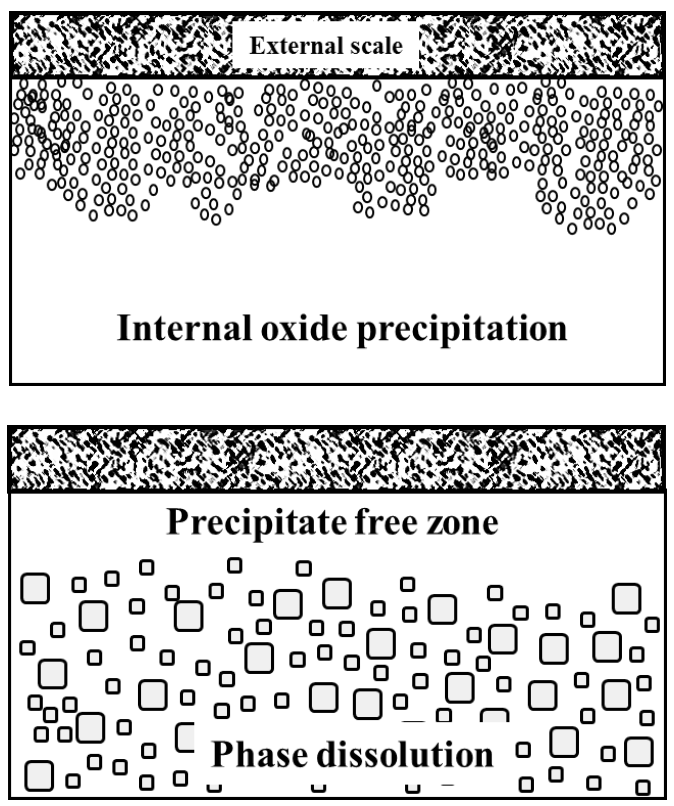
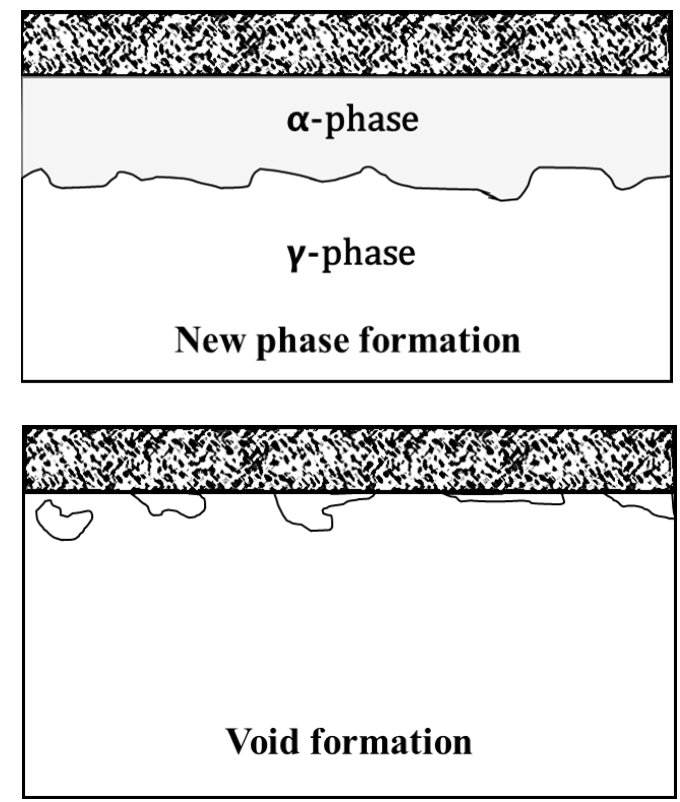

Figure 2- 15 Different modes of subsurface degradation as a result of oxidation [97] (Reproduced with permission from Elsevier).

If the alloying element(s) is/are sufficiently dilute, internal oxidation may lead to random precipitation of small oxide particles in the alloy beneath the external scale. This is sometimes also called subscale formation [53]. If the dissociation pressure of a metal oxides is higher than that of oxygen pressure, the dissolution of oxygen will occur at the metal/scale interface. This oxygen will diffuse into the metal and oxidize the most reactive element to form stable oxide. The internal oxide can form only if a reactive element diffuses outward more slowly than the inward diffusion of oxygen; otherwise, only an external scale would form [20]. 
The preferential nucleation of oxides at metal/scale interface may affect the formation of intermetallic phases. In this case, the dissolution of chromium in the subscale region of an alloy increases the diffusion rate of tungsten, thus increasing the tungsten activity at the metal/scale interface. The decrease in chromium content at the subsurface region also increases the carbon activity in the grain boundaries which lead to diffusion of carbon back to the bulk alloy [41] [97]. As a result of dissolution of carbide phases, the carbon content increases just beneath the chromium-depleted zone.

\subsubsection{Formation of new phase}

As discussed in the previous section phase formation and phase dissolution are both driven by selective oxidation of scale forming elements. In both cases, changes in the composition at the subsurface region result in a change of original microstructure. Phase formation is usually found in the form of an intermetallic compound. For an example, Hana [98] reported a subscale phase transformation during cyclic oxidation of a Ni-Cr-Al alloys at $1100^{\circ} \mathrm{C}$ in air. Specifically, the alloy consisted of binary $\beta-\mathrm{NiAl}$ and $\alpha-\mathrm{Cr}$ leading to selective aluminum removal from the alloy to form an $\mathrm{Al}_{2} \mathrm{O}_{3}$ scale. During thermal cycling, repeated $\mathrm{Al}_{2} \mathrm{O}_{3}$ scale spalling from the surface led to depletion of aluminum from the subsurface region. The external scale increase the dissolution of oxygen ions inside the alloy and thus internal precipitation of $\mathrm{Al}_{2} \mathrm{O}_{3}$ and $\mathrm{Cr}_{2} \mathrm{O}_{3}$ under the external scale occurred leading to eventual development of a $\gamma$-Ni phase. The formation of this $\gamma-\mathrm{Ni}$ also is the reason for a repeated scale spallation, because the thermal expansion coefficient of $\gamma$ - $\mathrm{Ni}$ is $13 \%$ higher than the $\beta$-NiAl [99].

An oxidation study on Ni-based superalloy IN-939 by Zhu [100] revealed stacking faults (twinning microstructure) in the subsurface zone due to the phase transformation driven by a 
composition change and also by local stresses associated with the transformation. Also, an isothermal oxidation study of nickel-base superalloy RR100 has been performed by Cruchley [101]. Here the formation of an external chromia scale is explained including formation of an internal oxidation zone with both intergranular and intragranular alumina oxide formation.

\subsubsection{Phase dissolution}

Generally a high oxidation-resistant alloy may be placed in a phase dissolution category [102]. For example, the high-temperature oxidation resistant nickel-base superalloys consist of nickelrich $\mathrm{FCC}-\gamma$ matrix with the uniform distribution of $\gamma^{\prime}-\mathrm{Ni}_{3} \mathrm{Al}$ precipitates. At high-temperatures, the major contribution to the high strength of nickel-base alloys is from these $\gamma^{\prime}-\mathrm{Ni}_{3} \mathrm{Al}$ precipitates [12] [24] [38] [44] [53]. The high-temperature oxidation of nickel-base superalloys involves external $\mathrm{Cr}_{2} \mathrm{O}_{3}$ scale formation with a branched $\mathrm{Al}_{2} \mathrm{O}_{3}$ internal subscale and thus, some of the intermetallic phases $\gamma^{\prime}-\mathrm{Ni}_{3} \mathrm{Al}$ are solutionized [103]. When the aluminum concentration in the subsurface matrix reaches a minimum, the $\gamma^{\prime}-\mathrm{Ni}_{3} \mathrm{Al}$ phase acts as an aluminum reservoir for further growth of $\mathrm{Al}_{2} \mathrm{O}_{3}$ oxide scale. The rate of $\mathrm{Al}_{2} \mathrm{O}_{3}$ subscale formation and the $\gamma^{\prime}-\mathrm{Ni}_{3} \mathrm{Al}$ precipitate dissolution also depends on the aluminum concentration in the precipitates. According to Chen [104], the $\gamma^{\prime}$ composition is precipitate-size dependent in RR1000 alloy. The aluminum content of secondary $\gamma^{\prime}$ precipitates is found to be greater that the primary $\gamma^{\prime}$ precipitates and thus the dissolution of finer precipitates is faster than that of the larger ones.

For most nickel-base superalloys the main grain boundary strengthening precipitates are chromium-based carbides, e.g. of the type $\mathrm{M}_{23} \mathrm{C}_{6}$ [105]. During high temperature service time, formation and growth rate of a chromia scale on the surface of the alloy results in the depletion 
of surface and grain boundary carbide precipitates which are rich in chromium. The dissolution of $\mathrm{M}_{23} \mathrm{C}_{6}$ helps to sustain the $\mathrm{Cr}_{2} \mathrm{O}_{3}$ scale growth.

In general, for the formation of an oxide scale BO, the concentration of $\mathrm{B}$ in the alloy is required to be larger than the critical concentration, $\mathrm{N}^{\alpha}{ }_{\mathrm{B}}$. When $\mathrm{BO}$ is formed as an external scale, the alloy is depleted in $\mathrm{B}$, as represented in Figure 2-16, where $\mathrm{N}^{\circ}$ B is the mole fraction of the original alloy $\mathrm{B}$ and $\mathrm{N}_{\mathrm{B}}^{\mathrm{i}}$ is the concentration of $\mathrm{B}$ at the oxide scale/alloy interface [17].

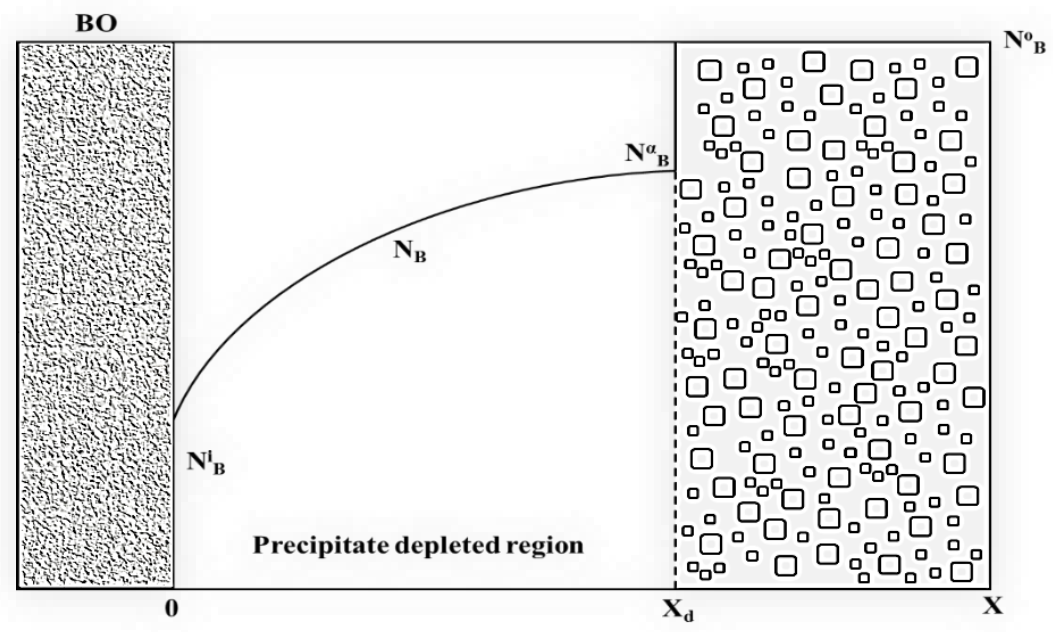

Figure 2- 16 Diffusion profile in the subsurface region of two-phase alloy AB undergoing selective oxidation causing dissolution of solute rich B-phase to form oxide scale of BO [53] (Reproduced with permission from Elsevier).

To maintain the equilibrium between precipitate and the local matrix, if the diffusion of solute element B through the precipitate depleted subsurface alloy region is fast enough to continue external scaling, the concentration of $\mathrm{B}$ at the scale/alloy interface $\mathrm{N}^{\mathrm{i}}{ }_{\mathrm{B}}$ will be constant. 
Diffusion analysis has been used to describe the concentration profile of $\mathrm{B}$ in the precipitate depleted or free zone as in Figure 2.21 [106]. By equating the flux of B in alloy with oxide scale results in the expression,

$$
N_{B}^{o}-N_{B}^{i}=\frac{u}{\gamma \exp \left(\gamma^{2}\right)}+\pi^{\frac{1}{2}} u \cdot \operatorname{erf}(\gamma)
$$

Where $X_{d}$ is the depth of the precipitate depleted or free zone and $u$ and $\gamma$ are the functions of rate constant $\mathrm{k}_{\mathrm{c}}$ which is given by the following expressions,

$$
\begin{aligned}
& u=\left(\frac{k_{c}}{4 D}\right)^{\frac{1}{2}} \\
& \gamma=\left(\frac{X_{d}}{4 D t}\right)^{\frac{1}{2}}
\end{aligned}
$$

\subsubsection{Void formation}

Generally, nickel-based superalloys form a stable oxide scale which inhibit further oxidation of alloy. The alloys interdiffusion at the metal/scale interface can lead to porosity and voids/cavity. The formation of voids and its growth in the subscale region of the alloys during oxidation can be explained by three main mechanisms [107] [108] [109],

i) Vacancy injection resulting from the fact that the diffusion of metal atoms into the scale which undergoes oxidation must be counterbalanced by an inward diffusion of oxygen. This type mechanism is called the Kirkendall effect. Further diffusion of metal atoms and oxygen ions can 
increase the vacancy concentration maximum at the metal/scale interface and these aggregate to form voids beneath the scale. This type of mechanism in alumina-forming nickel-based superalloys occurs due to migration of vacancies toward the scale/alloy interface through oxide, which corresponds to the outward diffusion of aluminum ions [15]. The Kirkendall effect is much faster in the phase boundaries and grain boundaries which have greater surface area than point defects or vacancies.

ii) The nucleation and growth of voids can be found in alloys containing carbon. The carbon reacts with the oxygen which is diffusing through the oxide scale to form bubbles of $\mathrm{CO}_{2}$ gasses. These gas bubbles have sufficient energy to nucleate the voids and further leads to the growth [53].

iii) The parabolic oxide layer growth leads to a volume change between the oxide layer and the alloy which in turn increases the tensile stresses. To accommodate this net volume change, creep cavity or voids will form beneath the oxide layer [71].

The tendency of scale formation in the alloys is also a function of the shape of a specimen and the surface-to-volume ratio [110] [111]. For example, if non-uniform oxidation takes place and if a specimen has finite dimensions, constraints are imposed on the system, particularly at edges and corners. This produces voids and cavities in these regions. Subsurface void formation affects the oxidation mechanism and the alloy properties. For example, preferred sites for the void nucleation are phase interfaces and grain boundaries in the subsurface region of the alloy and this may severely affect the mechanical integrity and properties of the alloy. 


\subsection{Summary of literature review}

In an aero engine the high-temperature exhaust gas creates an aggressive environment for the components in the high temperature zone. This environment results in creep, mechanical and thermal fatigue and also oxidation, all which greatly limit the service life. This can lead to material degradation and the periodic replacement of high temperature components and more support service required, both of which are expensive.

During selection of an alloy for turbine blades, apart from mechanical properties, hightemperature oxidation resistance also becomes an important factor in the selection criteria. The nickel-base superalloys are most oxidation resistant materials for high-temperature engineering applications. The oxidation resistance of these superalloys depend on the presence of number of alloying elements such as $\mathrm{Al}, \mathrm{Cr}, \mathrm{Ti}, \mathrm{Si}$ and $\mathrm{Ta}$ which forms a protective layer.

Each alloying element has a different affinity for oxygen and the stability of its oxide, determines selective oxidization. The participation of the alloying elements is regulated by free energy change. Since the oxide layer formation in nickel-base superalloys is not a single phase, there might exist a solid state reaction among these oxides, thus the growth is controlled by diffusion of oxygen ions through the oxide scale. The formation of oxides is influenced by a number factors such as alloy composition, temperature, diffusion rates and oxygen partial pressure.

Numerous studies showed that high-temperature oxidation of nickel-base superalloys may result in different oxide scales depending on the composition; chromia formers, alumina formers and $\mathrm{NiO}$ formers. The high-temperature oxidation may also result in compositional changes beneath the oxide scale causing new phase formation or precipitate dissolution in the subsurface region. 


\subsection{Scope of project}

The present work is to determine the effect of composition and microstructure on the oxidation resistance of three of three $\mathrm{Ni}$-based superalloys; polycrystalline cast IN738LC, single-crystal $\mathrm{N} 5$ and a powder metallurgy Ni-Cr-Fe alloy (with $6 \% \mathrm{Al}$ and $\mathbf{0 . 5 \%} \mathrm{Si}$ - "TAS"). These were subjected to static oxidation in air at $900^{\circ} \mathrm{C}$ and subsequently evaluated for relative oxidation resistance as well as pertinent microstructural changes.

Therefore the main aims for this project are to;

(1) Evaluate the oxidation resistance for the selected nickel-based superalloys in air by recording oxide scale growth and the spallation activity during high-temperature isothermal exposure for various times up to $1000 \mathrm{~h}$ at $900^{\circ} \mathrm{C}$.

(2) Record the oxide scale morphology and composition using cross section analysis involving SEM, EDS, AFM and AEM.

(3) Record the oxidation kinetics using mass gain and oxide scale thickness measurements over various oxidation durations.

(4) Discuss reasons for the relative levels of oxidation found with a view to providing a method of predicting the influence of alloying elements such as $\mathrm{Si}, \mathrm{Ti}, \mathrm{Ta}, \mathrm{Al}$ and $\mathrm{Cr}$ on elemental oxidation resistance. 


\section{EXPERIMENTAL PROCEDURES}

\subsection{Introduction}

The main aim of the work within this thesis is focused upon rationalizing the oxidation kinetics of nickel-based superalloys depending on their chemical composition and microstructure. The primary technique used to find the oxidation rate for each of the superalloys is based on isothermal oxidation experiments. These will be combined with the supporting thermodynamic modelling shown in the later parts of this chapter.

\subsection{Materials}

Three nickel-base superalloys were chosen for the present work, namely, polycrystalline cast IN738LC (low carbon alloy), single-crystal N5 and a powder metallurgy Ni-Cr-Fe alloy (with $6 \% \mathrm{Al}$ and $0.5 \% \mathrm{Si}$ - "TAS"). The compositions of both IN738LC and N5 materials were analysed by the PCC airfoils, Minerva Pvt. Ltd. In case of the powder metallurgy TAS material, the composition were taken from previous work by Murray [112]. The compositions of all three alloy specimens are summarized in Table 3-1.

Table 3- 1 Chemical compositions of IN738LC, N5 and TAS alloy in wt. \%.

\begin{tabular}{|c|c|c|c|c|c|c|c|c|c|c|c|c|c|c|c|c|}
\hline \multirow{2}{*}{ Alloy } & \multicolumn{16}{|c|}{ Alloying elements } \\
\hline & C & $\mathbf{S i}$ & $\mathrm{Cr}$ & $\mathbf{F e}$ & Al & Mo & $\mathbf{T i}$ & Co & $\mathbf{W}$ & $\mathbf{Z r}$ & B & $\mathbf{N b}$ & $\mathbf{T a}$ & $\operatorname{Re}$ & Hf & Nickel \\
\hline IN738LC & 0.112 & 0.04 & 16.02 & 0.03 & 3.4 & 1.77 & 3.44 & 8.47 & 2.58 & 0.028 & 0.009 & 0.9 & 1.71 & & & \\
\hline N5 & 0.06 & 0.12 & 7.14 & 0.09 & 6.14 & 1.44 & 0.02 & 7.44 & 4.94 & 0.02 & 0.004 & 0.02 & 6.41 & 2.92 & 0.16 & Balance \\
\hline TAS & & 0.5 & 11.22 & 8.42 & 6 & & & & & & & & & & & \\
\hline
\end{tabular}


The IN738LC and N5 were supplied in the as-received condition. The partial solution-treatment of IN738LC was carried out in a vacuum furnace at $1120^{\circ} \mathrm{C}$ for $2 \mathrm{~h}$ and cooled to room temperature using accelerated air or water quench. On the other hand, the single crystal N5 material was first heated to $1100^{\circ} \mathrm{C}$ and then in subsequent $50^{\circ} \mathrm{C}$ intervals $(10-15 \mathrm{~min}$ at each temperature) to $1289^{\circ} \mathrm{C}$ for $2.5 \mathrm{~h}$ and finally air cooled to room temperature. These partial solution-treated specimens were studied solely for morphological comparison. The PM-TAS specimens were prepared by a press and sinter technique as described by Murray [112]. These samples were not subjected to further ageing heat treatment. The microstructures of as received partial solution-treated IN738LC, N5 and the powder metallurgy TAS specimen are shown in Figure 3-1.
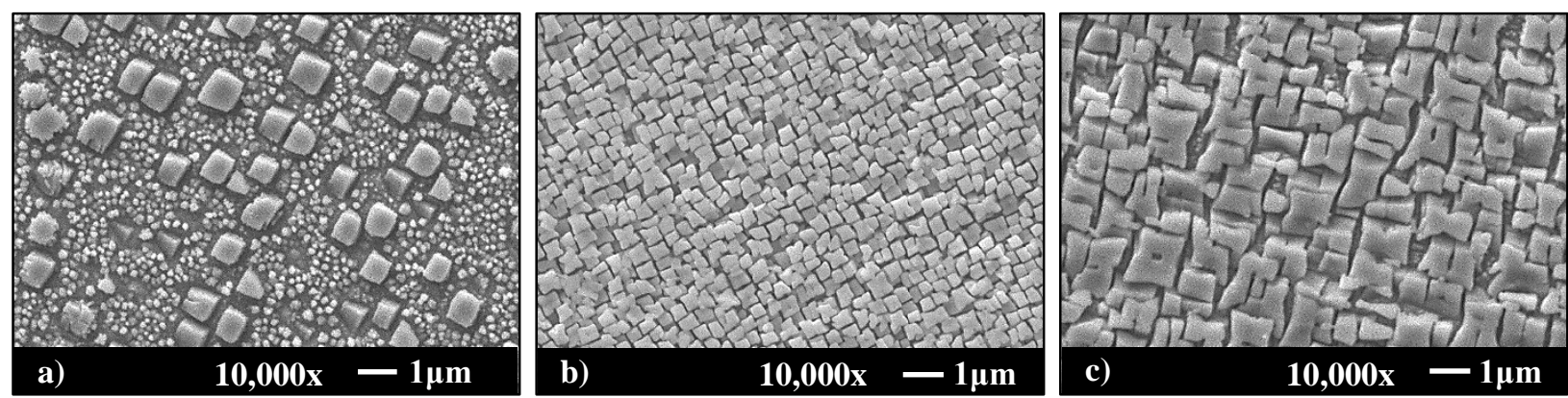

Figure 3- 1 Metallographic cross-sections of partial solution heat treated nickel-base superalloys; a) IN738LC, b) N5 and c) PM TAS.

\subsection{Heat treatment}

In order to precipitate the $\gamma^{\prime}$ phase, the above partial solution-treated alloys IN738LC and N5 were subjected to an ageing heat treatment. The IN738LC specimens were aged in a vacuum furnace at $845^{\circ} \mathrm{C}$ for $24 \mathrm{~h}$ and furnace cooled. In the case of $\mathrm{N} 5$, ageing had two steps, the first ageing treatment was carried out at $1079^{\circ} \mathrm{C}$ for $4 \mathrm{~h}$ and then $850^{\circ} \mathrm{C}$ for $20 \mathrm{~h}$ followed by furnace 
cooling to room temperature. The microstructures of the aged IN738LC and N5 as well as the asreceived PM TAS with precipitate volume fraction and sizes (using ImageJ software) are shown in Figure 3-2.
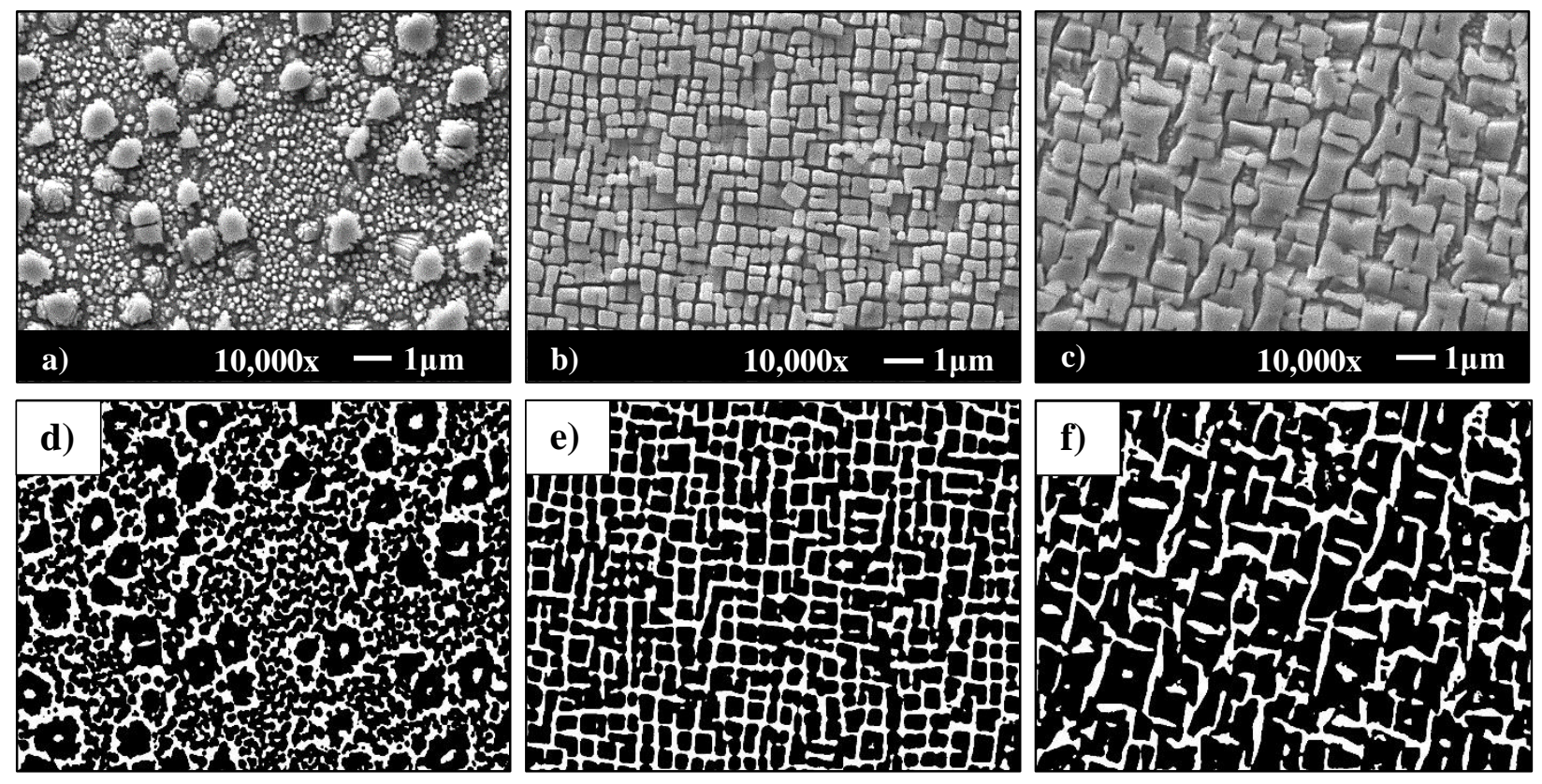

Figure 3- 2 Microstructure of a) IN738LC and b) N5 after ageing treatment in vacuum furnace, and c) PM TAS, d), e) and f) are the respective image analysis results.

\subsection{Sample preparation}

\subsubsection{Electrical discharge machining-wire cutting (EDM-WC)}

This is a thermal mass-reducing process that uses a continuously moving wire to remove material by means of rapid controlled repetitive spark discharges. A thin wire of molybdenum was used as an electrode. A dielectric fluid (water coolant) was used to flush the removed particles, regulate the discharge, and keep the wire and specimen cool. Specimens measuring $10 \times 8.5 \times 2$ mm were cut from heat aged IN738LC, N5 superalloys and the PM TAS superalloy using a 
Hansvedt EDM machine, which is shown in Figure 3-3. The wire cutting parameters of the EDM were kept constant for all three alloys; pulse-2.8 $\mu \mathrm{sec}$, on-time-2.5\%, peak amps-3.0, gap spacing-2, servo speed 13 and cut off-1.

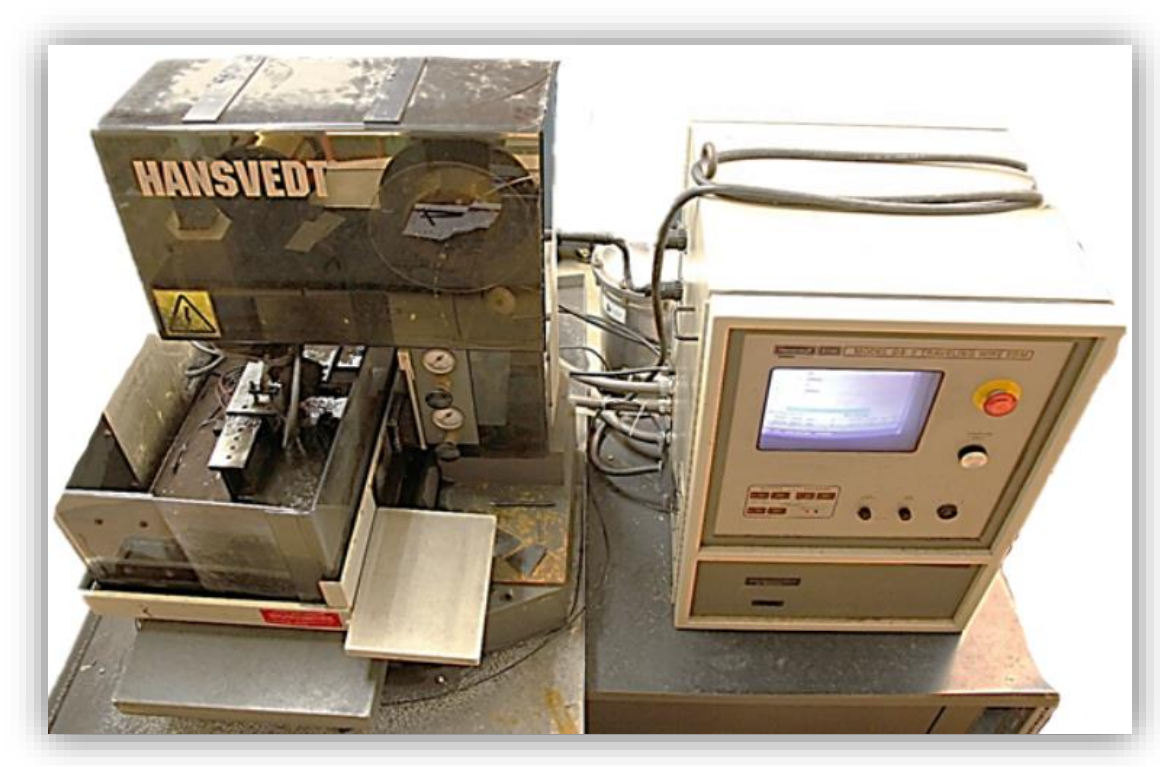

Figure 3- 3 Hansvedt electrical discharge machine

\subsubsection{Polishing, dimensioning and weighing}

The cut specimens of IN738LC, N5 and TAS were ground down to 600 grit finish using SiC grinding paper. Each sample and porcelain crucible container was weighed using a highly sensitive electronic scale, accurate to $\pm 0.0001 \mathrm{~g}$. The dimensions of each sample were measured and recorded using a digital micrometer so that the surface area of each specimen could be calculated. The polished samples were ultrasonically cleaned in water, rinsed in ethanol and then dried in air prior to oxidation testing. 


\subsection{Isothermal oxidation}

The $10 \times 8.5 \times 2 \mathrm{~mm}$ specimens of IN738LC, N5 and TAS were placed in a glazed porcelain crucible before being exposed isothermally at $900^{\circ} \mathrm{C}$. The furnace used was a Carbolite hightemperature box furnace, CWF-1300 (max: $1250^{\circ} \mathrm{C}$ ), as shown in Figure 3-4 and the furnace was calibrated using an external thermocouple. The size of the heat zone was confirmed by taking calibrated temperature readings in four corners and the centre. The isothermal oxidation tests were conducted at $900^{\circ} \mathrm{C}$ for various times up-to $1000 \mathrm{~h}$ in static air. The samples were withdrawn from the isothermal oxidation test at different intervals of time and left to cool in laboratory air. Once cooled, the samples were re-weighed and the weight change per unit surface area was calculated.
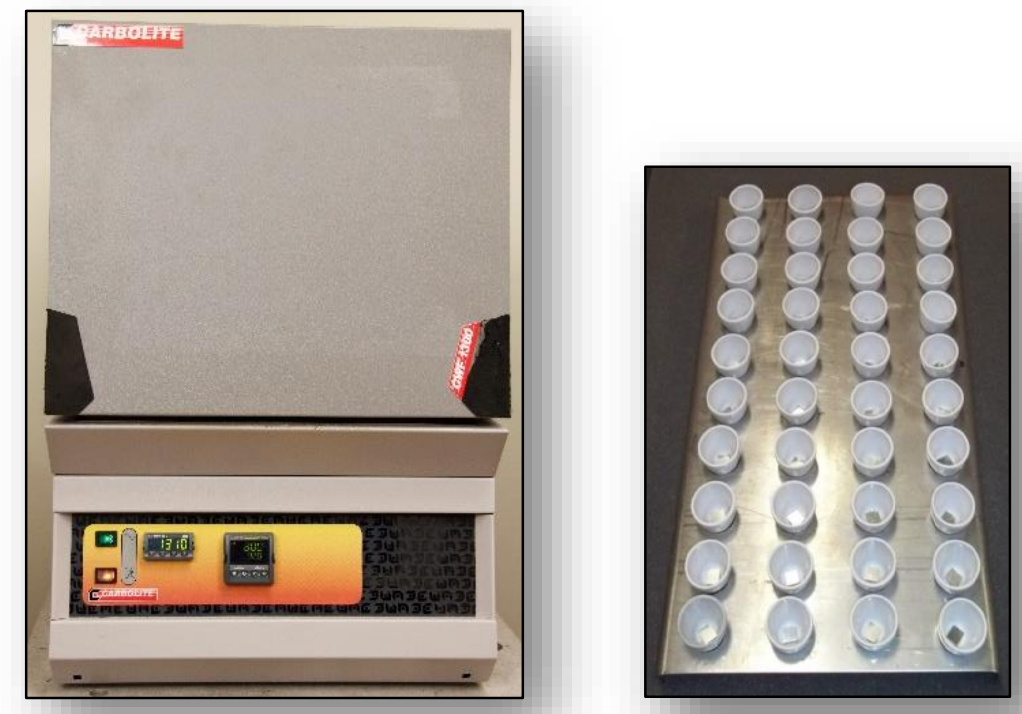

Figure 3- 4 a) Image of the Carbolite high temperature box furnace and b) Test setup with samples in glazed porcelain crucibles prior to oxidation. 


\subsection{Oxidized specimen characterization}

The oxidized specimens were analysed using several different characterization techniques in order to obtain the oxide structures which formed as well as, chemical composition and microstructure. These techniques were subsequently used to understand the oxidation mechanisms. Optical microscopy followed by scanning electron microscopy (SEM) with energy dispersive spectrometry (EDS) were used to obtain the cross-sectional images and to help identify the phase constitution of scale and the internal oxides. Electron probe microanalysis (EPMA) was used to obtain compositional changes at the scale/alloy interface. Auger electron spectroscopy (AES) and atomic force microscopy (AFM) were used to resolve the oxide layer for the initial oxidation period and to ascertain the approximate chemical composition of the oxide scale. The samples were typically mounted and polished using standard metallographic techniques.

\subsubsection{Cold mounting sample preparation of oxidized specimens}

In order to avoid the cracks at the oxide/alloy interface, oxidized specimens were implanted with Koldmount self-curing resin powder, which has excellent edge retention and abrasive resistance. Once the mounts are set, they are subjected to metallographic grinding and polishing. Briefly the mount samples were ground from 180 to 1200 grit on SiC paper, and then polished with $6 \mu \mathrm{m}$ followed by $1 \mu \mathrm{m}$ diamond suspension on polishing cloths. In order to remove the polishing residues, samples were cleaned thoroughly in an ultrasonic bath with acetone and dried. 


\subsubsection{Etching for alloy microstructure characterization}

For image analysis, in order to obtain a clear threshold between matrix, precipitates and oxide scale, etching was performed. The optimum etching solution for IN738, N5 and TAS was found to be as $12 \mathrm{ml}$ of $70 \% \mathrm{H}_{3} \mathrm{PO}_{4}+40 \mathrm{ml}$ of $70 \% \mathrm{HNO}_{3}+48 \mathrm{ml}$ of $98 \% \mathrm{H}_{2} \mathrm{SO}_{4}$. Finally, specimens were carbon coated to reduce the charging during SEM analysis.

\subsubsection{Optical microscope}

An optical microscope type of ZEISS-Aziovert 25 was used to analyse cross-sectional microstructure of the polished, etched surfaces and also to analyse the surface regions of the oxidized specimens. A digital camera attached to the microscope was used to obtain digital images. This also allowed for certain quantitative analyse, such as grain size and internal oxidation depth.

\subsubsection{Scanning electron microscopy (SEM) / EDS analysis}

An electron-microscopic investigation of the three alloys was made using a scanning electron microscope JEOL JSM-5900LV equipped with energy dispersive spectral analyzer INCA XMax. The beam accelerating voltage was varied from 10 to $20 \mathrm{keV}$, the coarse focusing of the specimen was kept at a working distance of $13 \mathrm{~mm}$ and the probe diameter or spot size was 36 . The documentation of the microstructure was made in the mode of secondary electron imaging (SEI). Individual phases were identified by qualitative X-ray microanalysis using INCA software. The composition analysis of oxide layer/layers were obtained in the form of point analysis, line scans, elemental mapping and quant mapping. In the present work the acquisition time for the composition analysis was fixed at $60 \mathrm{sec}$ and for the line scan, until peaks for the 
individual component reached to a steady state. The dead time was adjusted to $>20 \%$ by changing the spot size from 26 to 36 and by keeping working distance at $13 \mathrm{~mm}$.

\subsubsection{Electron probe microanalysis (EPMA)}

A CAMECA-SX 100 EPMA was used to obtain the concentration profiles across the oxidationaffected zone and to measure the oxide scale composition more accurately. The EPMA instrument was calibrated using pure element standards. The data were collected at $20 \mathrm{Kv}$ accelerating voltage using a point to point technique. The distance for data collection was specified and the microprobe was then automated to collect the data. Since the area affected zone due to X-rays is equivalent to about $5 \mu \mathrm{m}$, the EPMA was used in the later stage of oxidation, i.e. when oxide scale thickness reached more than $5 \mu \mathrm{m}$.

\subsubsection{Auger electron spectroscopy (AES)}

Auger electrons are produced whenever incident electrons interact with an atom with an energy exceeding the energy necessary to remove an inner shell usually $\mathrm{k}, \mathrm{l}$, and $\mathrm{m}$. electron from an atom. The interaction or scattering process leaves the atom in an excited state with a core hole, which is a missing inner shell electron. These excited atoms are unstable and the de-excitation occurs immediately, resulting in the emission of an electron from the valance band, termed as an Auger electron. Although primary excitation can be achieved by various energetic particles, most commercial equipment is made with an electron source. Electrons with the energy of $20 \mathrm{Kv}$ was generally used. Generation of an Auger electron requires the participation of at least three electrons, which therefore excludes the detection of hydrogen and helium. Auger electrons are emitted from the top 100-300nm of the surface of the specimen. These signals are used to develop the information on chemical composition from the top surface layers of the specimen. 
Chapter 3. Experimental procedures

The Auger electron microscope used in this thesis was type JAMP-9500F field emission system from the JEOL Company.

\subsubsection{Atomic force microscopy (AFM)}

A high resolution AFM (Nanoscope-digital instruments/veeco) was used to analyse the morphological features and topology of the oxide film on the cross-sectional oxidized specimens. In AFM no-contact tapping mode was applied to get the mapping. The surface topology raw data were forwarded to the Nanoscope- software which is a form digital instruments/veeco metrology group to visualize accurate 2D and 3D surface of the oxidized specimen.

\subsection{Hardness measurement}

Microhardness tests were used to study the effects of temperature and the exposure duration on microstructure of three alloys in this project. A Buehler Vickers microhardness testing device was used for all the hardness measurements in this study. The tests were carried out using load of $300 \mathrm{~g}$ on solution treated, aged and also on the oxidized specimens. Fifteen indentations were made on each sample and the average value was reported. 


\section{RESULTS}

\subsection{Introduction}

As explained in the previous sections of this thesis, high temperature alloys need to form a protective external scale to resist high-temperature oxidation. The properties of the oxide scale determine the extent to which protection can be provided. Ideally, the scale should exhibit a slow growth rate, good adherence to the substrate, a high stability and be continuous and free of defects such as micro-cracks and large voids [113]. Typically the oxide scale to meet these requirements for high-temperature oxidation resistance is based on either chromia or alumina [114] [115] [116].

The oxidation performance of commercial alloys is highly variable and accordingly, cannot be simply generalized. Oxidation resistance can vary dramatically with, for instance, alloy composition and structure, scale phase constitution and oxidation condition (temperature and environment). Thus it is very important to examine the behaviour of commercially-available superalloys to obtain a better understanding of the variables affecting oxidation resistance. This chapter analyses the oxidation behaviour of three nickel based superalloys; polycrystalline cast IN738LC, single-crystal N5 and a powder metallurgy Ni-Cr-Fe alloy (with 6\% $\mathrm{Al}$ and $0.5 \% \mathrm{Si}-$ “TAS") having different levels of alloying elements and microstructure. The results will allow for the comparison of base alloying elements and give an indication of the oxidation effects of minor alloying elements such as $\mathrm{Ti}, \mathrm{Si}$, and $\mathrm{Ta}$. 


\subsection{Isothermal oxidation}

Figures 4.1, 4.2 and 4.3 illustrates the isothermal oxidation results for all three superalloys oxidized at $900^{\circ} \mathrm{C}$ in static air, for times up to $1000 \mathrm{~h}$. No significant spallation of oxide was observed in any of the specimens. Figures 4-1a, 4-2a and 4-3a present the weight gain $\left(\mathrm{mg} . \mathrm{cm}^{-2}\right)$ as a function of oxidation duration (h) and Figures 4.1b, 4.2b and 4.3b present the parabolic weight gain $\left(\mathrm{mg}^{2} \cdot \mathrm{cm}^{-4}\right)$ as a function of exposure duration (s). From the weight gain (mg. $\left.\mathrm{cm}^{-2}\right)$ as a function of oxidation duration (h) plot, it is evident that all three alloys oxidize in a parabolic manner, although the composition and microstructure are very different. Thus plots (b) are the parabolic plots and the data fit should be linear if the scale growth is a diffusion controlled process.

From Figures 4-1a, 4-2a and 4-3a it is evident that the mass gain for the IN738LC is higher than the mass gain for the N5 and TAS. The higher oxidation rate constant, $\mathrm{k}_{\mathrm{p}}$ of IN738LC was found to be $2.79 \times 10^{-6} \mathrm{mg}^{2} \cdot \mathrm{cm}^{-4} \cdot \mathrm{s}^{-1}$. The alloys N5 and TAS showed the lowest steady state parabolic rate constants, $1.42 \times 10^{-7} \mathrm{mg}^{2} \cdot \mathrm{cm}^{-4} \cdot \mathrm{s}^{-1}$ and $1.64 \times 10^{-7} \mathrm{mg}^{2} \cdot \mathrm{cm}^{-4} \cdot \mathrm{s}^{-1}$ respectively. The parabolic rate constants suggest that the N5 and TAS alloys are more oxidation resistant than the IN738LC. From Figures 4-2b and 4-3b, the single crystal N5 and powder metallurgy TAS superalloys showed parabolic growth kinetics after an initial transient stage in which the weight gain kinetics were more rapid. The rates are given as $1.32 \times 10^{-6} \mathrm{mg}^{2} \cdot \mathrm{cm}^{-4} \cdot \mathrm{s}^{-1}$ and $5.53 \times 10^{-7} \mathrm{mg}^{2} \cdot \mathrm{cm}^{-4} \cdot \mathrm{s}^{-1}$ respectively. On the other hand, the polycrystalline IN738LC superalloy showed perfect parabolic behaviour without any transient stage. The rate constants of transient and steady state growth rates are summarized in Table 4-1. Although the aluminum composition in N5 and TAS is same, the transient stage rate, $\mathrm{k}_{\mathrm{p}}$ for N5 was higher than that of TAS. The transient stage for 
N5 was found to be under $15 \mathrm{~h}$, while TAS showed longest transient stage of about $32 \mathrm{~h}$. The difference in parabolic growth rate during the transient stage for N5 was about a factor of 10 times more than the TAS.
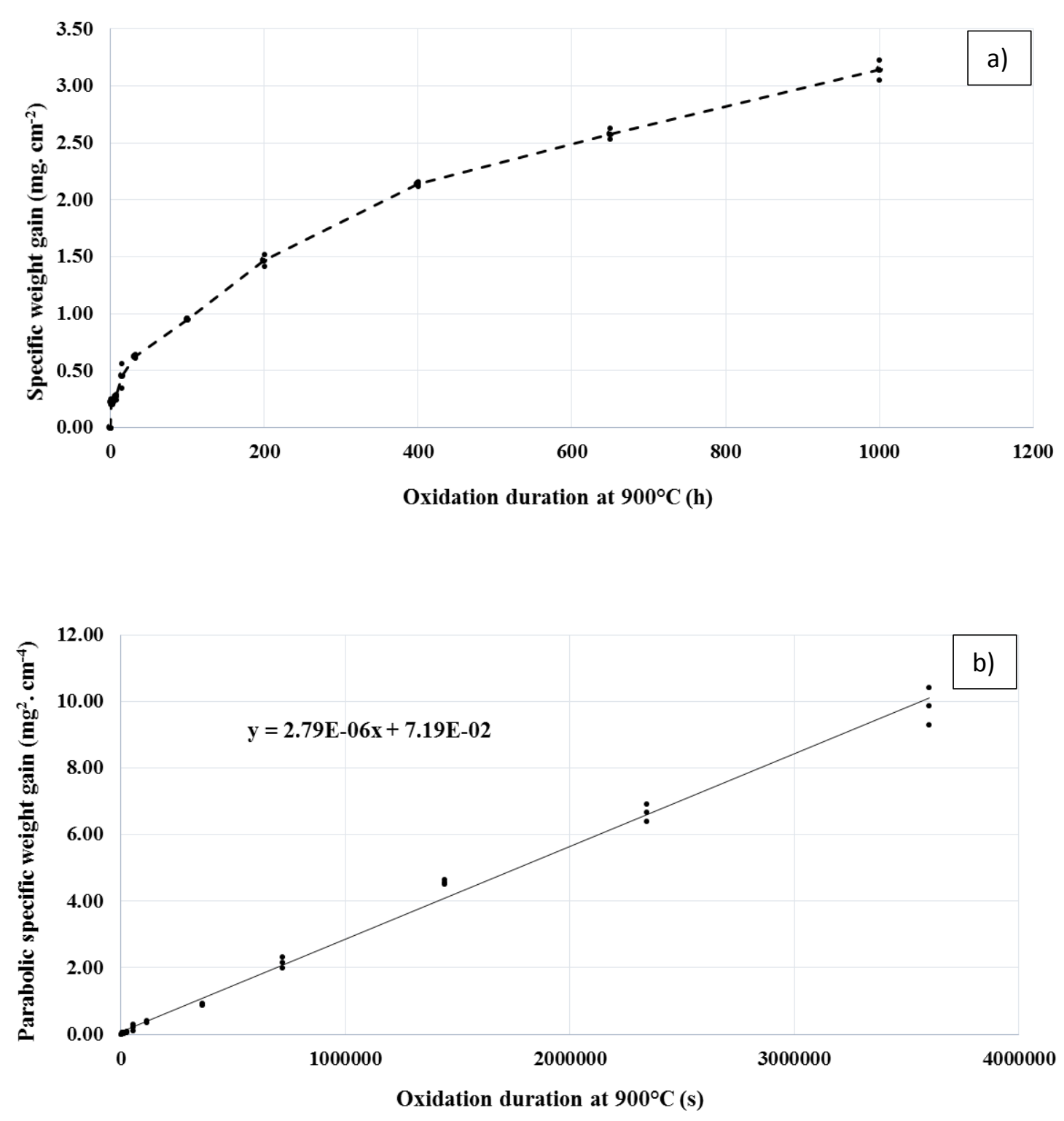

Figure 4- 1 Isothermal oxidation of IN738LC in static air at $900^{\circ} \mathrm{C}$ a) weight gain as a function of oxidation duration and b) parabolic weight gain as a function of oxidation duration. 

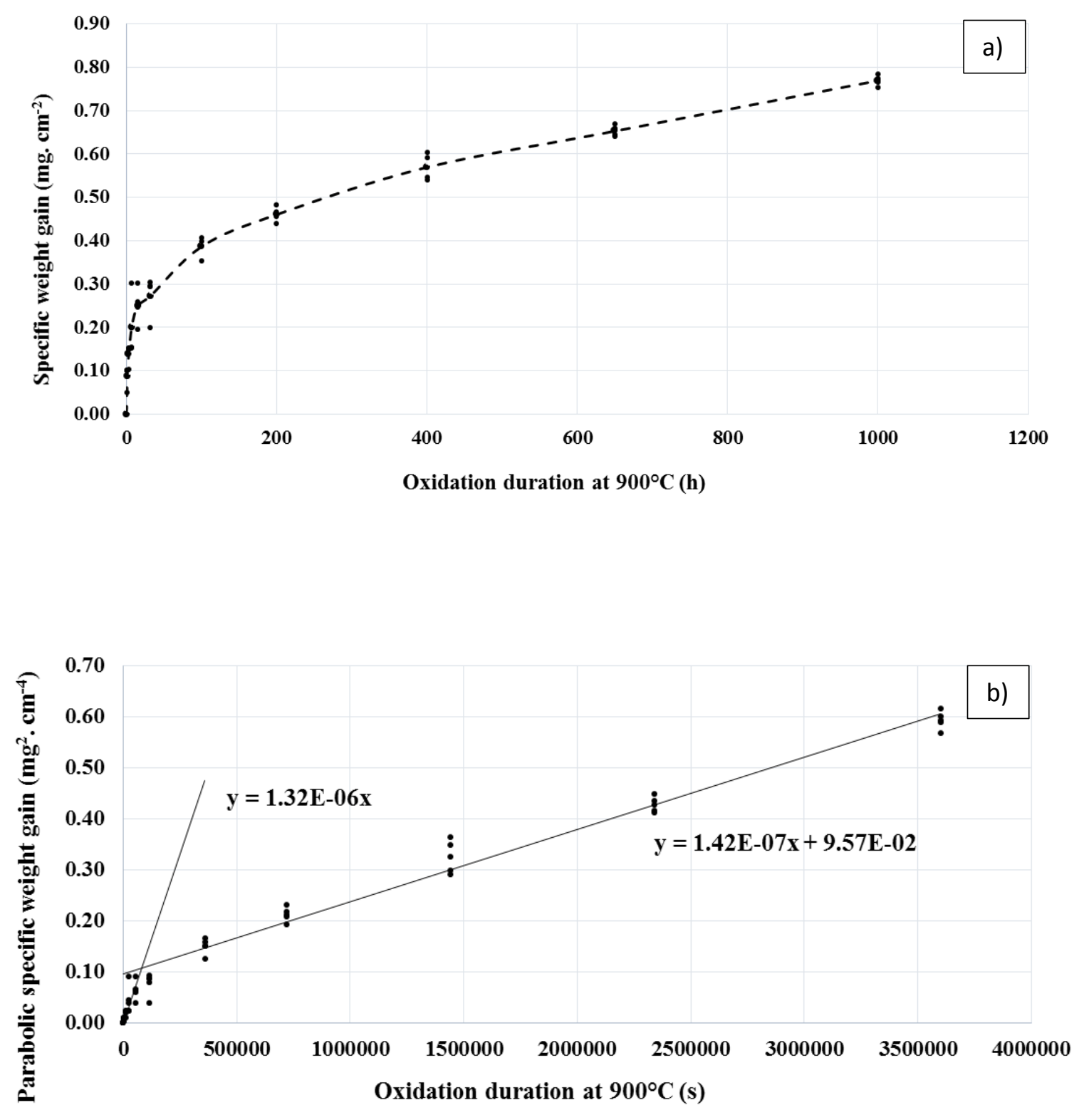

Figure 4- 2 Isothermal oxidation of N5 in static air at $900^{\circ} \mathrm{C}$ a) weight gain as a function of oxidation duration and b) parabolic weight gain as a function of oxidation duration. 

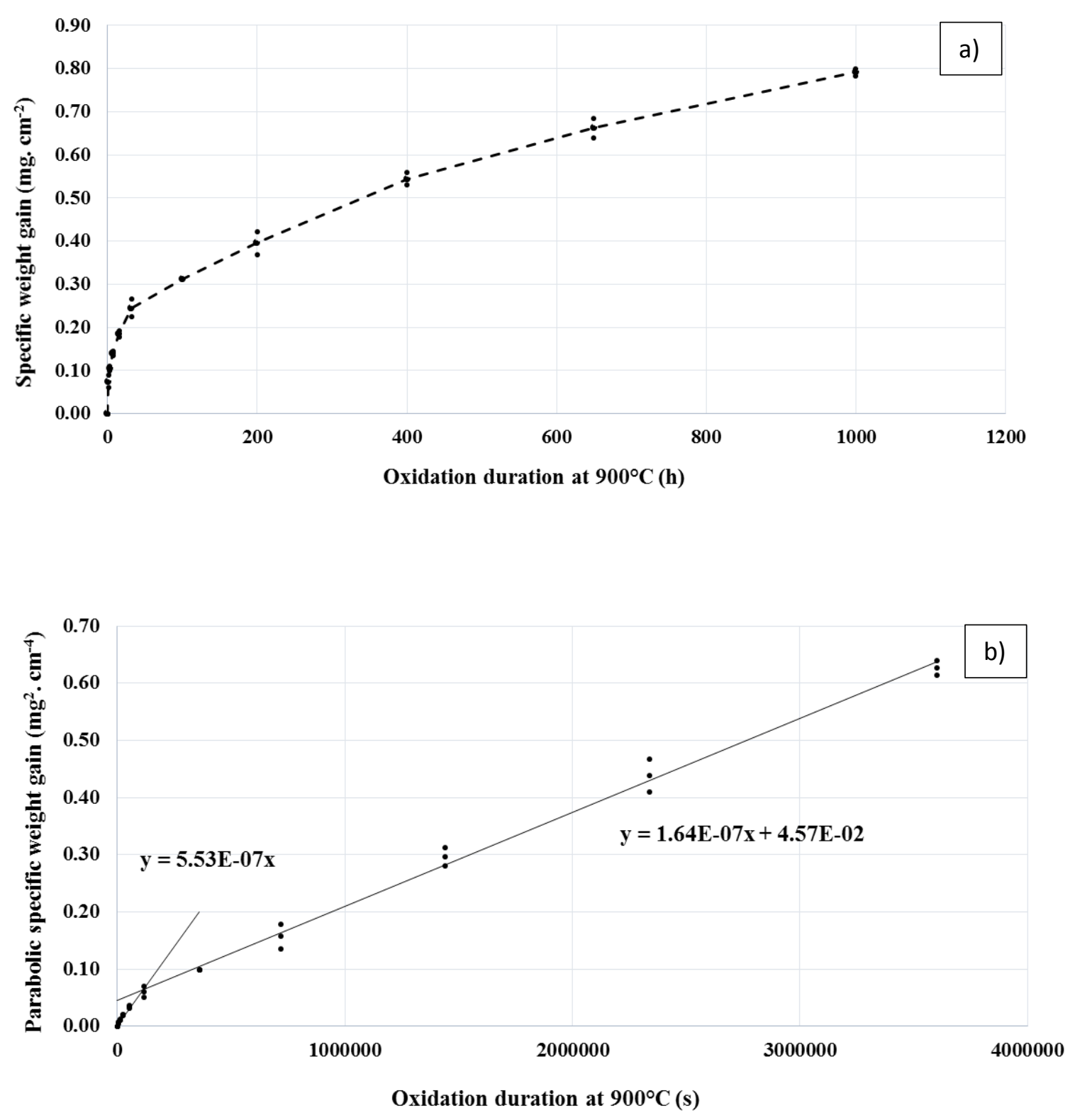

Figure 4- 3 Isothermal oxidation of PM-TAS in static air at $900^{\circ} \mathrm{C}$ a) weight gain as a function of oxidation duration and b) parabolic weight gain as a function of oxidation duration. 
Table 4- 1 Rate constant, $\mathrm{kp}$ for three superalloys oxidized at $900^{\circ} \mathrm{C}$ in static air.

\begin{tabular}{|c|c|c|c|}
\hline \multirow{2}{*}{ Alloys } & \multicolumn{2}{|c|}{ Transient stage } & Steady-state stage \\
\cline { 2 - 4 } & Duration $(\mathbf{s})$ & $\mathbf{k p},\left(\mathbf{m g}^{\mathbf{2}} \cdot \mathbf{c m}^{-\mathbf{4}} \cdot \mathbf{s}^{-\mathbf{1}}\right)$ & $\mathbf{k p},\left(\mathbf{m g}^{\mathbf{2}} \cdot \mathbf{c m}^{-\mathbf{4}} \cdot \mathbf{s}^{-\mathbf{1}}\right)$ \\
\hline IN738LC & & & $2.79 \mathrm{E}-06$ \\
\hline N5 & $\sim 54000$ & $1.32 \mathrm{E}-06$ & $1.42 \mathrm{E}-07$ \\
\hline TAS & $\sim 115200$ & $5.53 \mathrm{E}-07$ & $1.64 \mathrm{E}-07$ \\
\hline
\end{tabular}

From Table 4.1 it can be seen that the shorter transient duration was associated with a higher transient rate constant, while longer transient duration resulted in a smaller transient rate constant.

\subsection{Vickers Hardness}

The hardness values of IN738LC, N5 and PM-TAS alloys after solution treatment and age hardening were obtained using Vickers micro-hardness measurements; 15 readings were taken for each polished sample and the average hardness data are reported in Table 4.2. It can be seen from the Table 4.2 that there was no change in the solution treated and age hardened IN738LC specimen, while the N5 was higher by 60 points from solution treated to age hardened. The furnace sintered PM-TAS found to have the lowest hardness value among all three alloys. Also, from Table 4.2, it is evident that the hardness value after oxidation $1000 \mathrm{~h}$ at $900^{\circ} \mathrm{C}$ did not change significantly.

Table 4- 2 Vickers micro-hardness values for superalloys in various heat treated conditions.

\begin{tabular}{|c|c|c|c|}
\hline \multirow{2}{*}{ Alloy } & \multicolumn{3}{|c|}{ Vickers Hardness (300g) } \\
\cline { 2 - 4 } & As received & Age hardened & After 1000h at 900 ${ }^{\circ} \mathbf{C}$ \\
\hline IN738 & $382 \pm 20.1$ & $393 \pm 14.0$ & $372 \pm 17.0$ \\
\hline N5 & $398 \pm 11.2$ & $465 \pm 12.6$ & $420 \pm 15.2$ \\
\hline TAS & $342 \pm 39.7$ & - & $326 \pm 49.8$ \\
\hline
\end{tabular}




\subsection{Microstructural characterizations of oxidized specimens}

\subsubsection{Early stages of oxidation}

In Figures 4-4 and 4-5, cross-sectional SEM micrographs of the oxidized superalloys are shown after the exposure at $900^{\circ} \mathrm{C}$ up to three hours in static air. Although weight gains are seen after oxidation, the SEM analysis showed no distinct oxide layer formation on the surface of all three nickel-based superalloys.

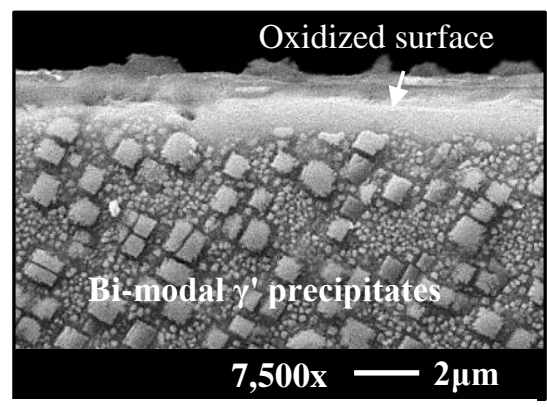

a)

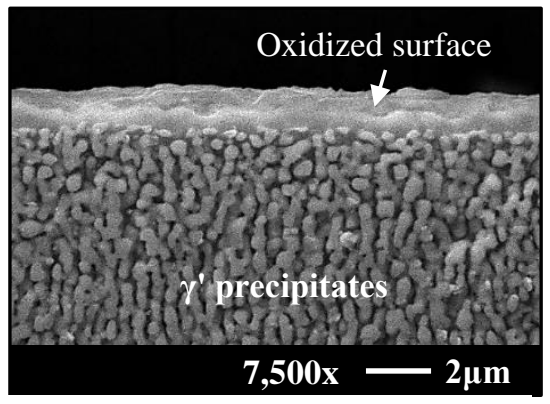

b)

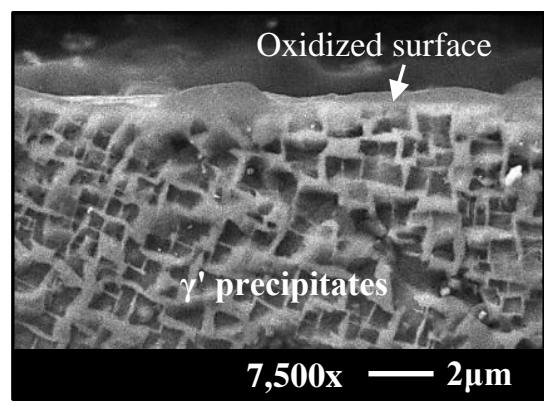

c)

Figure 4- 4 SEM microstructures of nickel-based superalloys exposed at $900^{\circ} \mathrm{C}$ in static air for one hour. a) IN738LC b) N5 and c) PM-TAS.

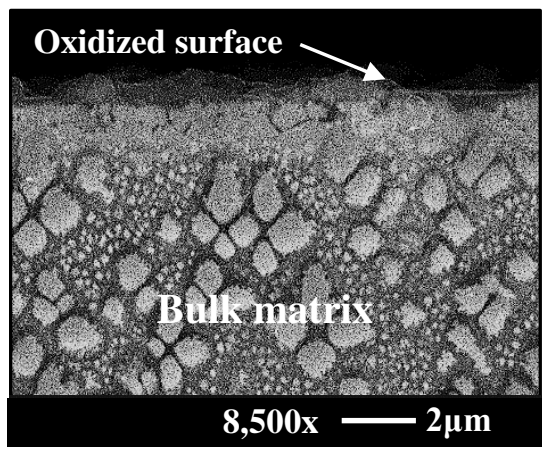

a)

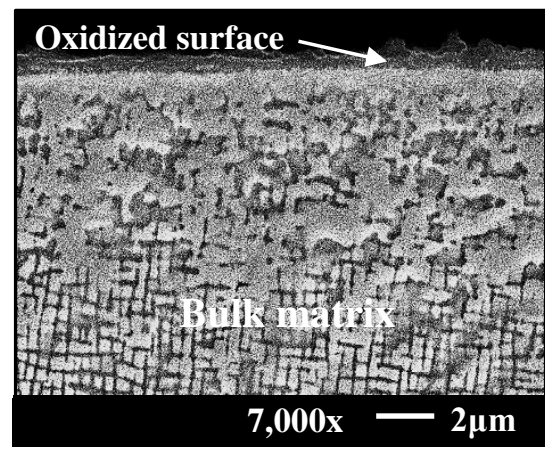

b)

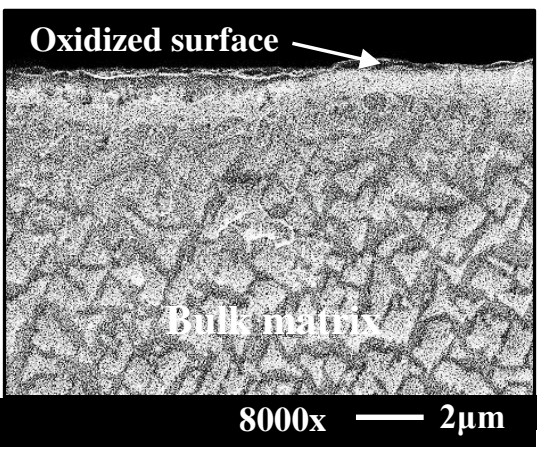

c)

Figure 4- 5 SEM microstructures of the nickel-based superalloys exposed at $900^{\circ} \mathrm{C}$ in static air for three hours. a) IN738LC b) N5 and c) PM-TAS. 
The morphological features of the oxide film formed after three hours of oxidation at $900^{\circ} \mathrm{C}$ for the three superalloy specimens were investigated by AFM. The images obtained, using a commercial Nanoscope AFM (tapping mode), are presented in Figure 4.6. The images revealed no sign of an oxide layer at the gas/metal interface.

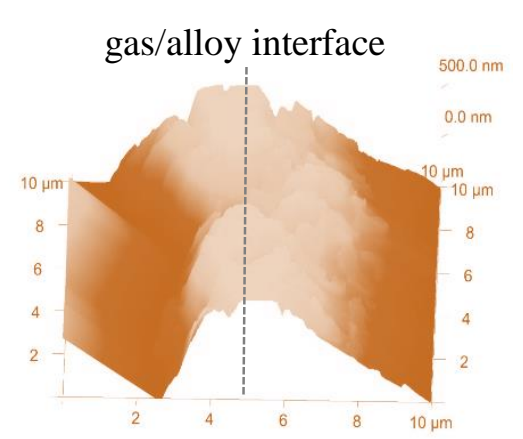

a)

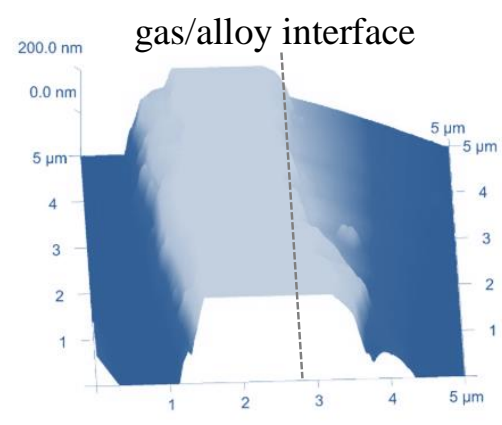

b)

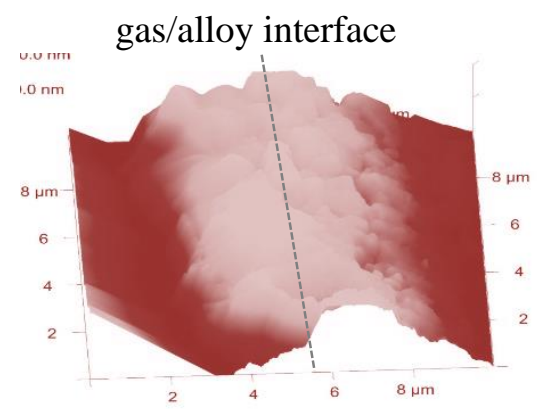

c)

Figure 4- 6 Typical AFM topographic 3D images of gas/alloy interface morphology after three hours of an oxidation at $900^{\circ} \mathrm{C}$. a) IN738LC b) N5 and c) PM-TAS.

To correlate the morphological features derived from AFM, the three hours oxidized specimens of IN738LC and N5 were analysed by AES depth profiling. The analysis obtained provided data for chemical composition change over a few nano-meters from the surface of the sample. The results are presented in Figure 4.7 and Figure 4.8. From the IN738LC spectra, Figure 4-7 it can be noticed that the outer surface is mainly titanium and oxygen. As sputter depth increases the titanium and oxygen concentration decreases reflecting the diffusion control process. Similarly the three hour oxidized N5 specimen spectra, Figure 4-8 depict the nickel and oxygen rich outer surface which decreases with increase in depth. 


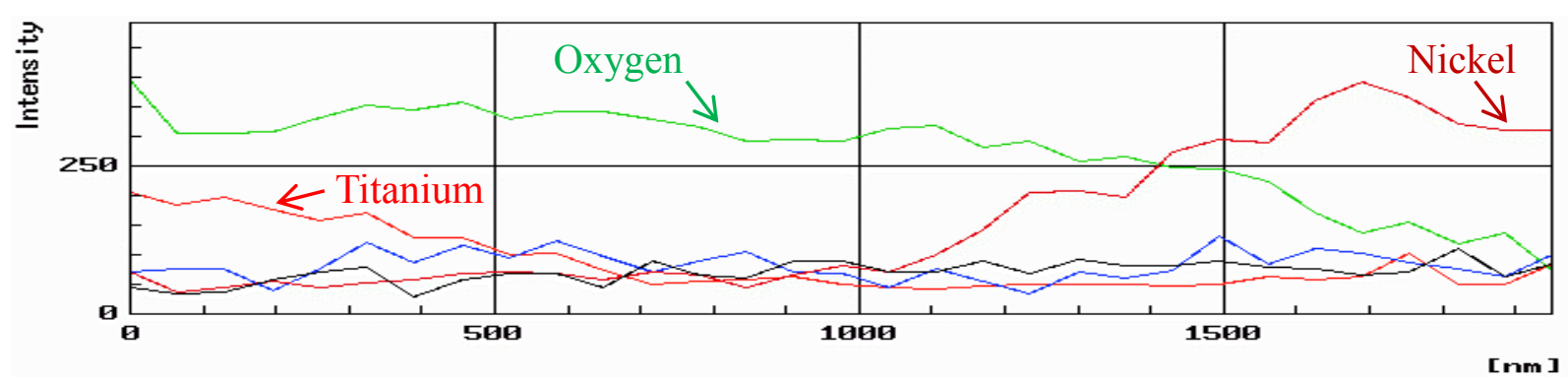

Figure 4- 7 Auger electron spectra of IN738LC oxidized at $900^{\circ} \mathrm{C}$ in static air for three hours.

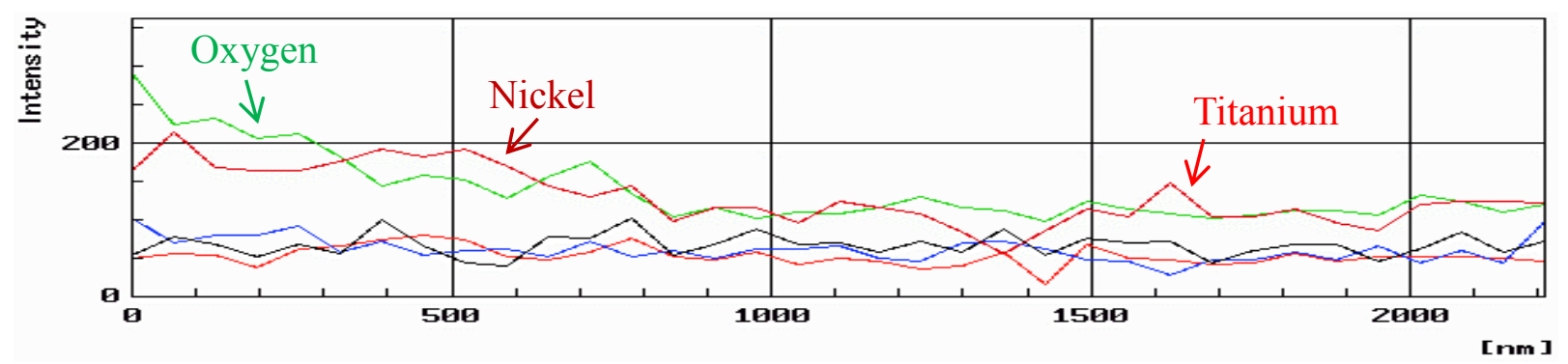

Figure 4- 8 Auger electron spectra of $\mathrm{N} 5$ oxidized at $900^{\circ} \mathrm{C}$ in static air for three hours.

\subsubsection{Long-time oxidation}

All three superalloy specimens oxidized at $900^{\circ} \mathrm{C}$ up to $1000 \mathrm{~h}$ were first observed with optical microscopy. From Figure 4-9, shows that IN738LC looks more oxidized than others. The external oxide scale formed on all three alloys appears continuous and in addition to this IN738 shows discontinuous layer adjacent to the external oxide layer. There are some cracks attached to the discontinuous layer, which propagate to the bulk of the IN738LC alloy. On the other hand, N5 and PM-TAS show a very thin oxide monolayer. From Figure 4-9, it is evident that the powder metallurgy TAS alloy does not have a homogeneous matrix. 

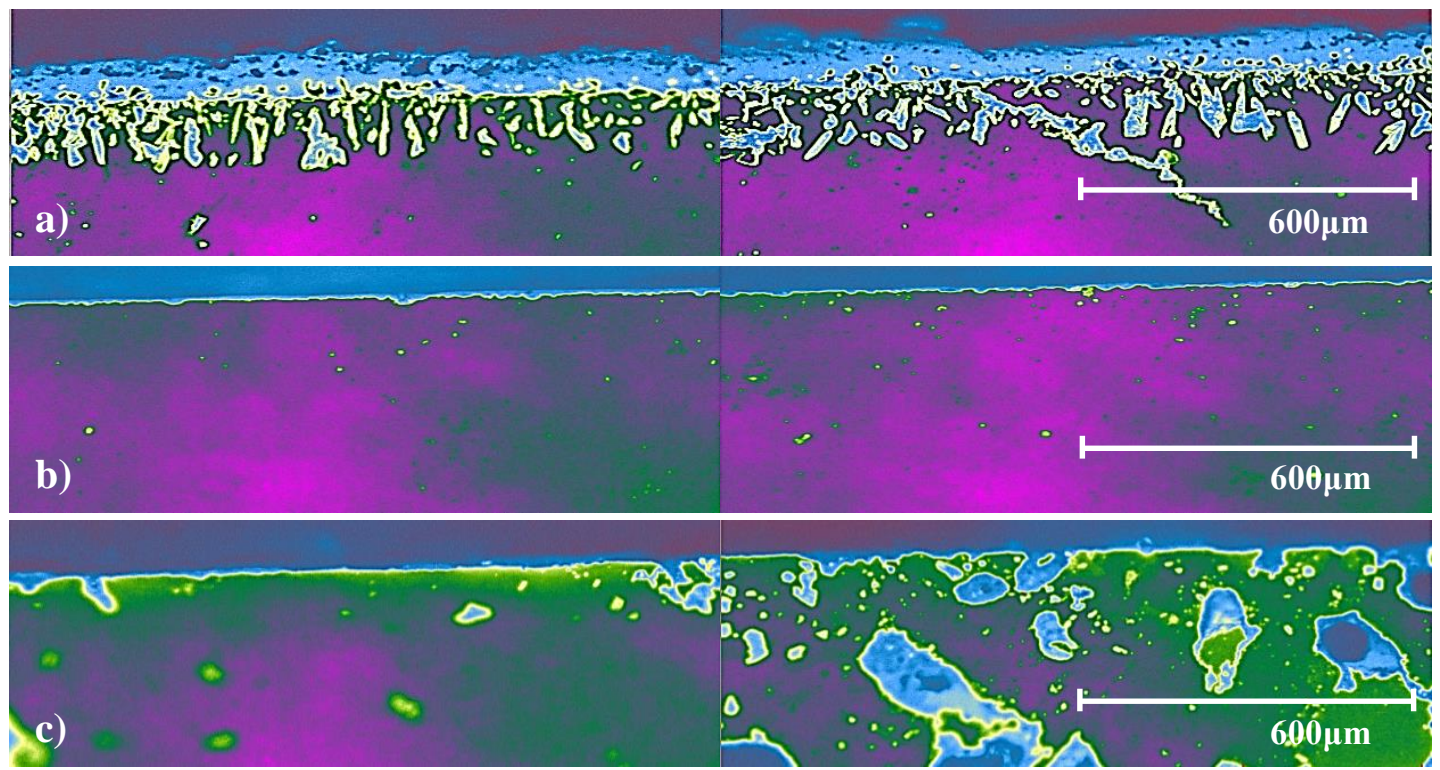

Figure 4- 9 Optical micrographs of nickel-based superalloys oxidized at $900^{\circ} \mathrm{C}$ for $1000 \mathrm{~h}$. a) IN738LC, b) N5 and c) PM-TAS.

The SEM microstructural analyses of the scale formed on IN738LC, N5 and PM-TAS alloys after seven hours of oxidation at $900^{\circ} \mathrm{C}$ are shown in Figure 4-10. It is evident from Figure 410a that the oxide scale growth in IN738LC is much more extensive compared to N5 and PMTAS, both of which show minimal sign of oxide layer formation. From Figure 4-10b, the formation of pit-like features are found to appear on the gas/alloy interface in N5.

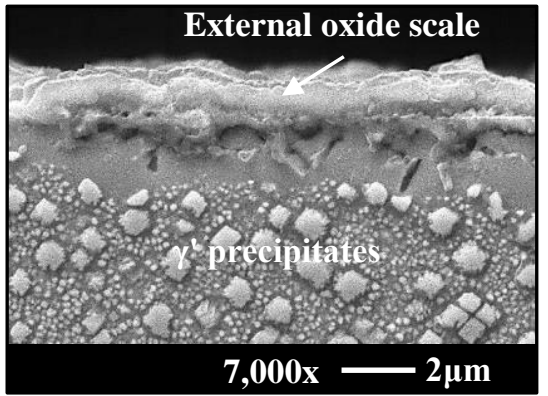

a)

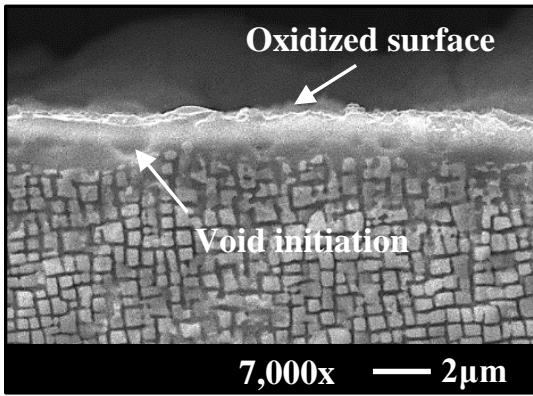

b)

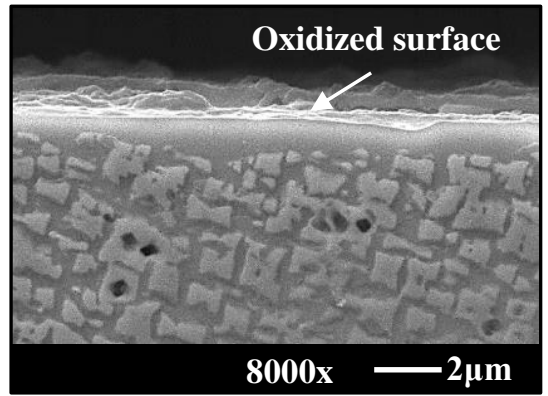

c)

Figure 4- 10 SEM structural images of nickel-based superalloys exposed to $900^{\circ} \mathrm{C}$ for seven hours. a) IN738LC, b) N5 and c) PM-TAS. 
From Figures 4-11, 4-12 and 4-13, it is observed that the thickness of the oxide scales formed on all three alloys increased with increase in oxidation duration. The formation and growth of a precipitate-free zone (PFZ) was found to be higher in IN738LC compared to N5 and TAS with increase in duration. The oxide scale morphology near the oxide/alloy interface is also found to be different in all three alloys. The IN738LC showed continuous dense external layer and fingerlike discontinuous internal oxide layer beneath the external layer. The single crystal N5 and PMTAS alloys exhibited excellent oxidation resistance, formed the thinnest scales and showed no evidence of internal oxides. During initial stages of N5 oxidation the small pit-like features which appeared at gas/alloy interface region increased in size and formed as voids between the scale/alloy interfaces. The SEM analysis of unetched specimens suggests that these voids are formed before electro etching.

The oxide scale thickness was measured using SEM. In the case of IN738LC that was exposed up to $1000 \mathrm{~h}$ the total thickness of the oxide scale is about $30 \mu \mathrm{m}$ and the thickness of the outer scale alone was measured to be $12 \mu \mathrm{m}$. On the other hand the N5 and TAS specimens after 1000h duration showed an external scale which was around $2 \mu \mathrm{m}$ thick.

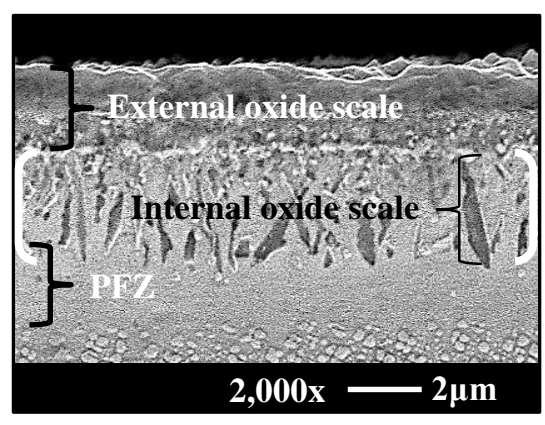

i)

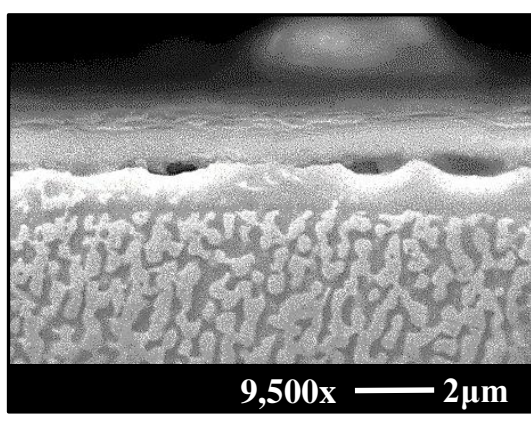

ii)

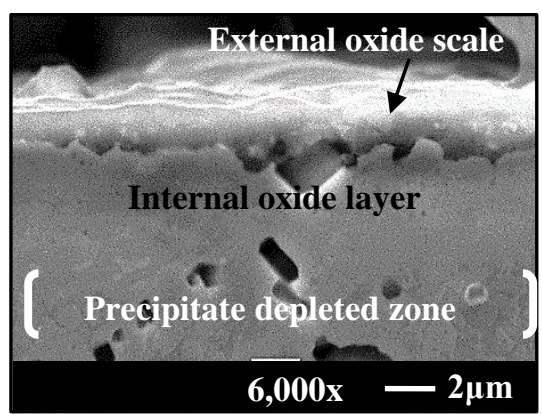

iii)

Figure 4- 11 SEM structural images of nickel-based superalloys exposed to $900^{\circ} \mathrm{C}$ for 200 h. i) IN738LC, ii) N5 and iii) PM-TAS. 


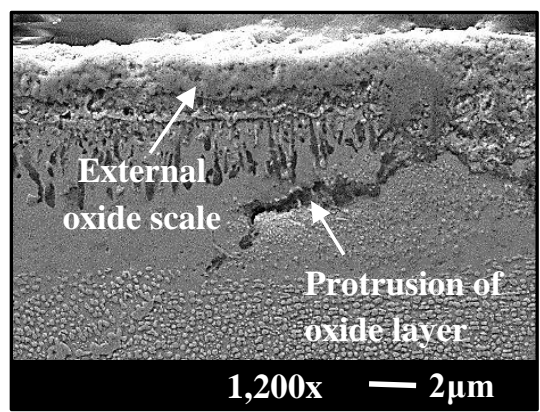

i)

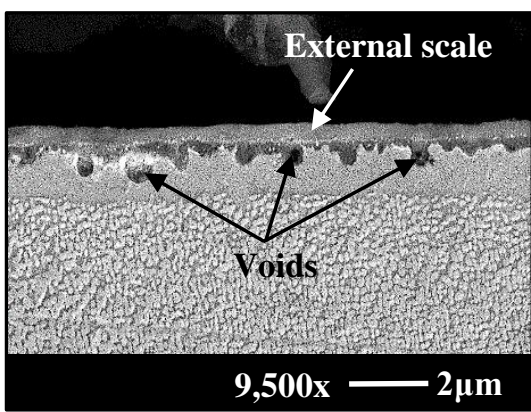

ii)

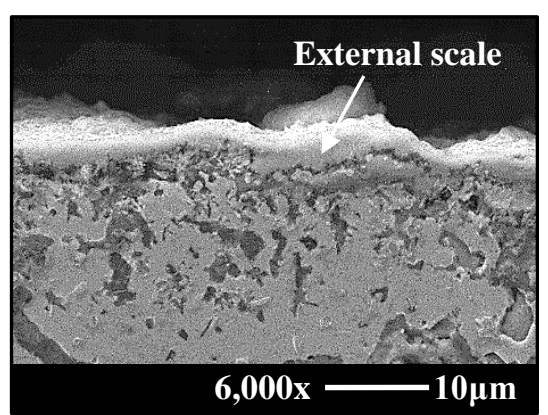

iii)

Figure 4- 12 SEM structural images of nickel-based superalloys exposed to $900^{\circ} \mathrm{C}$ for $600 \mathrm{hi}$ ) IN738LC, ii) N5 and iii) PM-TAS.

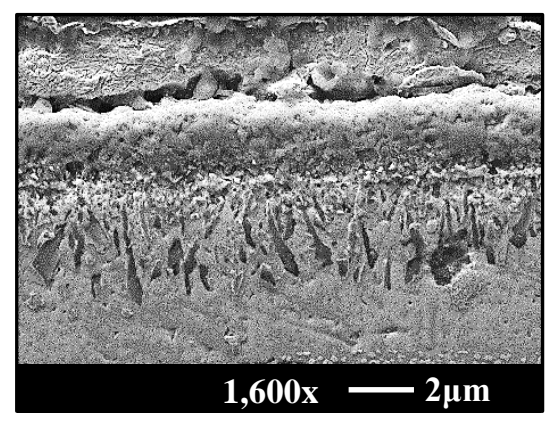

i)

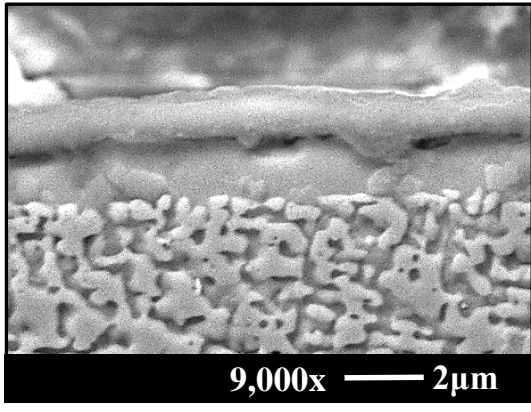

ii)

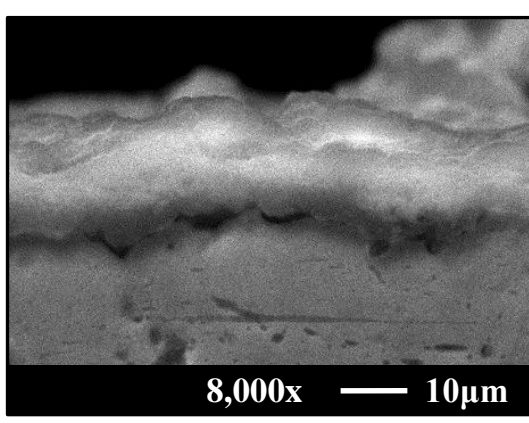

iii)

Figure 4- 13 SEM structural images of nickel-based superalloys exposed to $900^{\circ} \mathrm{C}$ for 1000 h. i) IN738LC, ii) N5 and iii) PM-TAS.

The variation of oxide scale thickness with respect to exposure duration of all three nickel-based i) superalloys up to $1000 \mathrm{~h}$ is illustrated in Figure 4-14. The single crystal N5 and TAS showed mono-layered scale, while IN738LC developed two layers. The growth of oxide scale in IN738LC was much higher than the N5 and TAS. The polycrystalline IN738LC superalloy showed larger scale thickness, which is consistent with the larger steady state parabolic rate 
constant in Table 4-1. The thicker oxide layer and deeper penetration of internal oxidation in IN738LC would have contributed to the weight gain.

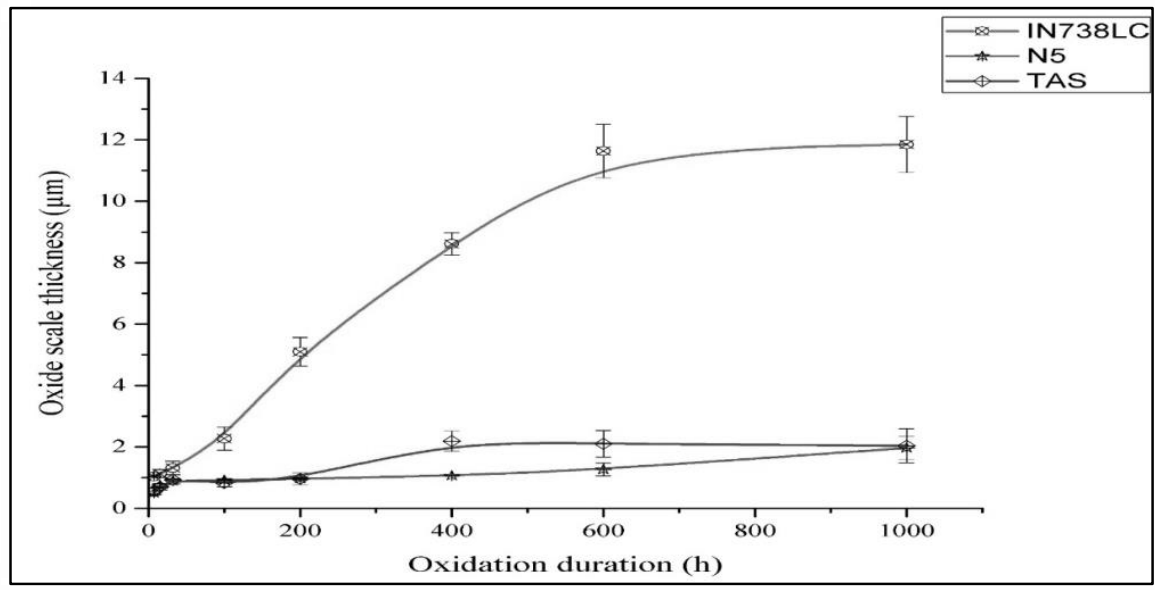

Figure 4- 14 Oxide scale growth plot for Ni-based superalloys exposed to air at $900^{\circ} \mathrm{C}$ for various times up to $1000 \mathrm{~h}$ with $95 \%$ confidence level.

\subsection{EDS chemical analysis}

A comprehensive EDS cross sectional analysis was performed on each sample to identify the oxides formed after $1000 \mathrm{~h}$. Elemental line scans were used to ascertain depth profiling also with point scans to identify each individual oxide layer.

\subsubsection{IN738LC after 1000h exposure}

The SEM microstructure for the 1000h oxidized IN738LC specimen shown in Figure 4-13 (i) was analysed by EDS elemental mapping and quant mapping. This revealed that the primary external surface oxide was $\mathrm{Cr}_{2} \mathrm{O}_{3}$ and $\mathrm{TiO}_{2}$ and the internal discontinuous oxide scale was $\mathrm{Al}_{2} \mathrm{O}$, as shown in Figures 4-15 and 4-16. The semi-quantitative analysis of oxide layers in Figure 4- 
16 shows that the external oxide layer consists of $40 \%-60 \%$ chromia and the discontinuous alumina layer adjacent to chromia measures $20 \%$ - $40 \%$. Also a protrusion developed in the oxide/scale interface that was mainly $\mathrm{Al}_{2} \mathrm{O}_{3}$ surrounded by small particles of $\mathrm{TiO}_{2}$. This alumina penetration is greater near the grain boundaries. It is also evident from the EDS mapping that titanium-rich phases were formed ahead of the alumina penetration near the grain boundaries. However, no oxygen was found to be associated with the titanium.

In the subsurface region oxidation-induced depletion MC carbide phase was also observed. The depleted MC carbide was rich in tantalum and titanium as seen in Figure 4-16. It can also be observed that a distinct thin approximately $0.5-1 \mu \mathrm{m}$ oxide scale is formed adjacent to discontinuous alumina layer, which is enriched in titanium, nickel, chromium suggesting that this could be a spinel of $\mathrm{Ni}(\mathrm{Cr}, \mathrm{Ti})_{2} \mathrm{O}_{4}$. In Figure 4-17, an EDS line scan measurement confirms the presence of a spinel composition.
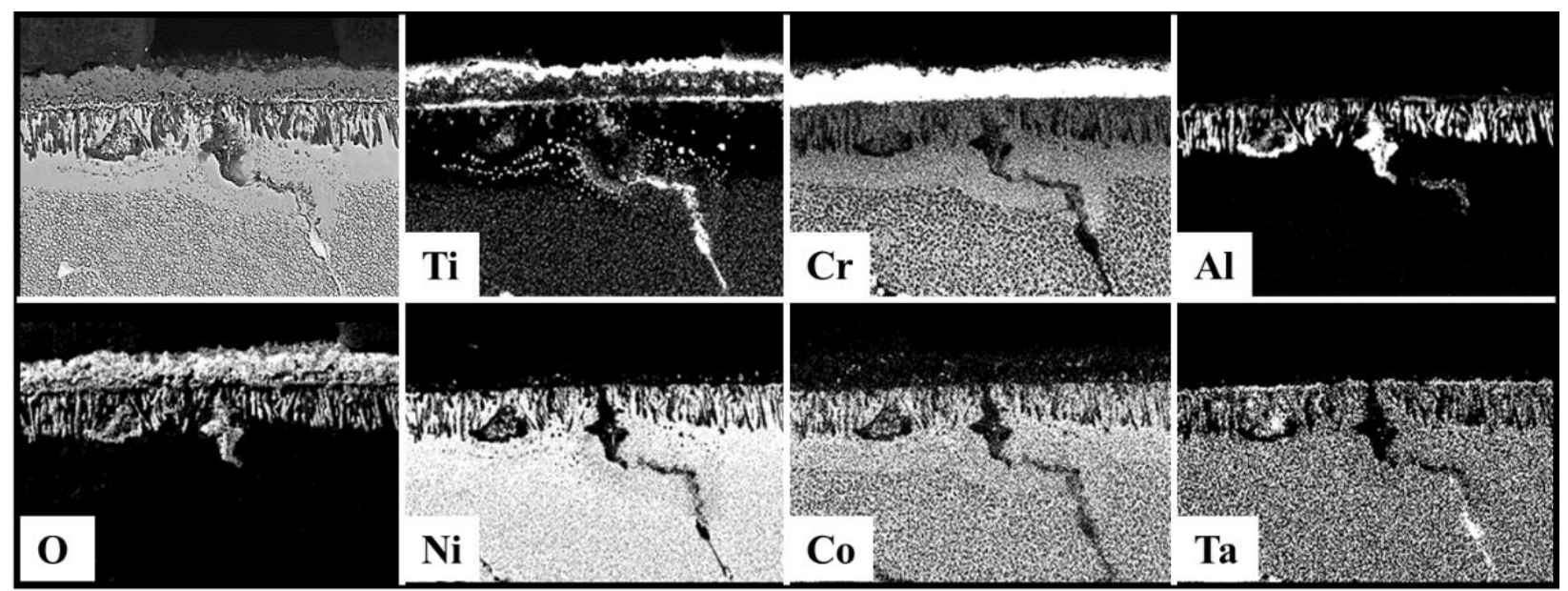

Figure 4- 15 BSE image and EDS maps of IN738LC after $1000 \mathrm{~h}$ at $900^{\circ} \mathrm{C}$ oxidation showing distribution of elements in the oxide scale. 


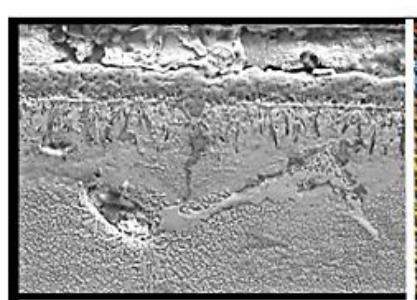

SEM- microstructure

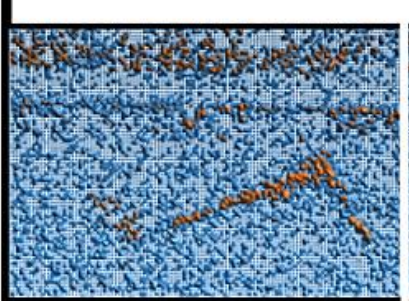

Tantalum

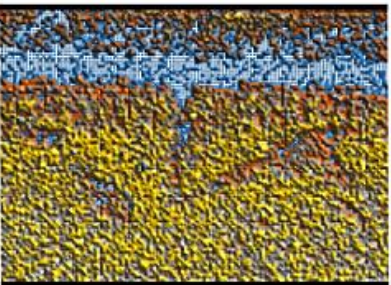

Nickel

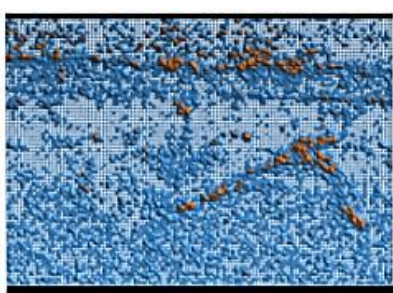

Titanium

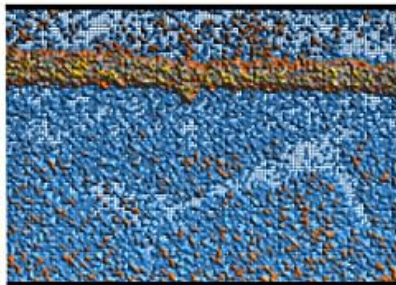

Chromium

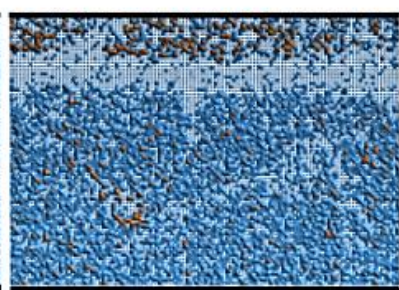

Cobalt

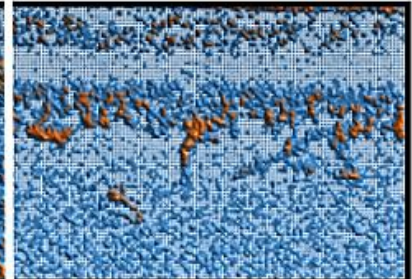

Aluminum

$0-20$

$20-40$

$40-60$

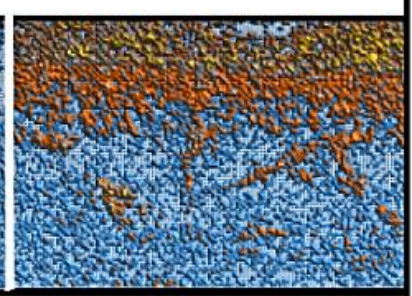

Oxygen

$60-80$

Figure 4- 16 BSE image and EDS quant mapping of IN738LC after $1000 \mathrm{~h}$ at $900^{\circ} \mathrm{C}$ oxidation showing distribution of elements in the oxide scale.

In Figure 4-17, the line scans start from the inner most point where the precipitate free zone is present and ends at the oxide/air interface. The results from the scans explain the presence of spinel and enrichment or depletion of oxide forming elements (i.e. $\mathrm{Cr}, \mathrm{Al}$ and $\mathrm{Ti}$ ) near the oxide/metal interface.

From Figure 4-17, the EDS signal intensity for titanium in the outermost surface matches well with that of oxygen, indicating that the top layer is composed of a titanium-rich oxide. Beneath this layer, a chromium-rich oxide layer was observed. As explained above, the thin layer underneath the chromium oxide layer was found to be a mixture of chromium, titanium, oxygen and oxygen confirming a spinel composition, $\mathrm{Ni}(\mathrm{Cr}, \mathrm{Ti})_{2} \mathrm{O}_{4}$. The EDS signal intensity of discontinuous finger-like structures were rich in alumina. From Figure 4-17, alloy depletion in 
$\mathrm{Al}$ in the subsurface region was also observed. The EDS point analysis of the Al-depleted region showed marginal reduction in aluminum concentration from $3.4 \mathrm{wt} . \%$ to $1.2 \mathrm{wt}$. $\%$ on average.
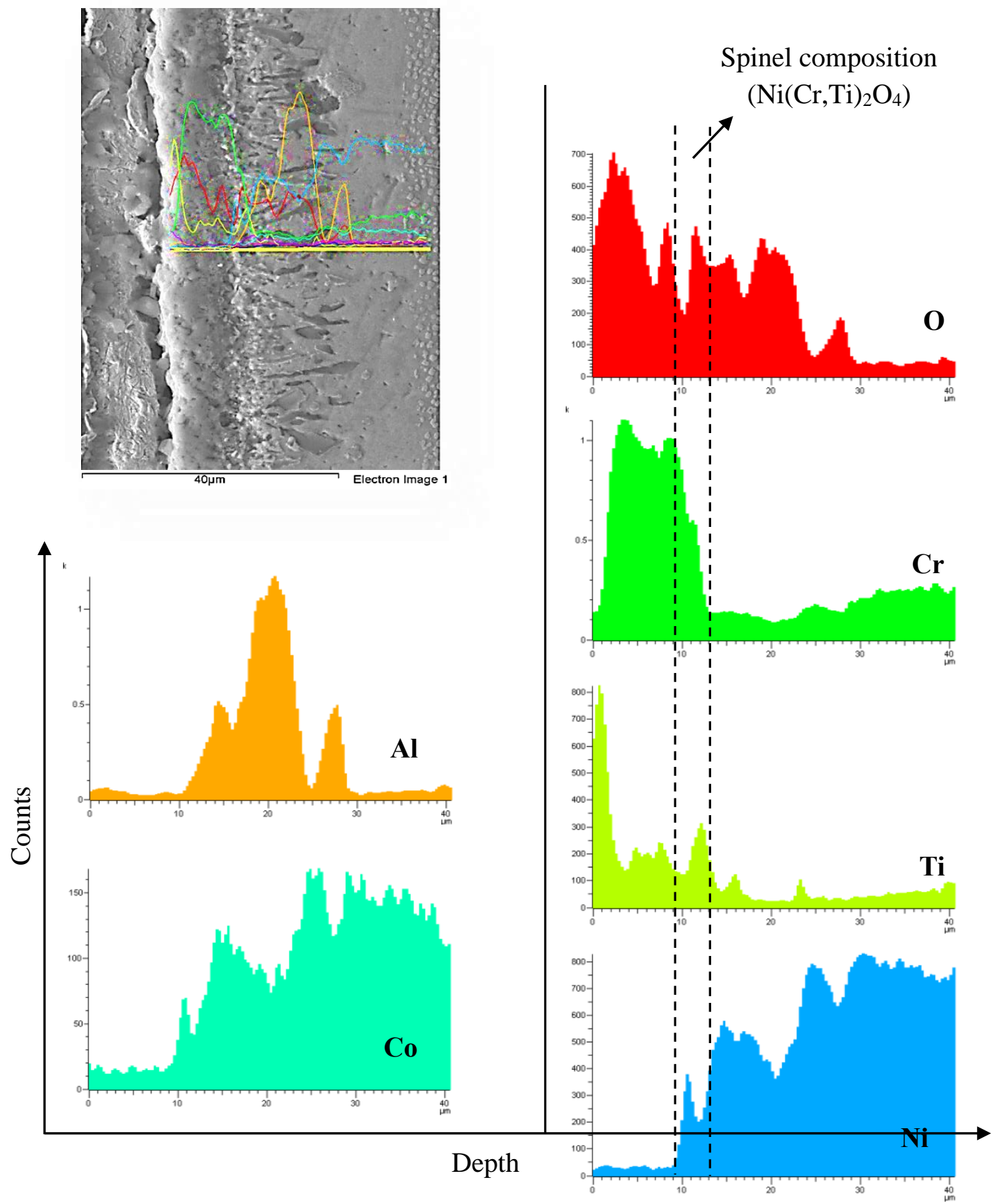

Figure 4- 17 An elemental EDS line scan across the oxide formed on IN738LC after 1000h at $900^{\circ} \mathrm{C}$ showing the site of interest and profiles for each element. 
The point scans of the IN738LC external oxide layer from seven hours to $1000 \mathrm{~h}$ are presented in

Figure 4-18 and Table 4-3. Throughout the oxidation duration, the outer layer consists of chromia with levels of approximately 49 wt. $\%$.
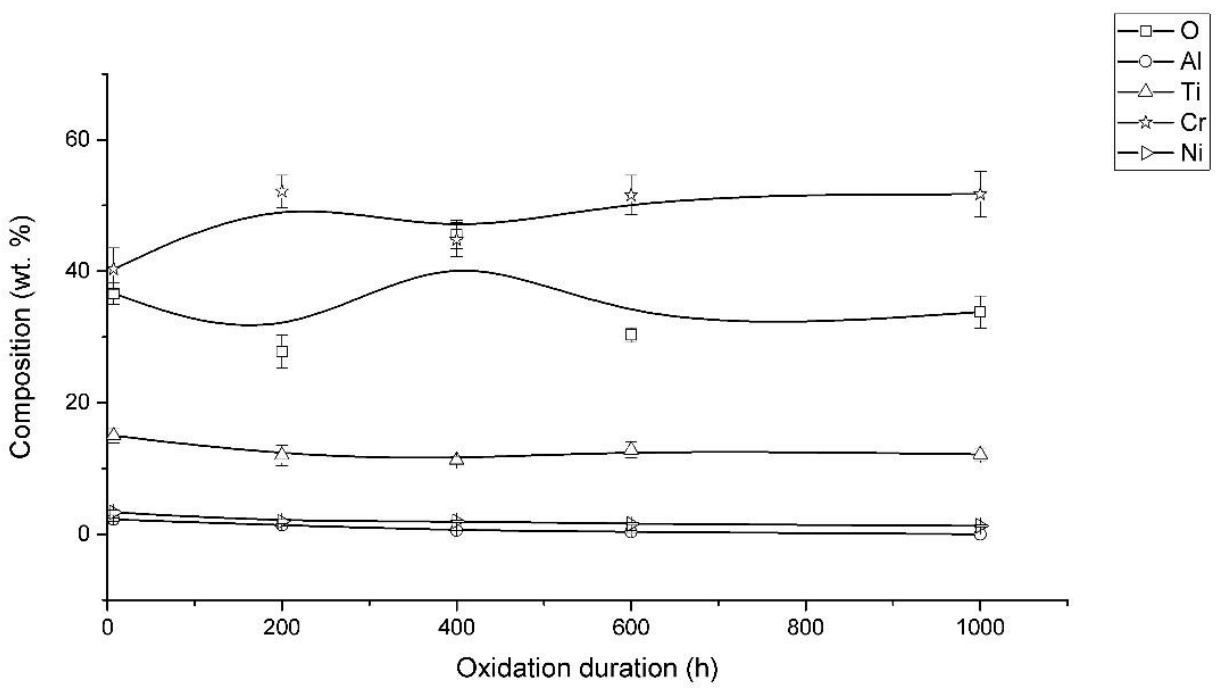

Figure 4- 18 EDS point scans of the external oxide layer on IN738LC as a function of oxidation duration from seven hours up to $1000 \mathrm{~h}$ at $900^{\circ} \mathrm{C}$.

Table 4- 3 The EDS point scan results for the external oxide scale on IN738LC with 95\% confidence level.

\begin{tabular}{|c|c|c|c|c|c|}
\hline \multirow{2}{*}{$\begin{array}{c}\text { Oxidation } \\
\text { duration }(\mathrm{h})\end{array}$} & \multicolumn{5}{|c|}{ Oxide layer composition (wt. \%) } \\
\cline { 2 - 6 } & $\mathrm{O}$ & $\mathrm{Al}$ & $\mathrm{Ti}$ & $\mathrm{Cr}$ & $\mathrm{Ni}$ \\
\hline 7 & $36.6 \pm 1.6$ & $2.3 \pm 0.3$ & $15 \pm 1.1$ & $40.3 \pm 3.2$ & $3.3 \pm 0.4$ \\
\hline 200 & $27.8 \pm 2.5$ & $1.4 \pm 0.1$ & $12.0 \pm 1.6$ & $52.2 \pm 2.4$ & $2.0 \pm 0.3$ \\
\hline 400 & $45.6 \pm 2.2$ & $0.6 \pm 0.1$ & $11.3 \pm 0.6$ & $44.8 \pm 2.6$ & $2.0 \pm 0.2$ \\
\hline 600 & $30.3 \pm 1.1$ & $0.4 \pm 0.2$ & $12.8 \pm 1.2$ & $51.6 \pm 3.0$ & $1.6 \pm 0.2$ \\
\hline 1000 & $33.8 \pm 2.4$ & $0 \pm 0$ & $12.2 \pm 1.0$ & $51.7 \pm 3.4$ & $1.3 \pm 0.2$ \\
\hline
\end{tabular}




\subsubsection{N5 after 1000h exposure}

The cross-section of a specimen of $\mathrm{N} 5$ held for $1000 \mathrm{~h}$ at $900^{\circ} \mathrm{C}$ in static air was investigated using SEM-EDS. The elemental distribution using X-ray quant mapping is illustrated in Figure 4-19 and Figure 4-20. The oxidized region on the alloy surface outwards to the atmosphere showed a monolayer of alumina. The EDS maps of the cross-section microstructure show that the continuous bright field on the surface is $\mathrm{Al}_{2} \mathrm{O}_{3}$ associated with $\mathrm{Cr}_{2} \mathrm{O}_{3}$ and $\mathrm{Ta}_{2} \mathrm{O}_{5}$. Rhenium and cobalt were present beneath the $\mathrm{Al}_{2} \mathrm{O}_{3}$ and $\mathrm{Cr}_{2} \mathrm{O}_{3}$ scale. No oxide was found in the cobalt and rhenium-rich region. In Figure 4-21, the elemental composition of the oxide scale is plotted from 15h to $1000 \mathrm{~h}$ and the composition data are summarized in Table 4-4.

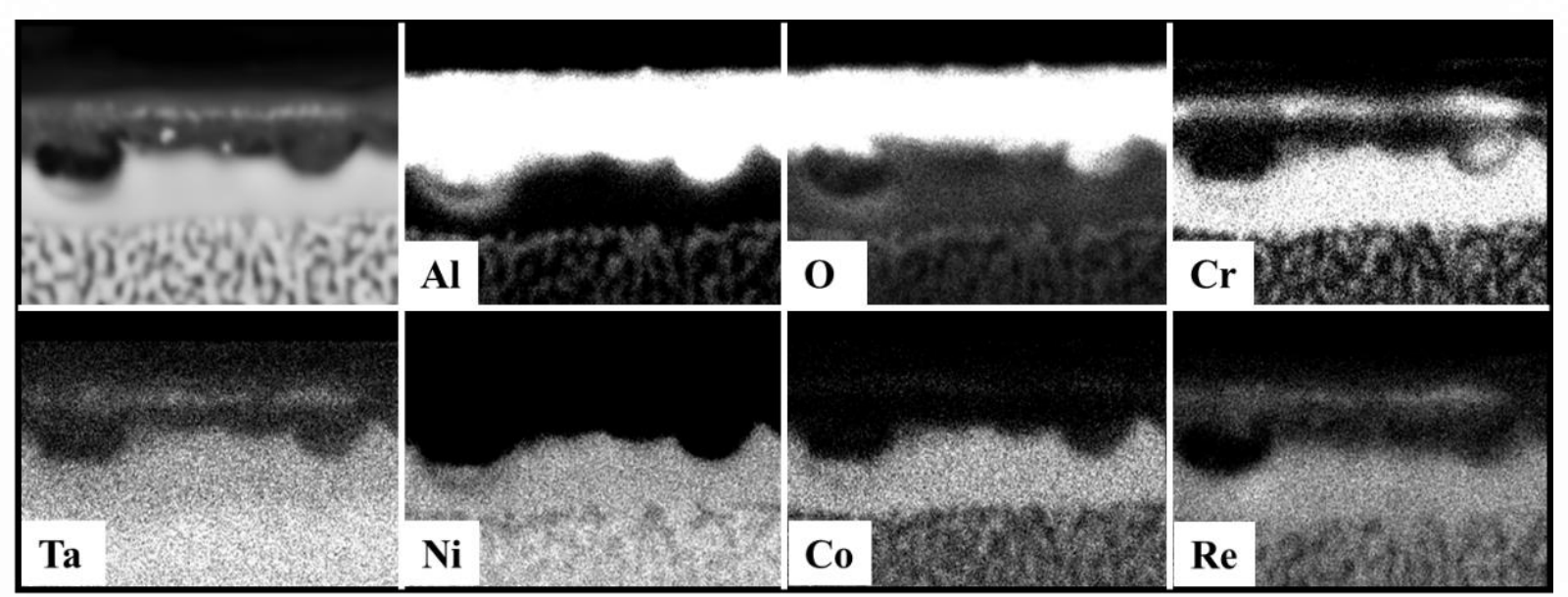

Figure 4- 19 BSE image and EDS maps of an N5 specimen oxidized up to $1000 \mathrm{~h}$ at $900^{\circ} \mathrm{C}$ showing a distribution of elements in the oxide scale. 


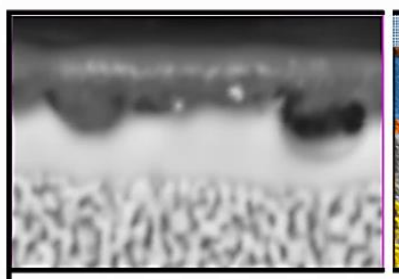

SEM- microstructure

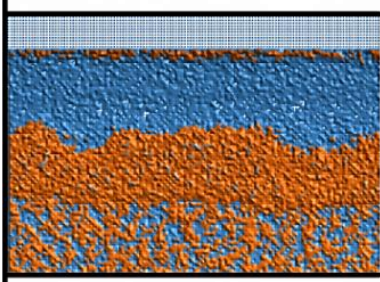

Cobalt

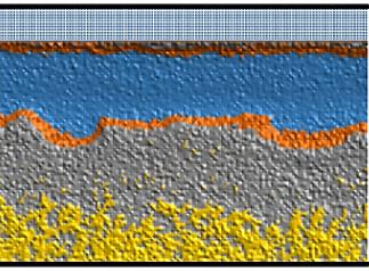

Nickel

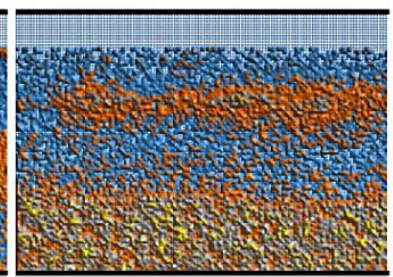

Tantalum

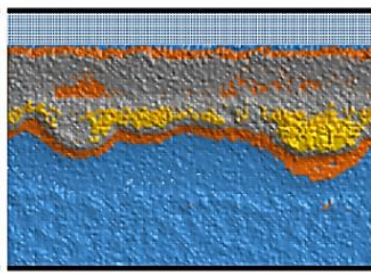

Aluminum

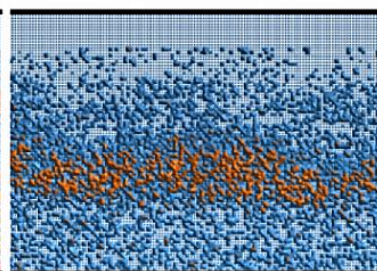

Rhenium

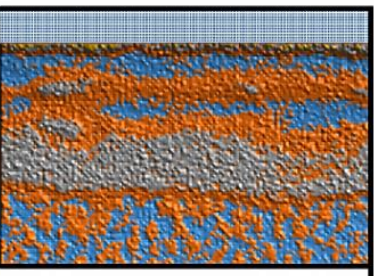

Chromium

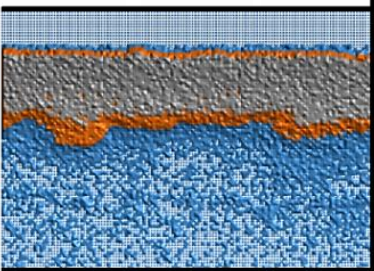

Oxygen

0 - 20

20 - 40

$40-60$

60 - 80

Figure 4- 20 BSE microstructure and EDS quant mapping of single crystal N5 oxidized specimen exposed at $900^{\circ} \mathrm{C}$ for $1000 \mathrm{~h}$ showing composition of elements.
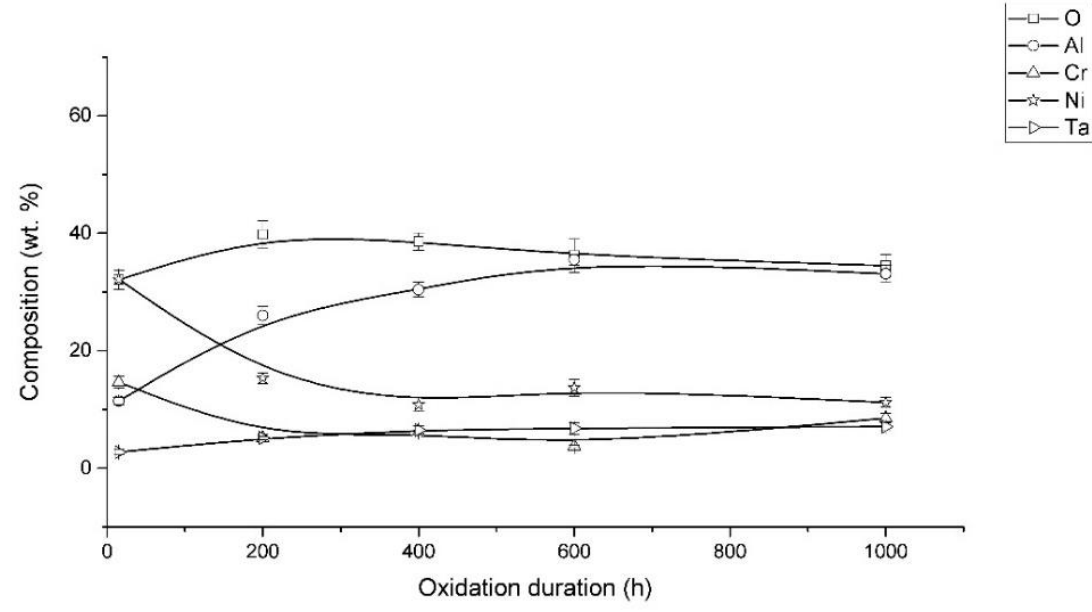

Figure 4- 21 The EDS point scans result of the oxide scale on N5 as a function of oxidation duration up to $1000 \mathrm{~h}$ at $900^{\circ} \mathrm{C}$. 
Table 4- 4 The EDS point scan results of the oxide scale on N5 with 95\% confidence level.

\begin{tabular}{|c|c|c|c|c|c|}
\hline \multirow{2}{*}{ Oxidation duration (h) } & \multicolumn{5}{|c|}{ Oxide layer composition (wt. \%) } \\
\cline { 2 - 6 } & $\mathrm{O}$ & $\mathrm{Al}$ & $\mathrm{Cr}$ & $\mathrm{Ni}$ & $\mathrm{Ta}$ \\
\hline 15 & $32.1 \pm 1.6$ & $11.4 \pm 0.6$ & $14.6 \pm 1.0$ & $32.2 \pm 1.8$ & $2.7 \pm 0.5$ \\
\hline 200 & $39.8 \pm 2.3$ & $25.9 \pm 1.6$ & $5.1 \pm 0.6$ & $15.3 \pm 0.9$ & $5.2 \pm 0.3$ \\
\hline 400 & $38.6 \pm 1.5$ & $30.3 \pm 1.3$ & $6.1 \pm 0.4$ & $10.8 \pm 1.2$ & $6.5 \pm 0.7$ \\
\hline 600 & $36.2 \pm 2.8$ & $35.4 \pm 1.0$ & $3.7 \pm 0.3$ & $13.7 \pm 1.4$ & $6.8 \pm 1.0$ \\
\hline 1000 & $34.4 \pm 1.9$ & $33.1 \pm 1.5$ & $8.5 \pm 0.9$ & $11.2 \pm 0.8$ & $7.1 \pm 0.7$ \\
\hline
\end{tabular}

The SEM microstructure of N5 oxidized for 32h shown in Figure 4-22a shows a thin alumina scale, below the oxide scale. There appear to be voids at the interface with further increase in the oxidation duration up to 1000 h, larger voids exist as shown in Figure 4-22b. The EDS point scans around the void region suggested the presence of a tantalum-rich thin oxide layer as showed in Figure 4-23 containing approximately 13 wt. \% of tantalum. The EDS spectra of point scans are showed in Figure 4-24.

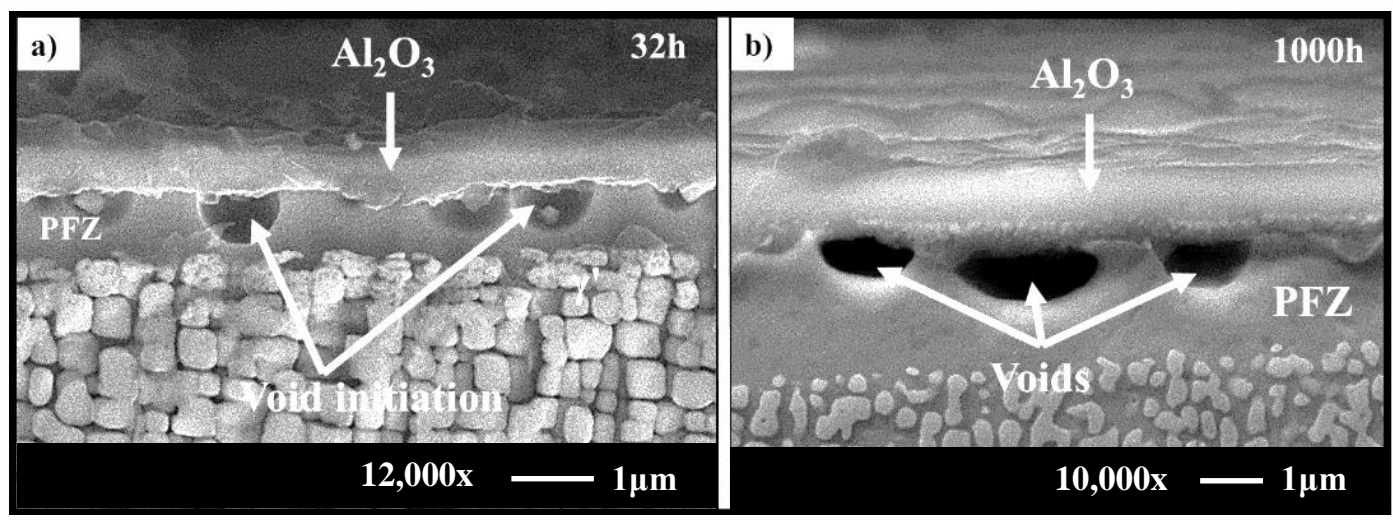

Figure 4- 22 SEM-microstructures showing voids at the scale/alloy interface in single crystal N5 exposed at $900^{\circ} \mathrm{C}$ a) Void initiation after $32 \mathrm{~h}$ and b) Larger voids after $1000 \mathrm{~h}$. 


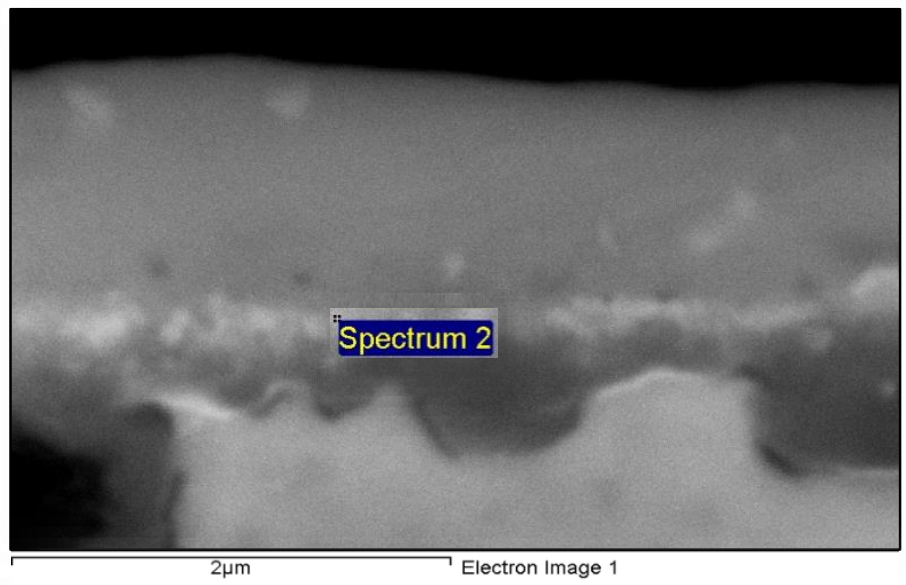

Figure 4- 23 The site of interest for the EDS point scan completed on the N5 oxide scale around the void region after $1000 \mathrm{~h}$ at $900^{\circ} \mathrm{C}$.

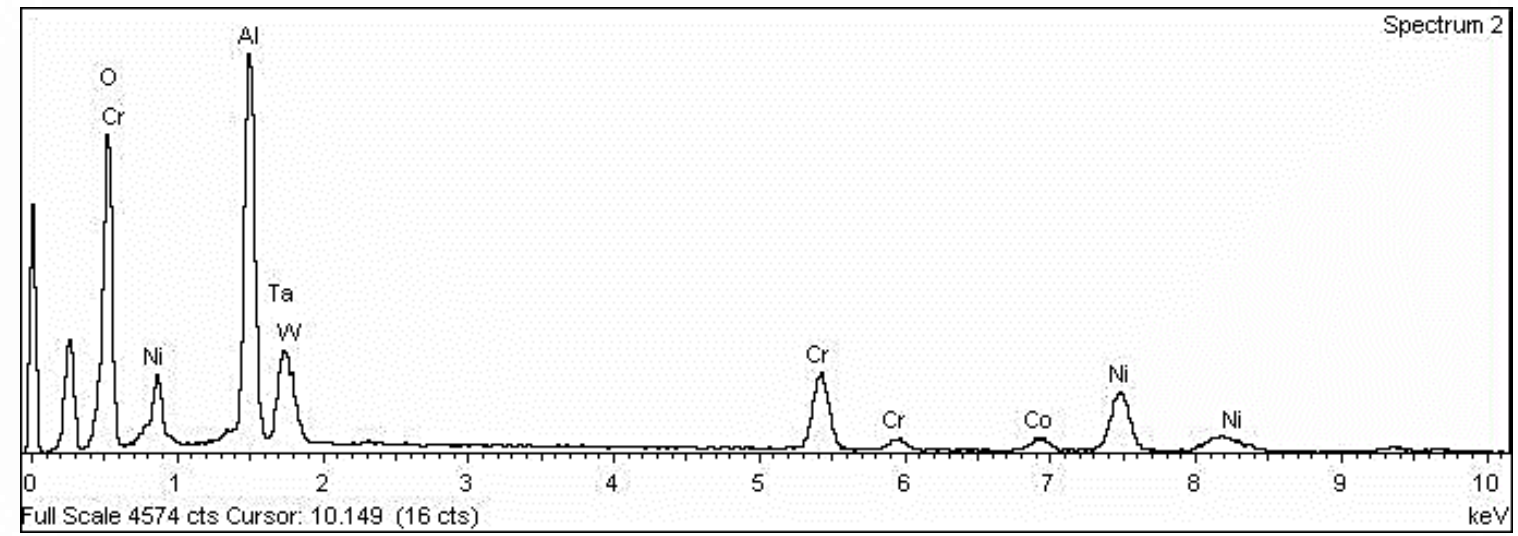

Figure 4- 24 The EDS point scan spectrum of a thin layer of the oxide scale of N5 after 1000h at $900^{\circ} \mathrm{C}$. 


\subsubsection{PM-TAS after 1000h exposure}

A SEM cross-sectional micrograph of PM-TAS alloy after $1000 \mathrm{~h}$ oxidation at $900^{\circ} \mathrm{C}$ was shown in Figure 4-13 (iii). Similar to the single crystal N5 superalloy, a thin oxide scale was shown over the top of the precipitate free zone in PM-TAS, but without voids at the metal/scale interface. In order to map the elements on the cross-sectional surface of the oxidized specimen, EDS elemental mapping was taken and presented in Figure 4-25. According to elemental mapping the outer region showing the bright region is aluminum associated with the oxygen, $\mathrm{Al}_{2} \mathrm{O}_{3}$. From Figure 4-26, EDS quant mapping shows that the oxide scale consists of 20 wt. \% 40 wt. $\%$ aluminum oxide after $1000 \mathrm{~h}$ exposure at $900^{\circ} \mathrm{C}$. There has also been aluminum depletion from 6 wt. $\%$ to 0.3 wt. $\%$ in the subsurface zone due to oxidation after $1000 \mathrm{~h}$ exposure. The EDS mapping also shows the presence of chromia adjacent to the alumina scale.

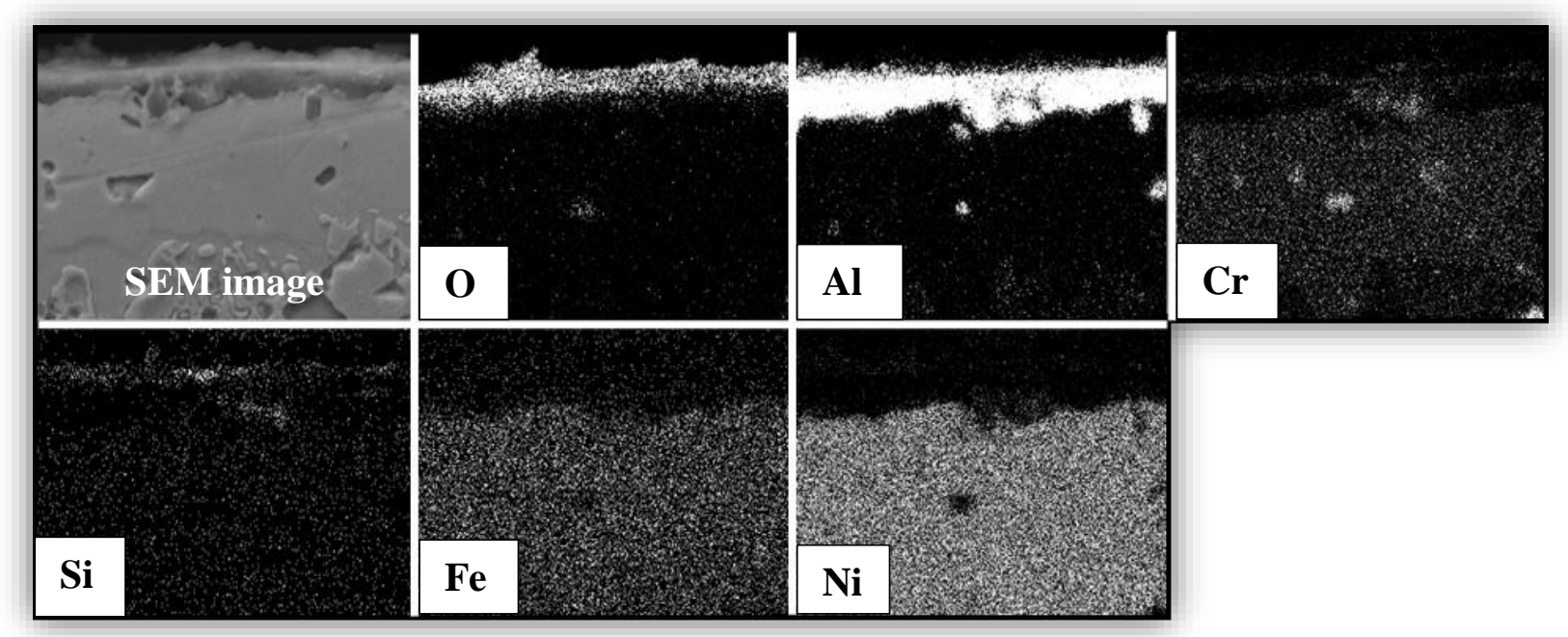

Figure 4- 25 SEM microstructure (site of interest) and EDS maps of a PM-TAS specimen oxidized at $900^{\circ} \mathrm{C}$ up to $1000 \mathrm{~h}$ showing a distribution of elements in the oxide scale. 


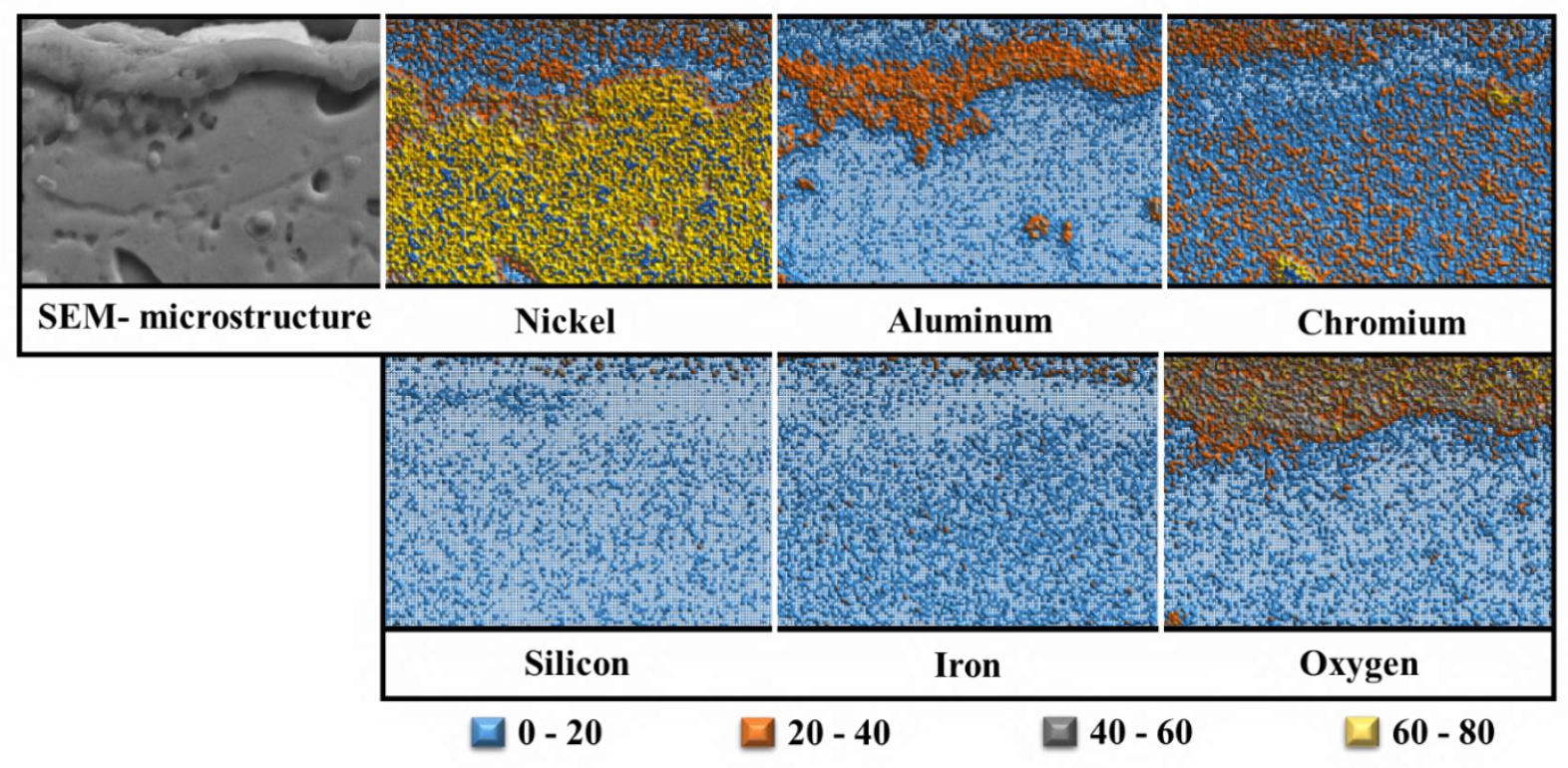

Figure 4- 26 SEM microstructure (site of interest) and EDS quant mapping of a PM-TAS specimen oxidized at $900^{\circ} \mathrm{C}$ up to $1000 \mathrm{~h}$ showing composition of elements.

The oxides were also analyzed using EDS line scans to evaluate the presence of silicon at the metal/scale interface. From Figure 4-27, the PM-TAS alloy showed aluminum-rich oxide scale as $\mathrm{Al}_{2} \mathrm{O}_{3}$. The scale adjacent to the alumina scale was found to be rich in chromium, silicon and oxygen, which confirms the spinel composition in the form of $\mathrm{Ni}(\mathrm{Cr}, \mathrm{Si})_{2} \mathrm{O}_{4}$, see Figure 4-27. 

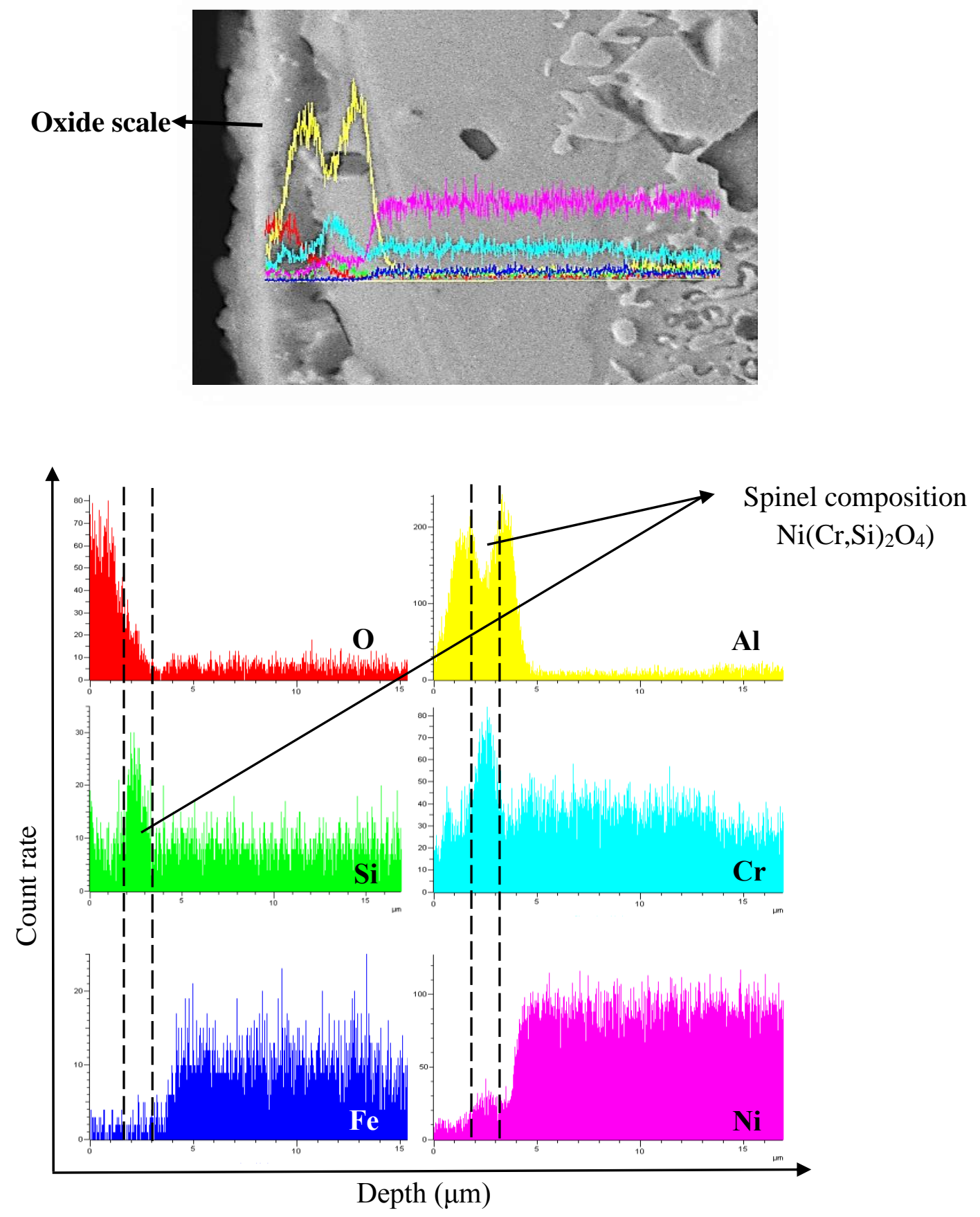

Figure 4- 27 An elemental EDS line scan across the oxide scale on PM-TAS after 1000h exposure at $900^{\circ} \mathrm{C}$ showing the site of interest and profiles for each element. 
The EDS point scans on the adherent oxide scale after $1000 \mathrm{~h}$ exposure at $900^{\circ} \mathrm{C}$ suggests an Alrich oxide with levels of approximately 44 wt. \% Al being detected. $\mathrm{Cr}$ and $\mathrm{Si}$ would suggest mixed oxides or a spinel. The oxide scale composition analysis of PM-TAS specimens from $15 \mathrm{~h}$ to $1000 \mathrm{~h}$ is shown in Figure 4-28 and the data have been summarized in Table 4-5.

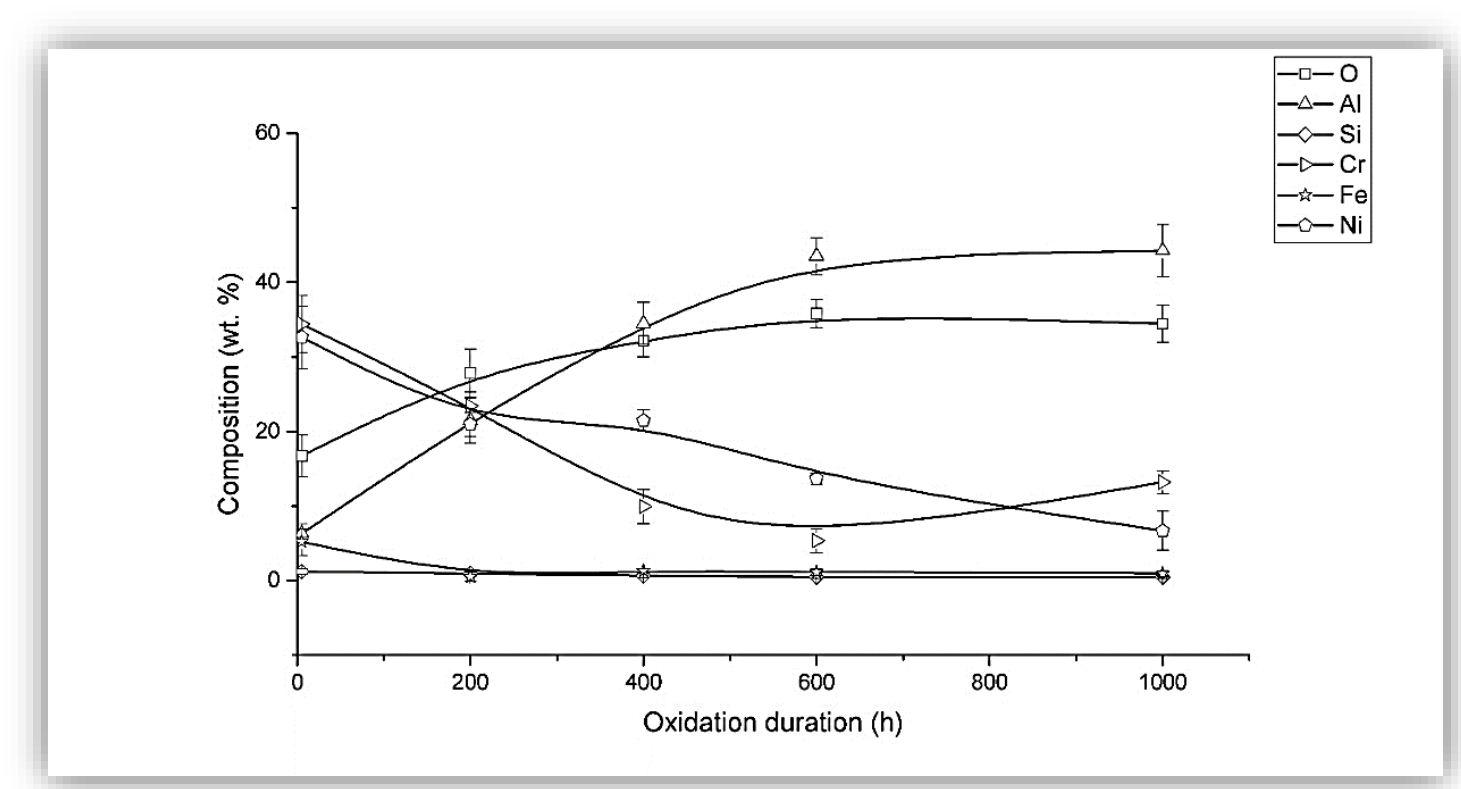

Figure 4- 28 The EDS point scans of oxide scale on PM-TAS against oxidation duration up to $1000 \mathrm{~h}$ at $900^{\circ} \mathrm{C}$.

Table 4- 5 The EDS point scans result of oxide scale on powder metallurgy TAS with 95\% confidence level.

\begin{tabular}{|c|c|c|c|c|c|c|}
\hline \multirow{2}{*}{ Oxidation duration (h) } & \multicolumn{7}{|c|}{ Oxide layer composition (wt. \%) } \\
\cline { 2 - 7 } & $\mathrm{O}$ & $\mathrm{Al}$ & $\mathrm{Si}$ & $\mathrm{Cr}$ & $\mathrm{Fe}$ & $\mathrm{Ni}$ \\
\hline 15 & $16.7 \pm 2.8$ & $6.2 \pm 1.3$ & $1.2 \pm 0.4$ & $34.4 \pm 3.8$ & $5.2 \pm 1.8$ & $32.6 \pm 4.2$ \\
\hline 200 & $47.8 \pm 3.2$ & $21.4 \pm 3.0$ & $0.9 \pm 0.4$ & $23.4 \pm 1.9$ & $0.5 \pm 0.6$ & $4.9 \pm 1.6$ \\
\hline 400 & $32.1 \pm 2.1$ & $34.4 \pm 2.8$ & $0.7 \pm 0.3$ & $9.9 \pm 2.3$ & $1.3 \pm 0.3$ & $21.5 \pm 1.5$ \\
\hline 600 & $35.8 \pm 1.9$ & $43.5 \pm 2.5$ & $0.5 \pm 0.2$ & $5.3 \pm 1.7$ & $1.1 \pm 0.5$ & $13.7 \pm 0.8$ \\
\hline 1000 & $24.4 \pm 2.5$ & $44.2 \pm 3.5$ & $0.5 \pm 0.2$ & $13.2 \pm 1.5$ & $0.9 \pm 0.4$ & $16.7 \pm 2.6$ \\
\hline
\end{tabular}


During oxidation of the powder metallurgy TAS alloy, beneath the precipitate free zone, a plate like structure was found which is shown in Figure 4-29. The EDS point scan of this structure revealed approximately 35 wt. \% of chromium content and which is also confirmed by EDS line scan. According to the EDS line scan, the chromium content in the plate-like structure was much higher compared to that of matrix and also surrounded by small amount of oxygen (5 wt. \%).

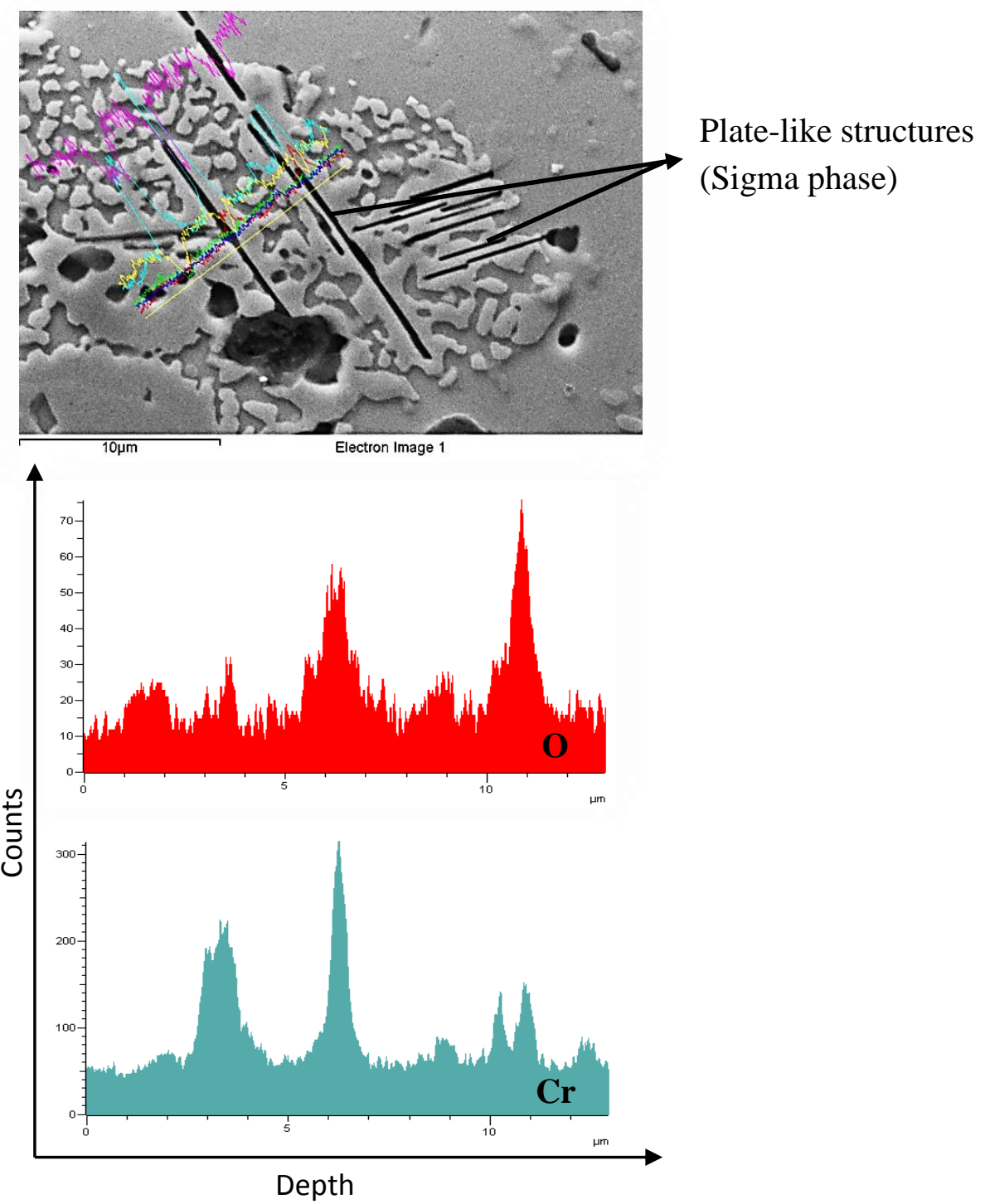

Figure 4- 29 An elemental EDS line scan across the plate-like structure in PM-TAS after 1000h at $900^{\circ} \mathrm{C}$ showing the site of interest and profiles for each element. 


\subsection{Summary of results}

The total mass gain after $1000 \mathrm{~h}$ oxidation at $900^{\circ} \mathrm{C}$ in ambient air for the three nickel-based superalloys was shown in Figures 4-1, 4-2 and 4-3. For IN738LC, the total mass gain after oxidation is approximately 4 times more than the N5 and PM-TAS. The superalloys N5 and PMTAS seem to have a very similar behaviour although they have a different chemical composition and microstructure, which is single crystalline for N5 alloy and powder metallurgy for the TAS alloy. One similarity between N5 and PM-TAS is both alloys have the same amount of aluminum content and the absence of titanium; the presence of alumina layer was deemed to be responsible for corrosion protection at $900^{\circ} \mathrm{C}$. The oxides formed on polycrystalline IN738LC had a thick multilayer oxide scale, where N5 and PM-TAS showed thin monolayer oxide scale.

These results are discussed in the following section with a view to providing reasons for the findings as well as a suggestion for why each alloy is superior over another on a relative basis under these conditions. 


\section{DISCUSSION}

In this section the isothermal oxidation test results will be discussed. All three superalloys were characterized and the results presented in the previous section. In this section, a detailed discussion of various similarities and differences in oxidation mechanisms are presented in order to explain the relative oxidation performance of all three nickel-based superalloys studied.

\subsection{Microstructure, chemical composition and hardness}

The chemical composition of all three nickel-based superalloys; IN738LC, N5 and PM-TAS has been presented in section-3 (Table 3-1). The age hardened IN738LC, N5 and powder metallurgy TAS alloys all have $\mathrm{L}_{2}$ type structured $\gamma^{\prime}$ precipitates. Prior to oxidation the volume fraction of the $\gamma^{\prime}$ precipitates was determined to be $60-70 \%$ for all three superalloys and the average precipitate sizes are $261 \pm 57 \mathrm{~nm}$ for IN738LC, $565 \pm 65 \mathrm{~nm}$ for N5 and $195 \pm 37 \mathrm{~nm}$ for PM-TAS. These volume fraction and precipitate size results remained unchanged during oxidation up to $1000 \mathrm{~h}$.

Therefore, any changes in the oxidation behaviour noted in the results and to be discussed in this section must be a function of either or both of precipitate size and/or specimen composition rather than either volume fraction of $\gamma^{\prime}$ precipitates or alloy processing method.

The optical microscopy results showed that even after $1000 \mathrm{~h}$ the resolution available only permitted identification of the oxide layer on IN738, necessitating use of SEM, AFM and Auger to complete the microstructural evaluation. As well, the hardness data after $1000 \mathrm{~h}$ oxidation at $900^{\circ} \mathrm{C}$ confirmed a similar level of intermetallic precipitates as found prior to oxidation. 


\subsection{Oxidation kinetics}

Although the present study consists of polycrystalline IN738LC and powder metallurgy TAS and single crystal, N5, grain boundary oxidation was not noted in the IN738LC and PM-TAS alloys; thus the oxidation kinetics reported were not dependent upon the microstructure (polycrystalline vs single crystal).

Figure 5-1 compares the plots of specific weight gain as a function of oxidation duration for all three superalloys after isothermal oxidation in air at $900^{\circ} \mathrm{C}$ up to $1000 \mathrm{~h}$. The curves show that the parabolic weight gain law, $\Delta \mathrm{W}=\mathrm{k}_{\mathrm{p}} \cdot \mathrm{t}^{2}+\mathrm{C}$ [15] [117] [118], was obeyed throughout the exposure duration. This shows that the oxidation kinetics are controlled by the diffusion of the reactive species (anions and/or cations) through the external scale and/or subjected alloy [49] [117], because diffusion-controlled high-temperature oxidation processes are governed by the parabolic rate law [15] [53].

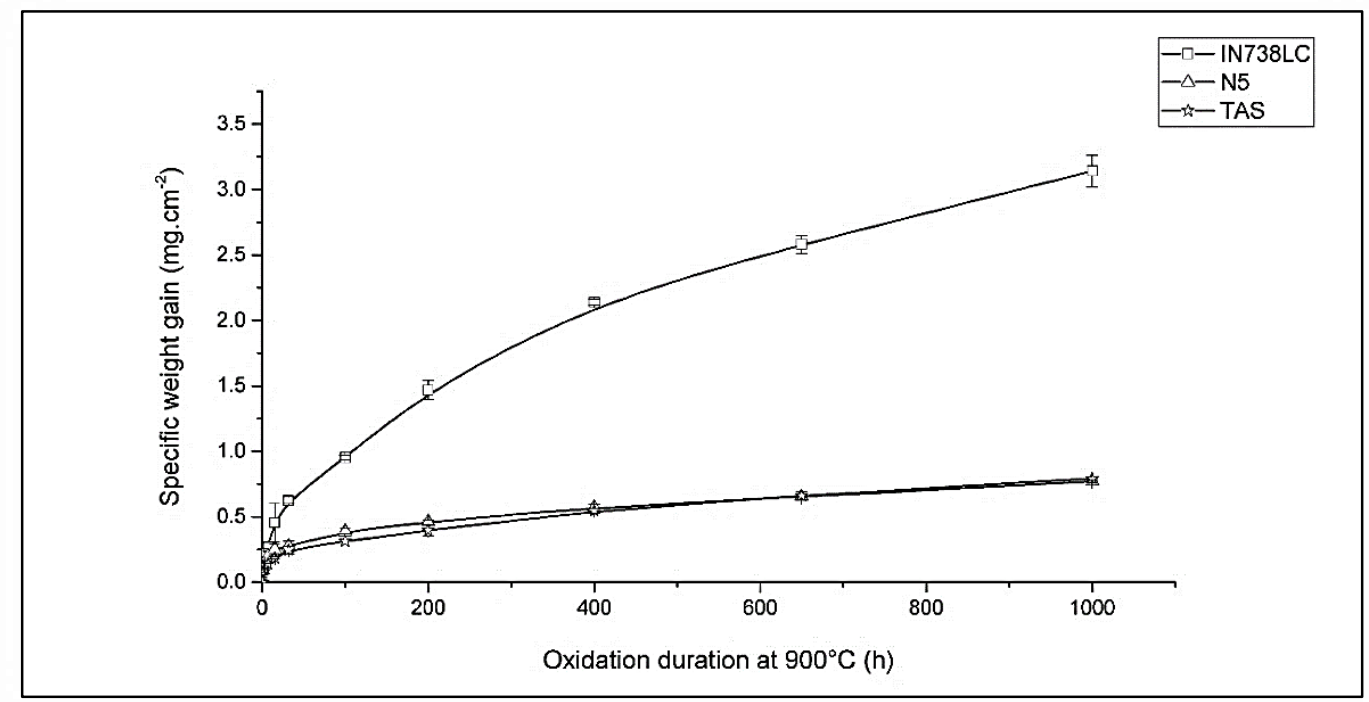

Figure 5- 1 Specific weight change with exposure duration for IN738LC, N5 and TAS specimens after isothermal oxidation in air at $900^{\circ} \mathrm{C}$ up to $1000 \mathrm{~h}$. 
A similar kind of parabolic behavior was shown by Rene 80 nickel based superalloy when oxidized in air, for up to $1000 \mathrm{~h}$ at $900^{\circ} \mathrm{C}$ by Cade et al [119].

The isothermal oxidation behaviour of a powder metallurgy quaternary nickel-based alloy with 0.5 wt. $\% \mathrm{Si}$ and 0.1 wt. $\% \mathrm{Y}, \mathrm{Ni}-12 \mathrm{Cr}-9 \mathrm{Fe}-6 \mathrm{Al}$ (wt. \%), was examined at $900^{\circ} \mathrm{C}$ in air up to 1000h by Murray et al. [112], and also showed that the scale growth kinetics of Ni-12Cr-9Fe-6Al (wt. \%), Ni-12Cr-9Fe-6Al-0.5Si (wt. \%), Ni-12Cr-9Fe-6Al-0.1Y (wt. \%) and Ni-12Cr-9Fe-6Al$0.5 \mathrm{Si}-0.1 \mathrm{Y}$ (wt. \%) alloys were in accordance with the parabolic rate law after $50 \mathrm{~h}$ exposure. A single crystal nickel-based superalloy, which contained 6.3 wt. \% Al, 6 wt. \% Cr and some Co, $\mathrm{Ti}, \mathrm{Mo}, \mathrm{W}$ and Ta, also showed similar parabolic growth kinetics when oxidized in air at $900^{\circ} \mathrm{C}$ [120].

From the analysis of the weight change as a function of oxidation duration experienced by N5 and PM-TAS alloys an initial transient oxidation stage was noted followed by a steady state oxidation stage. On the other hand, IN738LC alloys showed steady oxidation from the beginning of the oxidation. The transient oxidation stage has been shown in other studies to represent the concurrent oxidation of all major alloying elements present on the alloy surface, even though one oxide is usually greatly favoured from a thermodynamic standpoint [113]. This proceeds until the initial rapid kinetics have transitioned to a lower rate and the partial pressure of oxygen at the scale/alloy interface has been lowered, both of which favour the formation of a protective layer of the most stable oxide. The stable oxide layers, $\mathrm{Cr}_{2} \mathrm{O}_{3}, \mathrm{Al}_{2} \mathrm{O}_{3}$ or both, offer oxidation resistance during high temperature. This observation is consistent with the results of the current study. However the transient oxidation period decreased with increased exposure period. 
The transient oxidation behaviour is complex and is affected by many variables such as alloy composition and structure, surface preparation, exposure duration and temperature of oxidation [65] [121] [122] [123]. Indeed, the establishment of steady state scaling kinetics in many systems requires time and a considerable scale thickness. From Figures 4-2b and 4-3b, the N5 specimen showed a high transient-stage growth rate in a short transient duration, while the PM-TAS specimen had a low transient-stage growth rate in a long transient duration. SEM-EDS results revealed the presence of $\mathrm{Cr}_{2} \mathrm{O}_{3}$ external scale on IN738LC superalloy which had no transient oxidation stage. On the other hand, both the N5 and PM-TAS specimens had Al, Cr and Ta scales during the transient oxidation stage. Above this oxidation time (i.e., $15 \mathrm{~h}$ for N5 and $32 \mathrm{~h}$ for PM-TAS) the reaction kinetics became better fitted into the parabolic curves, after leaving the transient stage. This process is described by Hindam and Whittle [124], and is associated with the formation of protective a continuous oxide scales through diffusion of reacting species across the oxide scale.

The parabolic rate constant $\mathrm{k}_{\mathrm{p}}$ values obtained were compared with those obtained for other nickel-based alloys at same temperature, see Table 5.1 [84] [112] [119] [125] [126]. This table shows that N5 and PM-TAS in the present study have lower rate constants at $900^{\circ} \mathrm{C}$ relative to IN738LC. As well, IN738LC has a higher parabolic rate than some of the other commerciallyavailable nickel-based superalloys, as seen in Table 5-1. Therefore, these findings imply that IN738LC should have formed a thicker oxide film than the other alloys under the condition investigated. 


\begin{tabular}{|c|c|c|}
\hline \multirow{2}{*}{ Alloys } & \multirow{2}{*}{ Temperature $\left({ }^{\circ} \mathrm{C}\right)$} & Steady-s tate stage \\
\hline & & $\mathrm{kp},\left(\mathrm{mg}^{2} \cdot \mathrm{cm}^{-4} \cdot \mathrm{s}^{-1}\right)$ \\
\hline IN738LC & \multirow{9}{*}{900} & 2.79E-06 \\
\hline N5 & & $1.42 \mathrm{E}-07$ \\
\hline TAS & & $1.64 \mathrm{E}-07$ \\
\hline RR1000 & & $3.13 \mathrm{E}-06$ \\
\hline Rene 80 & & $2.26 \mathrm{E}-06$ \\
\hline Niomonic 75 & & $1.60 \mathrm{E}-05$ \\
\hline IN718 & & $1.47 \mathrm{E}-05$ \\
\hline Incoloy $800 \mathrm{H}$ & & 2.37E-05 \\
\hline IN740 & & 3.38E-04 \\
\hline
\end{tabular}

Table 5- 1 Parabolic rate constants, kp values for various nickel-based superalloys including alloys used for the present study [84] [112] [125] [126].

\subsubsection{Effect of scale thickness}

The oxidation kinetics of the specimens were further examined by the scale thickness measurements. The combined plots of scale thickness against the oxidation time for all three alloys were presented in Figure 4-14. They showed that the oxide scale thicknesses increased according to a parabolic function of time. This is similar to observations made on other nickelbased superalloys [84] [112] [125] [126]. However, the oxide scale thickness plots did not explain the mechanism of a more rapid oxidation kinetics during the transient stage that lasted up to $15 \mathrm{~h}$ for $\mathrm{N} 5$ and $32 \mathrm{~h}$ for PM-TAS. This oxide scale growth was parabolic as a result of formation of thicker oxide scale, where the reaction was dependent on the rate of diffusion of alloying elements [15]. Thus, the scale growth rate became diffusion controlled through the selective oxidation of $\mathrm{Al}$ and/or $\mathrm{Cr}$ to form only continuous and protective external $\mathrm{Cr}_{2} \mathrm{O}_{3}$ and $\mathrm{Al}_{2} \mathrm{O}_{3}$ scale as shown in Figures 4-11, 4-12 and 4.13. 
During the formation of only an $\mathrm{Al}_{2} \mathrm{O}_{3}$ scale, the oxidation rate became reduced, thereby leading to slower scale growth rate [15] [124] [127]. From Figure 5-1, alumina scale growth rate is much slower compared to that of chromia. This observation showed that the alumina scales are preferentially protective, and is consistent with the observation that the oxidation kinetics were diffusion controlled [128]. As the oxide scale thickness increased with increased oxidation duration, potential diffusion paths for inward diffusing oxygen anions and outward diffusing metal cations decreased, thus resulting in slower scaling kinetics.

The scaling kinetics of both single crystal N5 and powder metallurgy TAS specimens were very close from beginning to the end of the oxidation duration at $900^{\circ} \mathrm{C}$ as shown in Figure 4-14. In contrast, the polycrystalline IN738LC specimen displayed faster growth kinetics than the N5 and PM-TAS and the IN738LC curve deviated away from the other two at $900^{\circ} \mathrm{C}$.

\subsection{Scale formation on IN738LC, N5 and PM-PAS}

IN738LC exhibited very large differences in the oxidation behavior in air compared to that of N5 and PM-TAS. According to earlier studies of $\mathrm{NiCrAl}$ alloys with different contents of $\mathrm{Al}$ and $\mathrm{Cr}$, three types of oxidation behavior can be expected, which was shown in Figure 2-13 [65] [69]; (I) external $\mathrm{NiO}$ scale + internal $\mathrm{Al}_{2} \mathrm{O}_{3} / \mathrm{Cr}_{2} \mathrm{O}_{3}$ precipitates in the subsurface region, (II) external $\mathrm{Cr}_{2} \mathrm{O}_{3}$ scale + internal $\mathrm{Al}_{2} \mathrm{O}_{3}$ precipitates and (III) external $\mathrm{Al}_{2} \mathrm{O}_{3}$ scale.

The chemical compositions of the studied alloys were shown in Table 3.1, and it can be observed that IN738LC has a higher Cr and lower Al content than N5 and PM-TAS. Plotting the Cr and Al contents of the studied alloys in the oxidation map in Figure 5-2 reveals that based on their $\mathrm{Cr}$ and $\mathrm{Al}$ contents all three superalloys would be expected to form an external $\mathrm{Al}_{2} \mathrm{O}_{3}$ scale after isothermal oxidation. 
This contradicts the findings in Figures 4-10, 4-11, 4-12 and 4-13, which show that IN738LC forms a dense chromia scale and internal discontinuous alumina scale. The probable reason for this deviation may be that the oxidation map build for the ternary $\mathrm{NiCrAl}$ alloy was at $1000^{\circ} \mathrm{C}$ and the present study was done at $900^{\circ} \mathrm{C}$.

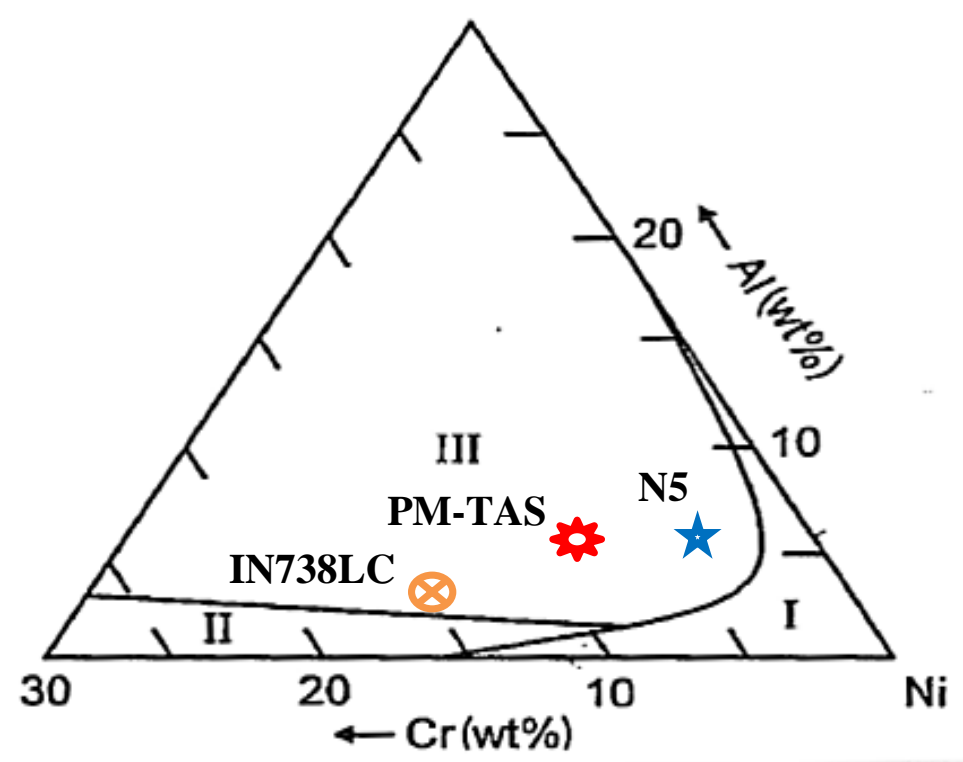

Figure 5- 2 Oxidation map for ternary $\mathrm{NiCrAl}$ alloys during isothermal oxidation in air at $1000^{\circ} \mathrm{C}$ [65] [69] (Reproduced with permission from University of Cambridge). Compositions of

IN738LC, N5 and PM-TAS are inserted in the oxidation map, taking only their $\mathrm{Cr}$ and $\mathrm{Al}$ contents into account.

\subsection{Scale morphologies}

The SEM microstructures of early stage of the oxidation (from one hour to three hours for IN738LC and up to seven hours in the case of N5 and PM-TAS) showed no distinct oxide layer on the surface of all three superalloys as seen in Figures 4-4 and 4-5, probably because the oxide layer thickness is less than the SEM resolution. The presence of the oxide layer was analysed by AFM followed by AES (Auger electron spectroscopy). The AFM results were not promising, because the instrument was not able to distinguish between the oxide layer and the matrix. 
The chemical composition result from the Auger depth analysis was not reliable due to two reasons. First, the bombardment of the surface by the ion beam causes atoms of the solid to be sputtered and also causes mixing of atoms beneath the surface, thus resulting in compositional change. Second, the bombardment of surface may cause some solids to decompose resulting in preferential sputtering of specific elements from the surface.

Examination of the surface morphologies of the oxides formed on IN738LC, N5 and PM-TAS in the later stages by SEM revealed that the scales were composed of a thick external and discontinuous subscale oxide layer for IN738LC and a thin monolayer in the case of N5 and PMTAS at $900^{\circ} \mathrm{C}$. The chromia-forming alloy IN738LC showed internal discontinuous oxide layer because $\mathrm{Ti}$ and $\mathrm{Al}$ are thermodynamically more stable than $\mathrm{Cr}$, thus $\mathrm{TiO}_{2}$ and/or $\mathrm{Al}_{2} \mathrm{O}_{3}$ could develop below the external chromia scale. The partial pressure of oxygen decreases from the scale/alloy interface into the alloy matrix, thus internal oxidation generally occurs according to their relative thermodynamic stability, from $\mathrm{TiO}_{2}$ and then $\mathrm{Al}_{2} \mathrm{O}_{3}$ to alloy matrix. The internal oxides formed in the current study obeyed such a sequence. From Figure 4-13 (i), an IN738LC alloy showed a relatively large internal oxidation layer of $\mathrm{Ni}(\mathrm{Cr}, \mathrm{Ti})_{2} \mathrm{O}_{4}, \mathrm{TiO}_{2}, \mathrm{Al}_{2} \mathrm{O}_{3}$ and $\mathrm{TiTaO}_{4}$. As well, the $\mathrm{Al}_{2} \mathrm{O}_{3}$ scale penetration depth was much greater than the external scale. Figure 4.13 explained that the protrusion of alumina scale resulted from the outward diffusion of aluminum along the short circuit paths such as grain boundaries and inward diffusion of oxygen ions. The protrusions of the scale-alloy interface will reduce the diffusion distance across the PFZ in $\mathrm{Al}$ i.e., the substrate alloy, through outward diffusion of $\mathrm{Al}^{3+}$ [15].

From Figures 4-13 (ii) and (iii), it is evident that the oxides formed on N5 and PM-TAS specimens were composed of thin films of $\mathrm{Al}_{2} \mathrm{O}_{3}$. The scale morphology changed from 
submicron thin films to a few microns across after longer exposure times as shown in Figure 4-

\section{4.}

The N5 scales exhibit discontinuous voids along the scale/alloy interface as shown in Figure 422, which eventually may lead to the scale spallation. The voids were expected to become less discernable with the growth of a denser scale at higher exposure time. The void formation could have been due to two major reasons. First, to accommodate the net volume change due to precipitate depletion and scale these voids can form, although there may also be a contribution of the Kirkendall effect. Several authors reported a similar kind of observation [71] [129] [130]. Second, the presence of 6 wt. \% tantalum in-homogeneously in the matrix will oxidize before aluminum to form $\mathrm{Ta}_{2} \mathrm{O}_{5}$ [71] [129]. Once the $\mathrm{Ta}_{2} \mathrm{O}_{5}$ oxide formed it will not adhere to the substrate and this may leads to void formation. In the present study we can see both mechanisms in place. The voids appeared along the alloy (PFZ)/scale interface and also a tantalum-rich layer can be seen above the void, both features as shown in Figure 4-23 and followed by the point analysis spectrum in Figure 4-24. The presence of voids or pores at the scale/alloy interface, in Figure 4-22 also allowed the outward diffusion of aluminum to contribute the scale growth rate, as identified by Feltin and Pettit and Hindam and Whittle [124] [131]. In the present work, although the voids can be seen at the scale/alloy interface region, the oxide scale thickness was not increased drastically.

The $\mathrm{Al}_{2} \mathrm{O}_{3}$ scales formed on the powder metallurgy TAS specimens appeared to be denser and adherent compared to that of the N5 as shown in Figures 4-11(iii), 4-12(iii) and 4-13(iii). As discussed previously, during initial stage or transient stage of oxidation, alumina forming powder metallurgy TAS specimen will tend to form some base-metal oxide, NiO. The scale kinetics data obtained for the PM-TAS alloy also support the assumption that the oxide scale growth is 
controlled by the movement of oxygen ions through the $\mathrm{Al}_{2} \mathrm{O}_{3}$ scale. With increase in the scale thickness, potential diffusion paths for oxygen and/or aluminum ions through the oxide scales decreased, thus leading to slower scale growth rate at higher exposure times [132]. The addition of 0.5 wt. \% of $\mathrm{Si}$ showed that a transient stage occurred at about $32 \mathrm{~h}$ and followed by the steady-state oxidation behaviour as shown in Figure 4-3. It is believed that both the presence of $\mathrm{Si}$ and the alumina scale formation result in the decrease of scale kinetics after the transient stage.

The addition of higher amount of Si to an alloy which contains Mo can create the TCP phases which are harmful to mechanical properties but may also increase the oxidation resistance by increasing the amount of $\gamma^{\prime}$ phase [75]. The other major changes with the addition of Si to a base material are a depression of liquidus and solidus temperatures and slight increase in the solvus temperature of $\gamma^{\prime}$ phase. In the present study, chromium rich $\sigma$-phases (TCP phases) were found and there occurrence during oxidation was not clearly understood. The presence of 0.5 wt. \% $\mathrm{Si}$ to the TAS alloy increased the volume fraction of the $\gamma^{\prime}$ phase much higher than that of the other alloys N5 and IN738LC.

\subsection{Effect of alloying elements}

For the three nickel based superalloys studied, the oxidation behaviour can be directly ascribed to different composition of the alloys. The oxidation behaviour of $\mathrm{Ni}-\mathrm{Cr}$ alloys with a varying $\mathrm{Cr}$ contents has been widely studied. Typically, the oxidation rate increases progressively until a certain Cr composition is reached and beyond this the rate decreases with addition [133]. This can be explained by the fact that the addition of a small amount of a second element increases the oxidation rate by increasing the number of cation vacancies and increasing the concentration of 
these second elements decreases it by forming a protective phases such as $\mathrm{Cr}_{2} \mathrm{O}_{3}$ and $\mathrm{NiCr}_{2} \mathrm{O}_{4}$. This type of behaviour can also be seen in NiCrAl alloys, where formation of a protective $\mathrm{Al}_{2} \mathrm{O}_{3}$ on the surface occurs, as this oxide is more stable than the $\mathrm{Cr}_{2} \mathrm{O}_{3}$.

The major difference in the chemical composition of the three nickel based superalloys is the presence of titanium in IN738LC which decreases the oxidation resistance compared to other alloys. The addition of $2 \% \mathrm{Ti}$ has been proposed by Taniguchi et al. [134] to enhance the oxidation resistance by forming an adherent oxide scale, although grain boundary oxidation was not reported. Generally, more than $2 \%$ Ti addition revealed the precipitate lattice distortion [13]. In the present case the IN738LC alloy contains 3.44 wt. \% of Ti which explains the increase in the oxide scale growth. The higher chromia growth rate of IN738LC could be related to the incorporation of $\mathrm{Ti}$ in the oxide scale. The presence of $\mathrm{Ti}$ creates vacancies in the scale by replacing $\mathrm{Cr}^{3+}$ with $\mathrm{Ti}^{4+}$ ions thereby increasing the concentration of $\mathrm{Cr}$-vacancies in the chromia scale [135].

$$
3 \mathrm{TiO}_{2}\left(+\mathrm{Cr}_{2} \mathrm{O}_{3}\right) \rightarrow 3 \mathrm{Ti}_{\mathrm{Cr}}^{*}+\mathrm{V}_{\mathrm{Cr}}^{\prime \prime \prime}+6 \mathrm{O}_{\mathrm{o}}^{x}\left(+\mathrm{Cr}_{2} \mathrm{O}_{3}\right)
$$

The presence of the titanium ions on a chromium lattice sites increases the positive charge which is represented in the equation-19 (right side). The triply charged chromium vacancy is given by $V_{C r}^{\prime \prime \prime}$ and $O_{O}^{x}$ is the oxygen on the oxygen sub-lattice.

In the present work, the mechanism of the chromia growth rate in the presence of higher $\mathrm{Ti}$ content in IN738LC alloy was studied using the thermodynamic software JMatPro. The Ti content was varied from $1-3.44$ wt. $\%$ and the resulting chromium activity was noted. From Figure 5-3, it is evident that the chromium activity increases with increase in the titanium content. The chromium activity $\left(\mathrm{a}_{\mathrm{Cr}}\right)$ for IN738LC at $900^{\circ} \mathrm{C}$ working temperature is 0.68 for 3.44 
wt. $\%$ of Ti and decreased to 0.48 when Ti concentration reduced to 1 wt. $\%$ as shown in Figure

5-4. Therefore, the chromium is more likely to oxidize in the presence of titanium.

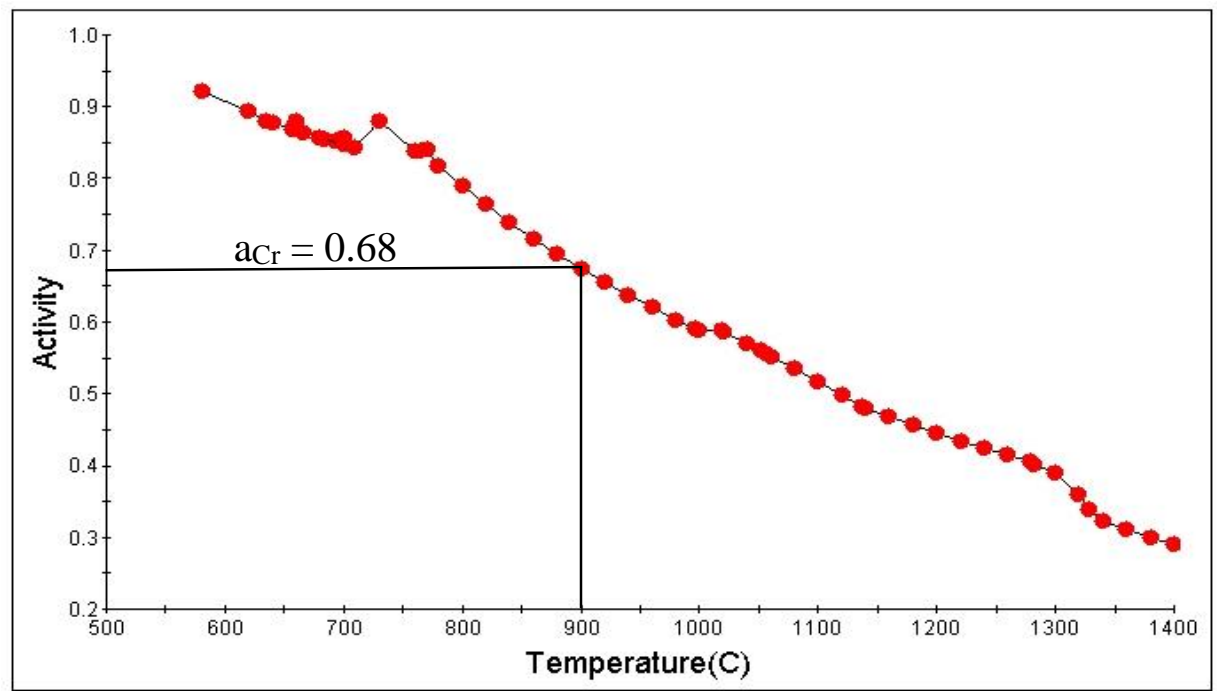

Figure 5- 3 JMatPro thermodynamic modelling; effect of 3.44 wt. \% Ti on chromium activity in IN738LC at $900^{\circ} \mathrm{C}$.

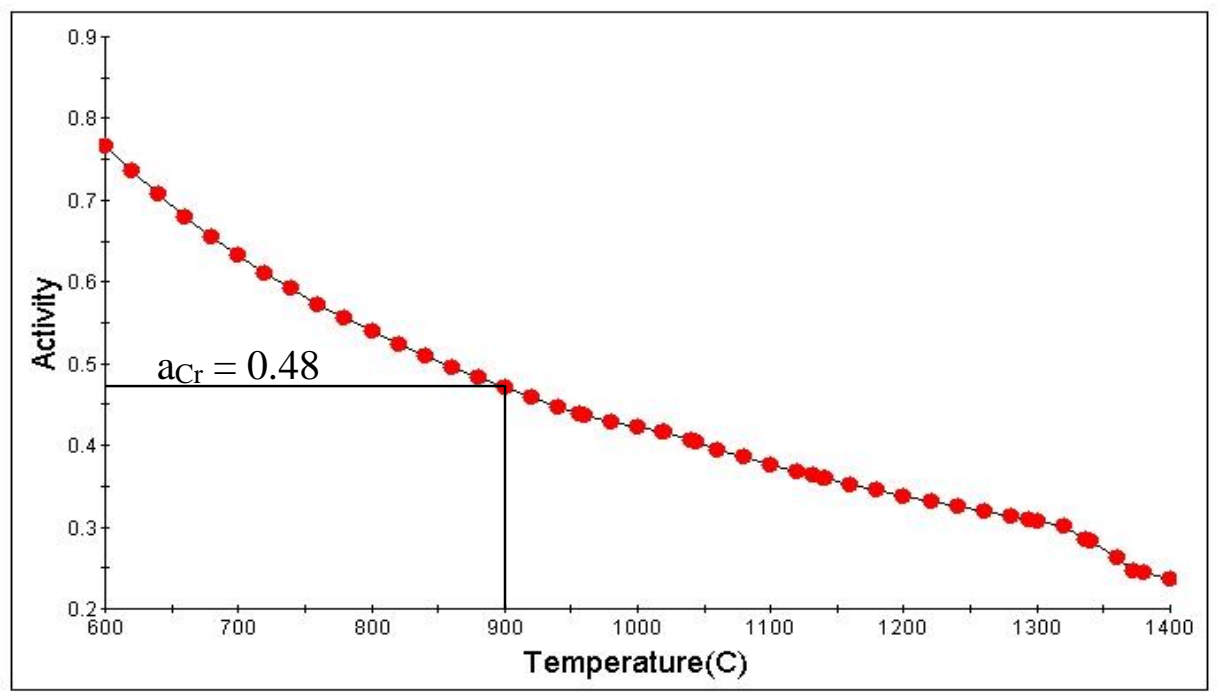

Figure 5- 4 JMatPro thermodynamic modelling; effect of $1 \mathrm{wt}$ \% Ti on chromium activity in IN738LC at $900^{\circ} \mathrm{C}$. 
Barrett et al [116] also studied the effect of different alloying elements such as Al, Co, Ti, Ta, W and Mo on the oxidation of a nickel-based superalloy at various temperatures. The most important factor for improved oxidation resistance was noted to be the presence of higher amount of aluminum. The best oxidation resistance was achieved by high $\mathrm{Al}(13$ at \%), $\mathrm{Cr}(10$ at $\%)$, Ti (2 at \%), $\mathrm{Nb}(1$ at \%) and high in $\mathrm{W}, \mathrm{Ta}, \mathrm{Mo}$ (3 at\% each) content. Therefore the absence of Ti in N5 and PM-TAS could be one of the reasons why they exhibit better oxidation resistance compared to IN738LC.

The tantalum addition causes the third element effect by promoting the alumina scale formation [15] [53]. For instance, for a dilute $\mathrm{Ni}-\mathrm{Al}$ that forms an external $\mathrm{NiO}$ scale and internal $\mathrm{Al}_{2} \mathrm{O}_{3}$ precipitates, this criterion states that addition of alloying elements which form oxides with a dissociation pressure lower than that of $\mathrm{NiO}$ but higher than that of $\mathrm{Al}_{2} \mathrm{O}_{3}$, may reduce the oxygen solubility in the alloy at the interface between the alloy and the external scale. The reduced oxygen solubility decreases the tendency for aluminum to oxidize internally thus promoting external alumina scale formation [15] [53] [65]. Similarly, the dissociation pressure of $\mathrm{Ta}_{2} \mathrm{O}_{5}$ is significantly lower than that of $\mathrm{Cr}_{2} \mathrm{O}_{3}$. Therefore, alloying the NiCrAl base alloy with $\mathrm{Ta}$ may indeed reduce the oxygen activity in the alloy matrix during oxidation and thus promote external alumina scale formation.

Silica is a thermodynamically more stable oxide than chromia and if present could form under a chromia scale during oxidation. The three nickel based superalloys had Si; 0.04\% with IN738LC, 0.12 wt. \% with N5 and 0.5 wt. \% with PM-TAS. However, from cross-sectional SEM images shown in Figures 4-11, 4-12 and 4-13, all three alloys did not show any Si-rich layer or precipitates at the scale/alloy interface other than the possible presence of minor Si in TAS as spinel as shown in Table 4.5. Interestingly, the morphology of the Si-rich oxides was reported to 
be alloy dependent by some researchers [120] [136], who concluded that the surface formation of Si-rich oxide particles helps to facilitate $\mathrm{Cr}_{2} \mathrm{O}_{3}$ scale formation and promotes oxidation resistance. However, Sato's experiments [137] on the variation of Si content in a single crystal superalloy showed marginal improvement in the alumina scale formation. The alloy also showed improvement in the oxidation resistant with the addition of 0.25 wt. \% $\mathrm{Si}$, but increase in parabolic rate was recorded with increase in $\mathrm{Si}$ content from $0.25 \mathrm{wt}$. \% to $0.5 \mathrm{wt}$. \%. The combination of Si-rich oxide phases at the alumina scale/alloy interface in PM-TAS alloys may reduce the diffusion of oxygen inward and chromium outward, thus lowering the scale growth rate. The distinct $\mathrm{SiO}_{2}$ layer formation is decided by the silicon quantity present in the alloy. It is been reported that an inner $\mathrm{SiO}_{2}$ layer can greatly worsen the extent of scale spallation [138] [139] [140]. However, no evidence of this phenomenon was found in this thesis. 


\section{SUMMARY AND CONCLUSIONS}

In order to estimate the extent of high-temperature oxidation, the chemical kinetics were rationalized using thermodynamics and kinetic theory based upon Wagner's theory of parabolic oxidation. The chemical kinetics of the oxide scale growth may be influenced by Gibbs free energy of formation and the presence of the alloying elements such as $\mathrm{Cr}, \mathrm{Al}, \mathrm{Si}, \mathrm{Ti}$ and $\mathrm{Ta}$.

In this study, the isothermal oxidation behaviour of three nickel-based superalloys namely, polycrystalline IN738LC, single crystal N5 and powder metallurgy TAS in ambient air has been studied at $900^{\circ} \mathrm{C}$ for up to $1000 \mathrm{~h}$. From the results the following conclusions can be drawn.

The specific weight, as well as oxide scale thickness of all three specimens, increased with increased oxidation duration according to parabolic rate law, which is typical for a protective oxide layer. However, the parabolic scaling rate of the IN738LC specimen is faster than the N5 and PM-TAS specimens, while N5 and PM-TAS had approximately the same oxidation rate. The decrease in the oxide scale growth and the weight gain with respect to N5 and PM-TAS may be because of the scale composition (alumina), which is thermodynamically more stable than the chromia scale which was formed on IN738LC. The transient oxidation behaviour was found to occur in the alumina-forming N5 and PM-TAS superalloys before reaching steady state. This transient behaviour may be caused by the oxidation of the base alloy to form $\mathrm{NiO}$.

The magnitude of the parabolic rate constant $\mathrm{k}_{\mathrm{p}}$ values for $\mathrm{N} 51.64 \mathrm{X} 10^{-7} \mathrm{mg}^{2} \mathrm{~cm}^{-4} \mathrm{~s}^{-1}$ and for TAS, $1.42 \times 10^{-7} \mathrm{mg}^{2} \mathrm{~cm}^{-4} \mathrm{~s}^{-1}$ were much lower than for the IN738LC, $2.79 \times 10^{-6} \mathrm{mg}^{2} \mathrm{~cm}^{-4} \mathrm{~s}^{-1}$. Hence, N5 and PM-TAS alloys are more oxidation-resistant than the IN738LC under these 
conditions. In fact the parabolic rate constant values of N5 and PM-TAS alloys are lower than most commercially available nickel based superalloys whereas IN738LC alloy exhibited a higher parabolic rate constant.

Both surface scanning electron microscopy (SEM) and cross-sectional examinations, showed that the oxide scales formed on the alloys were continuous and adherent to the substrate. The SEM-EDS analysis confirmed that the oxide scale formed on IN738LC was composed of a continuous external $\mathrm{Cr}_{2} \mathrm{O}_{3}$, with adjacent spinel $\left(\mathrm{Ni}(\mathrm{Cr}, \mathrm{Ti})_{2} \mathrm{O}_{4}\right)$ layer and a discontinuous internal $\mathrm{Al}_{2} \mathrm{O}_{3}$ scale in the subsurface region proving Type-II oxidation behaviour. However, both $\mathrm{N} 5$ and PM-TAS alloys showed $\mathrm{Al}_{2} \mathrm{O}_{3}$-monolayer on the surface suggesting Type-III oxidation behaviour.

The rapid growth of chromia scale on IN738LC was attributed to the Ti addition of 3.44 wt. \%, which increases the growth rate of the $\mathrm{Cr}_{2} \mathrm{O}_{3}$-scale by injecting vacancies in the chromia scale thereby decreasing the formation of a protective $\mathrm{Al}_{2} \mathrm{O}_{3}$-scale. The chromium activity increases with an increase in the $\mathrm{Ti}$ content which was confirmed by thermodynamic modelling using JMatPro software. Finally, the presence of the Ta with Ti in IN738LC promoted the internal $\mathrm{Al}_{2} \mathrm{O}_{3}$-scale formation by acting as an oxygen getter, hence preventing the chromia growth by titanium incorporation. 


\section{FUTURE WORK}

Based upon the research work presented here, the following suggestions are made for future work.

First, the effect of tantalum during initial stage of oxidation is not well understood. The void formation in single crystal N5 specimen is not clear. It may have been caused by the formation of $\mathrm{Ta}_{2} \mathrm{O}_{5}$ or alternatively may be due to net volume change between the oxide scale and the precipitate free zone. Further XRD work for N5 is necessary to identify which oxides develop during the early stages of oxidation.

Second, it was found from chapter 3 that the oxidation rate is a function of surface area of the material. This implies that smaller the precipitate size higher the oxidation rate. To test this hypothesis, nickel-based superalloys with different precipitate size (mono-modal), should be evaluated for oxidation rate. Together, the precipitate composition study as a function of size needs to be done using TEM analysis.

Finally, the specimens should be tested under cyclic oxidation both to have good comparison with isothermal oxidation test results and to provide a more realistic basis for comparison of these alloys under aero-engine service conditions. 


\section{REFERENCES}

[1] R. C. Reed, The superalloys - Fundamentals and applications, New York: Cambridge University Press, 2006.

[2] S. Zhang and C. Zhao, Aerospace Materials Handbook, New York: CRC Press, 2013.

[3] N. J. Simms, A. E. Oropesa and J. R. Nicholls, Hot corrosion of coated and uncoated single crystal gas turbine materials, Weinheim: WILEY-VCH Verlag GmbH and Co, 2008.

[4] H. Oskarsson, Materials challenges in industrial gas turbines, Journal of Iron and Steel Research, International, vol. 14, no. 5, pp. 11-14, 2007.

[5] T. J. Carter, Common failures in gas turbine blades, Engineering Failure Analysis, vol. 12, no. 2, pp. 237-247, 2005.

[6] M. C. Kushan, S. C. Uzgur, Y. Uzunonat and F. Diltemiz, Allvac 718 plus $^{\mathrm{TM}}$ superalloy for aircraft engine applications, Recent Advances in Aircraft Technology, Turkey: INTECH, 2012.

[7] A. Mazur, R. A. Luna, J. A. Juarez-Islas and A. A. Campos, Failure analysis of a gas turbine blade made of IN738LC alloy, vol. 12, pp. 474-486, 2005.

[8] Y. Danis, C. Arvieu, E. Lacoste, T. Larrouy and J. Quenisset, An investigation on thermal, metallurgical and mechanical states in weld cracking of IN738LC superalloy, Materials and Design, vol. 31, no. 1, pp. 402-416, 2010.

[9] M. Konter and M. Thumann, Materials and manufacturing of industrial gas turbine components, Journal of Materials Processing Technology, vol. 117, no. 3, pp. 386-390, 2001.

[10] B. Williams, Powder metallurgy superalloys for high temperatures, High Performance Applications, IPMD 15th Edition, Shrewsbury, 2012.

[11] ASM metals handbook, Fatigue and Fracture, vol. 19, Materials Park, Ohio: ASM international, 1996.

[12] M. J. Donachie and S. J. Donachie, Superalloys, vol. 2, Ohio: ASM Metals Handbook, 2002.

[13] C. T. Sims, N. S. Stolof and W. C. Hagel, Superalloys II - High-temperature materials for aerospace and industrial power, New York: John Wiley and Sons, 1987. 
[14] B. Geddes, H. Leon and X. Huang, Superalloys: Alloying and performance, vol. 1, Materials park, Ohio: ASM International, 2010.

[15] N. Birks, G. Meier and F. Petit, Introduction to the high-temperature oxidation of metals, Cambridge: University of Cambridge, 2006.

[16] T. Pollock and S. Tin, Ni-based superalloys for advanced turbine engines: chemistry, microstructure and properties, Journal of Propulsion and Power, vol. 22, pp. 361-374, 2006.

[17] T. J. Brown and J. E. Wilson, Two new $1800^{\circ} \mathrm{C}$ alloys for cast turbine blades, Metal Progress, vol. 74, no. 5, pp. 83-87, 1958.

[18] F. C. Campbell, Elements of metallurgy and engineering alloys, Materials Park, Ohio: ASM International, 2008.

[19] D. Coutsouradis, A. Davin and M. Lamberigts, Cobalt-base superalloys for applications in gas turbines, Material Science and Engineering, vol. 88, pp. 11-19, 1987.

[20] R. D. Joseph, Heat resistant materials, Materials Park, Ohio: ASM International, 1997.

[21] M. D. Charre, The microstructure of superalloys, New York: CRC Press, 1997.

[22] R. C. Ecob, R. A. Ricks and A. J. Porter, The measurement of precipitate/matrix lattice mismatch in Ni-base superalloys, Scripta Metallurgica, vol. 31, no. 2, pp. 43-53, 1982.

[23] C. R. Brook, Heat treatment, structure and properties of non-ferrous alloys, Ohio: ASM International, 1982.

[24] Thakur. A, Microstructural responses of a nickel-base cast IN738 superalloy to a variety of pre-weld heat treatments, MSc thesis, University of Manitoba, Winnipeg, 1997.

[25] R. A. Schwarzer, Electron backscatter diffraction in materials science, Clausthal University of Technology: Springer, 2009, pp. 97-106.

[26] D. Baither, C. Renthenberger, H. P. Karnthaler and E. Nembach, Three alternative experimental methods to determine the anti-phase boundary energies of the gamma prime precipitates in superalloy, Philosophical Magazine, vol. 82, pp. 1795-1805, 2002.

[27] N. S. Stoloff, Wrought and P/M superalloys, vol. 1, Ohio: ASM International Handbook, 2003.

[28] T. J. Garosshen and G. P. McCarthy, Carbide precipitation in a Nickel-base superalloy, The Metallurgical and Materials Transactions, vol. 16A, pp. 1213-1222, 1985. 
[29] H. E. Collins, Relative stability of carbide and intermetallic phases in nickel-base superalloys, ASM International Handbook, vol. 62, pp. 82-104, 1968.

[30] Y. S. Lim, D. J. Kim, S. S. Hwang, H. P. Kim and S. W. Kim, $\mathrm{M}_{23} \mathrm{C}_{6}$ precipitation behavior and grain boundary serration in Ni-based Alloy 690, Materials Characterization, vol. 96, pp. 28-39, 2014.

[31] A. J. Ardell, Cumulative distribution functions associated with particle coarsening processes, Metallography, vol. 5, no. 3, pp. 285-294, 1972.

[32] A. Hazotte, T. Grosdidier and S. Denis, Gamma prime precipitate splitting in Ni-based superalloys: a 3-D finite element analysis, Scripta Metallurgica, vol. 34, p. 601, 1996.

[33] R. Schlatter, Melting and refining technology of high temperature steel and superalloys, Latrobe steel company, Pensylvania, 1972.

[34] G. N. Maniar and H. Abrams, Metallography - A practical tool for correlating the structure and properties of materials, Philadelphia: ASTM International, 1973.

[35] W. D. Cao and R. L. Kennedy, New development in wrought 718-type superalloys, Acta Metallurgica and Material, vol. 18, pp. 39-46, 2004.

[36] M. Lamm and R. F. Singer, The effect of casting conditions on the high cycle fatigue properties of the single crystal nickel-base superalloys, PWA-1483, The Minerals, Metals and Materials Society and ASM International, vol. 38A, pp. 1177-1183, 2007.

[37] T. J. Milan, L. Borishlav, M. Zoran, B. Ilija, D. Biljana and C. Ivana, Processing and some applications of nickel, cobalt and titanium-base alloys, Metalurgija - Journal of Metallurgy, vol. 13, no. 2, pp. 91-106, 2007.

[38] D. A. Akinlade, W. F. Caley, N. L. Richards and M. C. Chathurvedi, Microstructural and thermal processing effects on adding 1 and $3 \mathrm{w} / \mathrm{o}$ Ti to a powder metallurgy processed quaternary $\mathrm{Ni}-\mathrm{Cr}-\mathrm{Fe}-\mathrm{Al}$ alloy, Material Science and Engineering, vol. 528, pp. 996-1002, 2011.

[39] R. A. Fuys, R. G. Craig and K. Asgar, Physical properties of a nickel-base alloy prepared by isostatic pressing and sintering of the powdered metal, Journal of Oral Rehabilitation, vol. 3, pp. 151-160, 1976.

[40] D. C. Murray, N. L. Richards and W. F. Caley, On improving the oxidation resistance of a Ni-based superalloy produced by powder metallurgy, Canadian Metallurgical Quarterly, vol. 52, pp. 439-448, 2013.

[41] O. A. Ojo, On liquation cracking of cast inconel 738LC superalloy welds, $\mathrm{PhD}$ thesis, University of Manitoba, Winnipeg, 2004. 
[42] IN738LC, Technical data, INCO, New York.

[43] NIDI, High temperature, high strength nickel-base alloys, Nickel Development Institute, 1995.

[44] A. Akhtar, S. Hegde and R. C. Reed, The oxidation of single-crystal nickel-based superalloys, Journal of Materials, vol. 58, pp. 37-42, 2006.

[45] W. S. Walston, K. S. O'Hara, E. W. Ross, T. M. Pollock and W. H. Murphy, Rene N6: Third generation single crystal superalloys, The Minerals, Metals and Materials Society, 1996.

[46] N. Sauders and A. P. Miodownik, CALPHAD (Calculation of Phase Diagrams): A comprehensive guide, vol. 1, Guildford: Elsevier Science Ltd, 1998.

[47] N. B. Hannay, Treatise on solid state chemistry: Reactivity of solids, vol. 4, New York: Plenum press, 1921.

[48] A. K. Jena and M. C. Chathurvedi, Phase transformations in materials, New Jersey: Prentice Hall, 1992.

[49] P. Kofstad, Defects and transport properties of metal oxides, Oxidation of Metal Oxides, vol. 44, pp. 3-25, 1994.

[50] P. G. Shewmon, Diffusion in solids, New York: McGraw-Hill, 1966.

[51] H. Mehrer, Diffusion in solids, Berlin: Springer, 1965, pp. 69-91.

[52] T. D. Richard, Understanding solids: The science of materials, West Sussex: John Wiley and Sons Ltd, 2004.

[53] D. J. Young, High temperature oxidation and corrosion of metals, Oxford: Elsevier Science Ltd, 2008.

[54] R. E. Reed-Hill, Physical metallurgy principles, Boston: PWS publisher, 1973.

[55] W. D. Callister, Materials science and engineering an introduction, $6^{\text {th }}$ ed., New York: John Wiley and Sons Inc., 2003.

[56] D. A. Jones, Principles and prevention of corrosion, New Jersey: Prentice Hall, 1996.

[57] M. G. Fontana, Corrosion engineering, New York: McGraw-Hill, 1967.

[58] F. P. Fehlner and N. F. Mott, Low temperature oxidation, Oxidation of Metals, vol. 2, no. 1, pp. 59-99, 1970.

[59] L. L. Shreir, Corrosion, $2^{\text {nd }}$ ed, vol. 1, New York: Butterworth and Co Ltd, 1976. 
[60] C. Wagner, Beitrag zur theorie des anlaufvorgangs, Physical chemistry B, vol. 41, pp. 92104, 1933.

[61] D. J. Young and B. A. Pint, Chromium volatilization rates from $\mathrm{Cr}_{2} \mathrm{O}_{3}$ scales into flowing gases containing water vapor, Oxidation of Metals, vol. 66, no. 3-4, pp. 137-153, 2006.

[62] W. J. Quadakkers and M. J. Bennett, Oxidation induced lifetime limits of thin walled, iron based, alumina forming, oxide dispersion strengthened alloy components, Materials Science and Technology, vol. 10, pp. 126-131, 1994.

[63] H. E. Evans, A. T. Donaldson and T. C. Gilmour, Mechanisms of breakaway oxidation and application to a chromia-forming steel, Oxidation of Metals, vol. 52, pp. 379-402, 1999.

[64] L. Xichao, Z. Lili, Q. Yuhai, X. Jingiun and L. Meishuan, Breakaway oxidation of $\mathrm{Ti}_{3} \mathrm{AlC}_{2}$ during long-term exposure in air at $1100^{\circ} \mathrm{C}$, Corrosion Science, 2015.

[65] C. S. Giggins and F. S. Pettit, Corrosion of metals and alloys in mixed gas environments at elevated temperatures, Oxidation of Metals, vol. 14, no. 5, pp. 363-413, 1980.

[66] D. P. Whittle, High temperature alloys for gas turbines, Oxidation of Metals, pp. 109-123, 1978.

[67] V. M. J. Robert, Effects of $\mathrm{C}$ and $\mathrm{Hf}$ concentration on phase relations and microstructure of a wrought powder-metallurgy superalloy, metallurgical transactions A, vol. 8A, pp. 259263, 1977.

[68] D. E. Jones and J. Stringer, The effect of small amounts of silicon on the oxidation of highpurity Co-25 wt. \% Cr at elevated temperature, Oxidation of Metals, vol. 9, no. 5, pp. 409413, 1975.

[69] F. S. Pettit and G. H. Meier, Oxidation and hot corrosion of superalloys, Superalloys 1984 (Fifth international symposium), pp. 651-687, 1984.

[70] S. Cruchley, M. P. Taylor, H. E. Evans, M. C. Hardy and S. Stekovic, Chromia layer growth on a Ni-based superalloy: Sub-parabolic kinetics and the role of titanium, Corrosion science, vol. 75, pp. 58-66, 2013.

[71] S. W. Yang, Effect of Ti and Ta on the oxidation of a complex superalloy, Oxidation of metals, vol. 15, no. 5-6, pp. 375-397, 1981.

[72] B. D. Craig and D. S. Anderson, Handbook of corrosion data, Materials Park, Ohio: ASM international, 1995. 
[73] G. D. Smith and S. J. Patel, The role of niobium in wrought precipitation-hardened Nickelbase alloys, Superalloys 718, 625, 706 and various derivatives, The Minerals, Metals and Materials Society, pp. 135-154, 2005.

[74] A. Jalowicka, W. Nowak, D. J. Young, V. Nischwitz, D. Naumenko and W. J. Quadakkers, Boron depletion in a nickel-base superalloy induced by high temperature oxidation, Oxidation of Metals, vol. 83, no. 3-4, pp. 393-413, 2015.

[75] C. A. Barrett, R. V. Miner and D. R. Hull, The effects of Cr, AI, Ti, Mo, W, Ta, and Nb on the cyclic oxidation behaviour of cast Ni-base superalloys at 1100 and $1150 \mathrm{C}$, Oxidation of Metals, vol. 20, no. 5-6, pp. 255-278, 1983.

[76] A. S. Khanna, W. J. Quadakkers, P. Kofstad and C. Wasserfuhr, The effect of trace impurities of $\mathrm{S}, \mathrm{P}$ and $\mathrm{B}$ on the high temperature oxidation of NiCrAl-based alloys, in EUROCORR, Proc., II, EG-007, NL, 1989.

[77] K. A. Unocic, D. N. Leonard and B. A. Pint, Effect of boron on the oxidation behavior of NiCrAlYHfTi in $\mathrm{H}_{2} \mathrm{O}$ and $\mathrm{CO}_{2}$ environments, Surface and coatings technology, vol. 260, pp. 17-22, 2014.

[78] N. Czech, F. Schmitz and W. Stamm, Microstructural analysis of the role of rhenium in advanced MCrAlY coatings, Surface and coatings technology, vols. 76-77, pp. 28-33, 1995.

[79] C. T. Liu, X. F. Sun, H. R. Guan and Z. O. Hu, Effect of rhenium addition to a nickel-base single crystal superalloy on isothermal oxidation of the aluminide coating, Surface and Coatings Technology, vol. 194, pp. 111-118, 2005.

[80] T. Amanoa, H. Isobe, N. Sakai and T. Shishido, The effects of yttrium addition on hightemperature oxidation of heat-resistant alloys with sulfur, Journal of Alloys and Compounds, vol. 344, pp. 394-400, 2002.

[81] Y. Zhang, D. Zhu and D. A. Shores, Effect of yttrium on the oxidation behaviour of cast Ni-30Cr alloy, Acta Metallurgica Materials, vol. 43, no. 11, pp. 4015-4025, 1995.

[82] F. Weng, H. Yu, C. Chena and K. Wana, High-temperature oxidation behavior of Ni-based superalloys with $\mathrm{Nb}$ and $\mathrm{Y}$ and the interface characteristics of oxidation scales, Surface Interface Analysis, vol. 47, pp. 362-370, 2015.

[83] J. H. Chen, P. M. Rogers and J. A. Little, Oxidation behavior of several chromia-forming commercial nickel-base superalloys, Oxidation of Metals, vol. 47, no. 5-6, pp. 381-410, 1997. 
[84] M. P. Taylor, H. E. Evans, S. Stekovic and M. C. Hardy, The oxidation characteristics of the nickel-based superalloy, RR1000, at temperatures of $700^{\circ} \mathrm{C}-900^{\circ} \mathrm{C}$, Materials at High Temperatures, vol. 29, no. 2, pp. 145-150, 2012.

[85] A. D. Dalvi and D. E. Coates, A review of the diffusion path concept and its application to the high-temperature oxidation of binary alloys, Oxidation of Metals, vol. 5, no. 2, pp. 113$135,1972$.

[86] J. E. Croll and G. R. Wallwork, The design of iron-chromium-nickel alloys for use at high temperatures, Oxidation of Metal, vol. 1, no. 1, pp. 55-71, 1969.

[87] G. R. Wallwork, The oxidation of alloys, Reports on Progress in Physics, vol. 39, pp. 401485, 1976.

[88] I. Zaplatynsky, Volatilization of oxides during oxidation of some superalloys at $1200^{\circ} \mathrm{C}$, Oxidation of Metals, vol. 11, no. 6, pp. 289-305, 1977.

[89] J. L. Smialek and A. Garg, Microstructure and oxidation of a MAX Phase/superalloy hybrid interface, NASA, Cleveland, 2014.

[90] M. W. Brumm and H. J. Grabke, The oxidation behaviour of NiAl-phase transformations in the alumina scale during oxidation of $\mathrm{NiAl}$ and $\mathrm{NiAl}-\mathrm{Cr}$ alloys, Corrosion Science, vol. 33, no. 11, pp. 1677-1690, 1992.

[91] G. C. Rybicki and J. L. Smialek, Effect of the $\theta-\alpha-\mathrm{A}_{2} \mathrm{O}_{3}$ transformation on the oxidation behaviour of $\beta-\mathrm{NiAl}+\mathrm{Zr}$, Oxidation of Metals, vol. 31, no. 3-4, pp. 275-304, 1989.

[92] I. Levin and D. Brandon, Metastable alumina polymorphs: crystal structures and transition sequences, Journal of American ceramic society, vol. 81, no. 8, pp. 1995-2012, 2012.

[93] C. Zeng, Y. Ling, S. Li, Y. Rao and Y. Chen, The effect of chromium on the $\gamma$ to $\alpha$ phase transition of alumina coating formed on $316 \mathrm{~L}$ SS by a cathodic micro arc deposition (CMAD) process, Surface and Coatings Technology, vol. 263, pp. 15-20, 2015.

[94] A. M. Huntz, Oxidation of alumina forming materials, University of Paris, Lemhe, 2000.

[95] W. J. Quadakkers, A. Elschner, W. Speier and H. Nickel, Composition and growth mechanisms of alumina scales on FeCrAl-based alloys determined by SNMS, Applied surface science, vol. 52, pp. 271-287, 1991.

[96] B. A. Pint, J. R. Martin and L. W. Hobbs, The oxidation mechanism of $\theta-\mathrm{Al}_{2} \mathrm{O}_{3}$ scales, Solid State Ionics, vol. 78, no. 1-2, pp. 99-107, 1995.

[97] D. J. Young and B. Gleeson, Alloy phase transformation driven by high-temperature corrosion processes, Corrosion Science, vol. 44, pp. 345-357, 2002. 
[98] S. Hana and D. J. Young, Oxidation - nitridation of Ni-Cr-Al alloys, Materials Research, vol. 7, no. 1, pp. 11-16, 2004.

[99] M. A. Phillips and B. Gleeson, Beneficial effects of rhenium additions on the cyclic oxidation resistance of $\beta-\mathrm{NiAl}+\alpha-\mathrm{Cr}$ alloys, Oxidation of metals, vol. 50, no. 5-6, pp. 399427, 1998.

[100] J. Zhu, G. R. Holcomb, P. D. Jablonski, A. Wise, J. Li, D. E. Laughlin and S. Sridhar, Subsurface characterization of an oxidation-induced phase transformation and twinning in nickel-based superalloy exposed to oxy-combustion environments, Materials Science and Engineering A., vol. 550, pp. 243-253, 2012.

[101] S. Cruchley, M. P. Taylor, H. E. Evans, M. C. Hardy and D. J. Child, Characterisation of subsurface oxidation damage in Ni-based superalloy RR1000, Materials Science and Technology, vol. 30, no. 15, pp. 1884-1889, 2014.

[102] F. Gesmundo and B. Gleeson, Oxidation of multicomponent two-phase alloys, Oxidation of Metals, vol. 44, no. 1-2, pp. 211-237, 1995.

[103] R. Molins and E. Andrieu, Analytical TEM study of the oxidation of nickel-based superalloys, Journal of Physics, vol. 03, no. C9, pp. 469-475, 1993.

[104] Y. Q. Chen, E. Francis, J. Robson, M. Preuss and S. J. Haigh, Compositional variations for small-scale gamma prime $\left(\gamma^{\prime}\right)$ precipitates formed at different cooling rates in an advanced Ni-based superalloy, Acta Materialia, vol. 85, pp. 199-206, 2015.

[105] C. K. Sudbrack, S. L. Draper, T. T. Gorman, J. Telesman, T. P. Gabb and D. R. Hull, Oxidation and the effects of high temperature exposures on notched fatigue life of an advanced powder metallurgy disk superalloy, The Minerals, Metals and Materials Society, pp. 863-872, 2012.

[106] P. Carter, B. Gleeson and D. J. Young, Calculation of precipitate dissolution zone kinetics in oxidising binary two-phase alloys, Acta Materialia, vol. 44, no. 10, pp. 40334038, 1996.

[107] B. Gleeson, High-temperature corrosion of metallic alloys and coatings, Weinheim: Wiley-VCH, 2013.

[108] D. Caplan, R. J. Hussey, G. I. Sproule and M. J. Graham, The mechanism of cavity formation during high temperature oxidation of nickel, Scripta Metallurgica, vol. 16, pp. 759-760, 1982.

[109] R. H. Bricknell and D. A. Woodford, The mechanism of cavity formation during high temperature oxidation of nickel, Acta Materialia, vol. 30, pp. 257-264, 1982. 
[110] J. R. Ligenza, Oxidation of silicon by high-pressure steam, Journal of the Electrochemical Society, vol. 109, no. 2, pp. 73-76, 1962.

[111] T. Cheng and P. F. Tortorelli, Silicon carbide oxidation in high-pressure steam, Journal of American Ceramic Society, vol. 96, no. 7, pp. 2330-2337, 2013.

[112] D. C. Murray, On improving the oxidation resistance of a Ni-based superalloy produced by powder metallurgy, M.Sc. thesis, Dalhousie University, Halifax, 2012.

[113] J. L. Smailek and G. H. Meier, Superalloys II, Chapter II, Sims, C T; Stollof, N S; and Hagel, W C, High-temperature oxidation., New York: John Wiley and Sons, 1987.

[114] J. L. Smailek, C. A. Barrett and J. C. Schaeffer, Design for oxidation resistance, vol. 20, Materials Park, Ohio: ASM handbook, 1997, p. 589.

[115] J. R. Nicholls and M. J. Bennett, Cyclic oxidation - guidelines for test standardisation, aimed at the assessment of service behaviour, High-Temperature Alloys, vol. 17, no. 3, p. $413,2000$.

[116] C. A. Barrett, A statistical analysis of elevated temperature gravimetric cyclic oxidation data of Ni and Co-base superalloys based on an oxidation attack parameter, TM-105934, NASA Lewis research center., Cleveland, Ohio, 1987.

[117] V. O. Kubaschewski and B. E. Hopkins, Oxidation of metals and alloys, London: Butterworths, 1962.

[118] W. W. Smeltzer and D. J. Young, Oxidation properties of transition metals, Progress in Solid State Chemistry, vol. 10, no. 1, pp. 17-54, 1975.

[119] B. G. Cade, W. F. Caley and N. L. Richards, Comparison of oxidation performance of two nickel-based superalloys for turbine applications, Canadian Metallurgical Quarterly, vol. 53, no. 4, pp. 460-468, 2014.

[120] K. P. Lillerud and P. Kofstad, Sulfate-induced hot corrosion of nickel, Oxidation of Metals, vol. 21, no. 5-6, pp. 233-270, 1984.

[121] B. Chattopadhyay and G. C. Wood, The transient oxidation of alloys, Oxidation of Metals, vol. 2, no. 4, pp. 373-399, 1970.

[122] M. J. Bennett, B. A. Bellamy, C. F. Knight, N. Meadows and N. J. Eyre, Improvement by cerium and yttrium ion implantation of the oxidation behaviour of a $20 \mathrm{Cr}-25 \mathrm{Ni}$ niobiumstabilized stainless steel in $\mathrm{CO}_{2}$, Materials Science and Engineering, vol. 69, pp. 359-373, 1985. 
[123] D. P. Whittle and J. Stringer, Improvements in high temperature oxidation resistance by additions of reactive elements or oxide dispersions, Philosophical Transactions of The Royal Society of London A, vol. 295, no. 1413, pp. 309-329, 1980.

[124] H. Hindman and D. P. Whittle, Microstructure adhesion and growth kinetics of protective scales on metals and alloys, Oxidation of Metals, vol. 18, no. 5-6, pp. 245-284, 1982.

[125] K. Subhash, R. Jayahanthan and S. Prakash, High temperature cyclic oxidation and hot corrosion behaviours of superalloys at $900^{\circ} \mathrm{C}$, Bulletin of Material Science, vol. 33, no. 3, pp. 299-306, 2010.

[126] K. Zhao, Y. B. Zhou, Y. H. Ma, L. H. Lou and Z. Q. Hu, Effect of microstructure on the oxidation behavior of two nickel-based superalloys, Corrosion Science, vol. 61, no. 10, pp. 961-967, 2005.

[127] L. Huang, X. F. Sun, H. R. Guan and Z. Q. Hu, Oxidation behaviour of directionally solidified Ni-based superalloy DS 951 in air, Oxidation of Metals, vol. 64, no. 5-6, pp. 303-318, 2005.

[128] M. Wenderoth, R. Volkol, S. Vorberg, B. Fisher and Glatzel, Isothermal oxidation behaviour of a precipitation-hardened Pt-base alloy with addition of $\mathrm{Al}, \mathrm{Cr}$ and $\mathrm{Ni}$, International Journal of Materials Resources, vol. 98, no. 6, pp. 463-467, 2007.

[129] J. Wang, M. Chen, S. Zhu and F. Wang, Ta effect on oxidation of a nickel-based singlecrystal superalloy and its sputtered nano-crystalline coating at $900-1100^{\circ} \mathrm{C}$, Applied Surface Science, vol. 345, pp. 194-203, 2015.

[130] W. P. Wu, Y. F. Guo and Y. S. Wang, Influence of stress state on the evolution of misfit dislocation networks in a Ni-based single crystal superalloy, Philosophical Magazine, vol. 92, no. 12, pp. 1456-1468, 2012.

[131] E. J. Feltin and F. S. Petitt, Use of Pt and Rh to improve oxide adherence on Ni-8Cr-6Al alloys, Oxidation of Metals, vol. 10, no. 3, pp. 23-28, 1976.

[132] H. Hindam and W. W. Smeltzer, Growth and microstructure of $\alpha-\mathrm{Al}_{2} \mathrm{O}_{3}$ on $\beta-\mathrm{NiAl}$, Journal of Electrochemical Society, vol. 127, pp. 1630-1635, 1980.

[133] F. H. Stott, T. Hodgkiess and G. C. Wood, Factors affecting the high-temperature oxidation behaviour of some dilute nickel and cobalt-base alloys. Oxidation of Metals, vol. 11, no. 3, pp. 141-150, 1977.

[134] S. Taniguchi and T. Scibata, Cyclic oxidation of Ni3Al-0.1B base alloys containing Ti, $\mathrm{Zr}$ or Hf addition, Oxidation of Metals, vol. 25, no. 3-4, pp. 201-216, 1986. 
[135] A. Naoumidis, H. A. Schulze, W. Jungen and P. Lersch, Phase studies in the Cr-Mn-Ti oxide system at different partial pressures, Journal of European Ceramic Society, vol. 7, no. 1, p. $55,1991$.

[136] D. E. Jones and J. Stringer, The effect of small amounts of Si on the oxidation of highpurity Co-25Cr at elevated temperatures, Oxidation of Metals, vol. 9, no. 5, pp. 209-213, 1975.

[137] A. Sato, Y. L. Chiu, E. A. Marquis and R. C. Reed, Characterisation of oxide scale formation on a new single crystal superalloy for power generation applications, Materials at High-Temperatures, vol. 29, no. 3, pp. 272-278, 2012.

[138] F. H. Stott, G. J. Gabriel, F. I. Wei and G. C. Wood, The development of siliconcontaining oxides during the oxidation of Fe-Cr-base alloys, vol. 38, Weinheim: Werkstoffe and Korrosion, 1987.

[139] D. Caplan and M. Cohen, Scaling of Fe-26Cr alloys at 870C-2700C, Journal of Electrochemical Society, vol. 112, no. 5, pp. 471-477, 1965.

[140] H. E. Evans, D. A. Hilton, R. A. Holm and S. J. Webster, Influence of Si addition on the oxidation resistance of a stainless steel, Oxidation of Metals, vol. 19, no. 1-2, pp. 379$402,1983$. 